\title{
Novel Therapeutic Targets and Biomarkers for the Treatment of Progressive Supranuclear Palsy
}

\author{
Imogen F C Tyer, Alison M Hill* \\ *corresponding author, A.M.Hill@exeter.ac.uk, Geoffrey Pope Building, University \\ of Exeter, Stocker Road, Exeter, EX4 4QD, UK.
}

Imogen F C Tyer: it257@exeter.ac.uk, ORCID ID: 0000-0001-8393-7023

Alison M Hill: A.M.Hill@exeter.ac.uk, ORCID ID: 0000-0001-8084-3048

\begin{abstract}
Progressive supranuclear palsy (PSP) is a sporadic parkinsonism tauopathy characterised by the deposition of aggregations of abnormal, hyperphosphorylated four-repeat tau (4R-tau). A revised clinical diagnostic criterion for PSP allows early presentations for the full spectrum of clinical phenotypes to be recognised enabling doctors to make a more accurate diagnosis. The major genetic risk factor for sporadic PSP is a common variant in the gene encoding microtubule-associated protein tau (MAPT). Research into the biochemical and pathological pathways of tau is vital to improve the chances of developing an effective diagnostic biomarker to monitor tau pathogenesis. Neuroimaging biomarkers, such as tau PET ligands, are proving the most successful tool in providing a differential diagnosis between neurodegenerative disorders. There are currently no effective treatments for PSP, however tau-directed therapies in the last five years have rapidly advanced. Latest tau therapies are proposed to have disease-modifying effects by reducing toxic aggregations of tau through manipulating tau gene expression. After encouraging results from long awaited trials, additional funding is being injected into this field and with new results expected, this proves an exciting area for scientific discovery. This paper reviews advances in pathophysiology, diagnosis, biomarkers and disease-modifying therapeutic treatments for PSP.
\end{abstract}

Keywords: PSP: progressive supranuclear palsy, 4R-tau: four-repeat tau, MAPT: microtubule-associated protein tau, PET: positron emission tomography. 


\section{Contents}

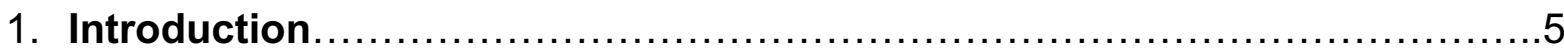

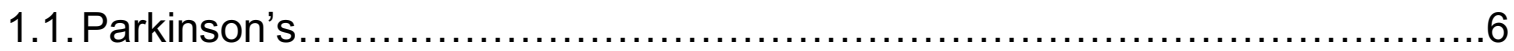

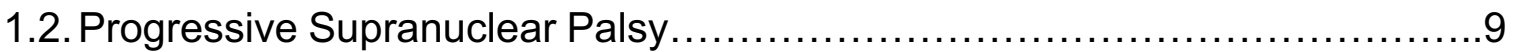

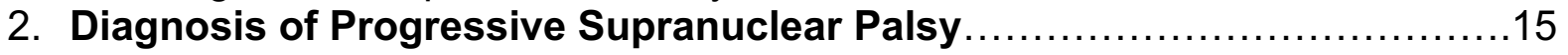

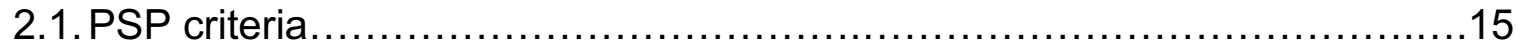

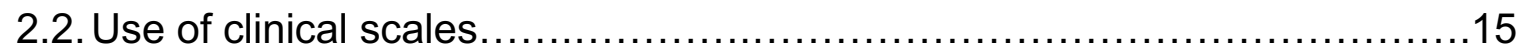

2.3. Comparison of PSP clinical phenotypes..................................16

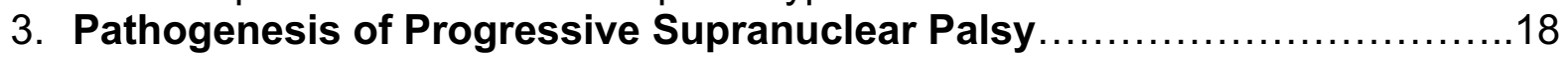

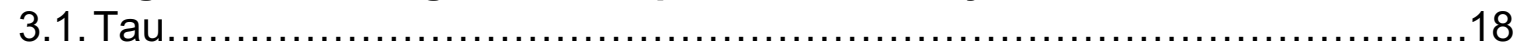

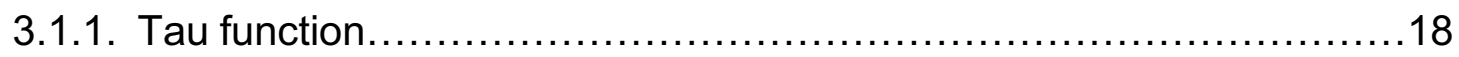

3.1.2. Abnormal post-translational modification of tau.......................18

3.1.2.1. Hyperphosphorylation.....................................22

4. Differences in pathogenesis between PSP phenotypes......................24

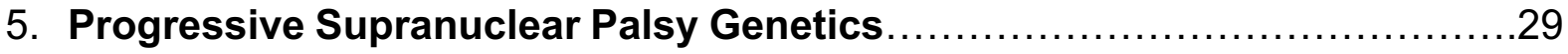

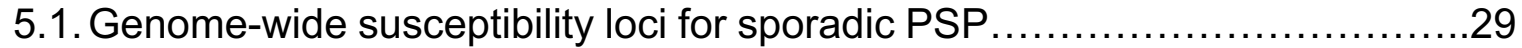

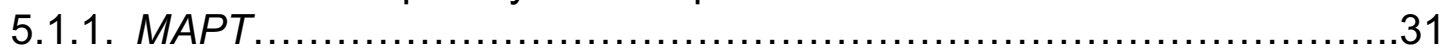

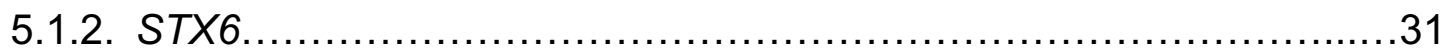

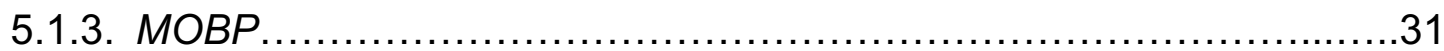

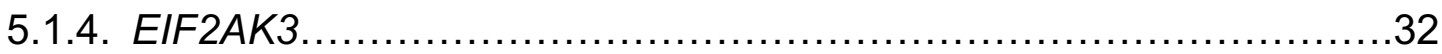

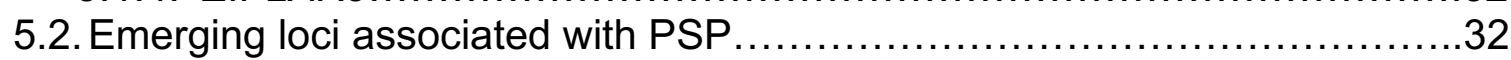

6. Comparisons of Progressive Supranuclear Palsy with Related

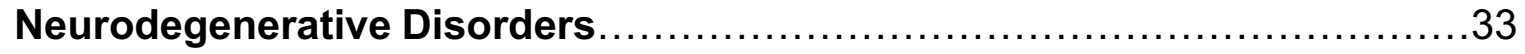

6.1. Differences in the clinical picture between AD, PD and PSP ...................33

6.2. Differences in brain pathology between $A D$ and PSP ........................36

7. Potential Therapeutic Biomarkers for Progressive Supranuclear Palsy ......39

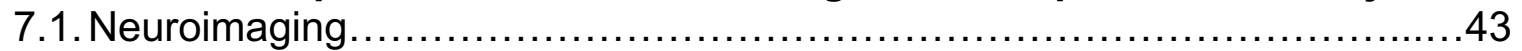

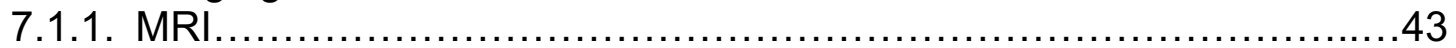

7.1.1.1. MRPI......................................................44

7.1.1.2. Diffusion Tensor, Diffusion Weighted, Free Water and Diffusion

Kurtosis Imaging ................................................... 44

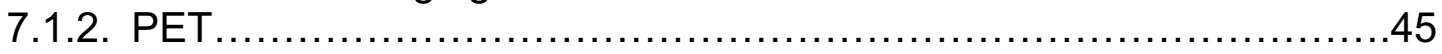

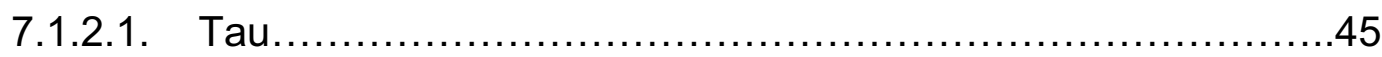

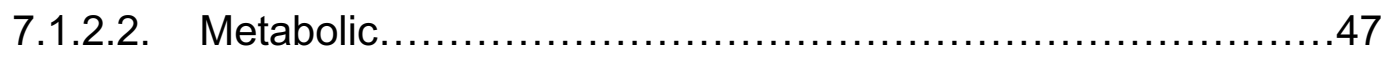

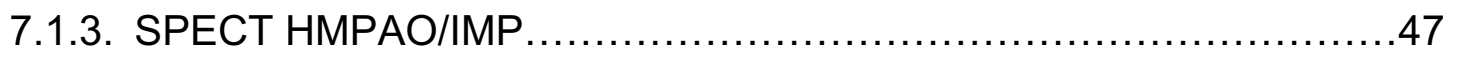

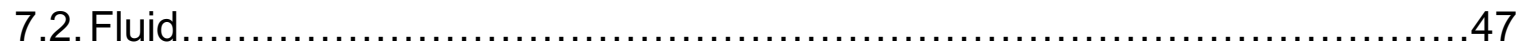

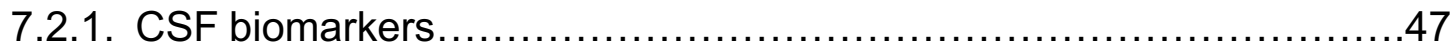

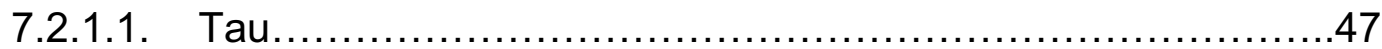

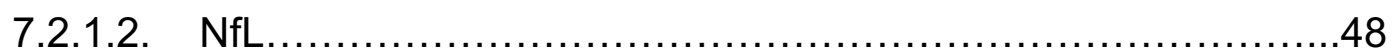

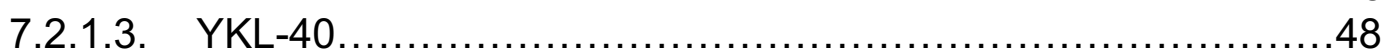

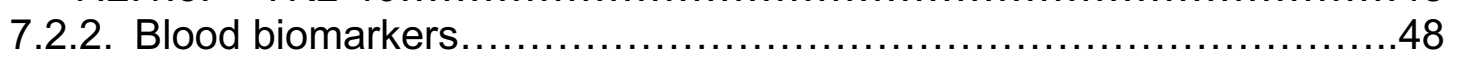

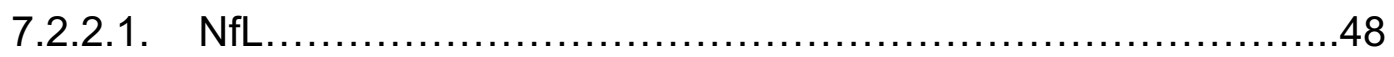

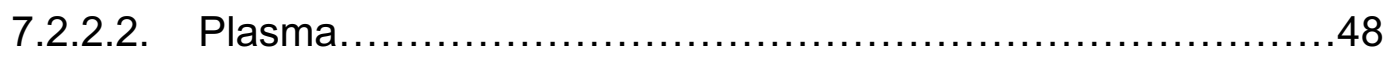

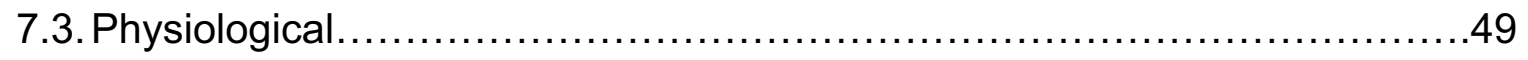

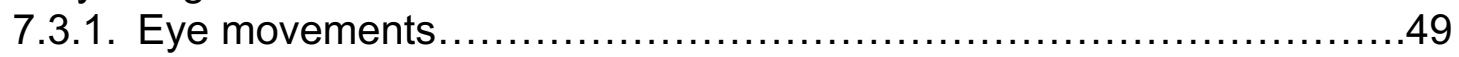

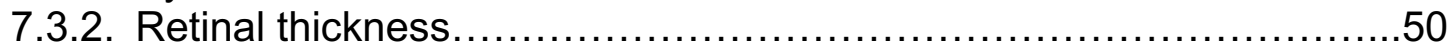

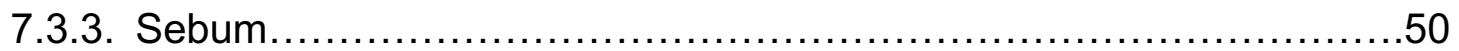

8. Therapeutic Targets for Progressive Supranuclear Palsy ...................51

8.1. Reduction of abnormal post-translational modifications ........................51 


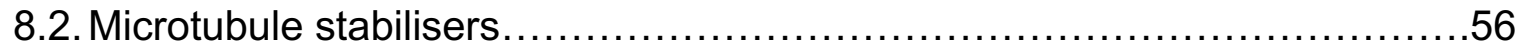

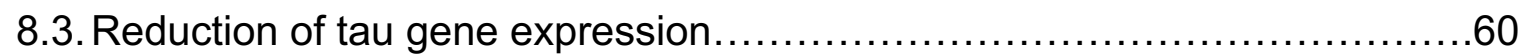

8.3.1. Anti-sense oligonucleotides.....................................60

8.3.2. Alternative RNA splicing modulators..................................60

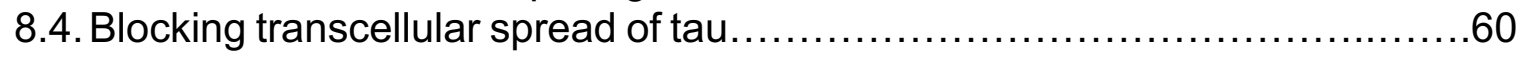

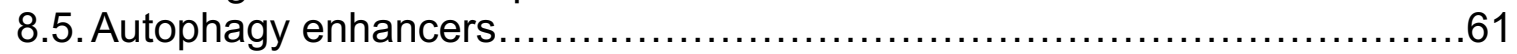

8.6. Attenuation of microglial activation and inflammation.......................61

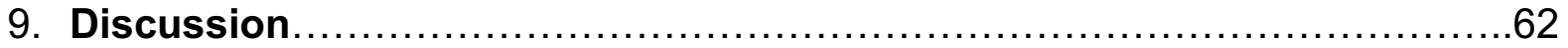

9.1. Current therapeutic strategies and associated problems $\ldots \ldots \ldots \ldots \ldots \ldots \ldots 62$

9.2. Evidence of drug administration, efficacy and delivery .......................62

9.3. Potential application of novel drugs for use in combination with existing

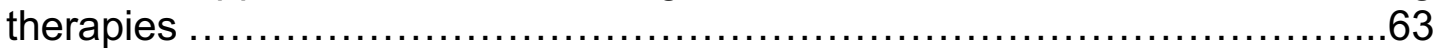

9.4. Proposed therapeutic direction and future implications.....................63

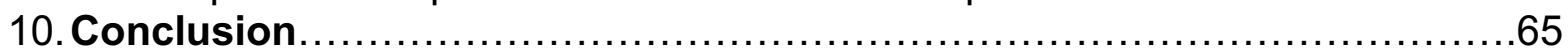

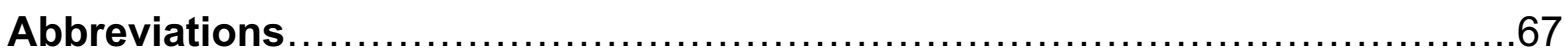

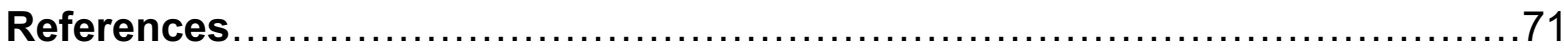




\section{Introduction}

Every hour two people are diagnosed with Parkinson's (PD) in the UK. ${ }^{1}$ Parkinson's is a heterogenous, progressive neurodegenerative disorder involving a plethora of molecular pathways and associated with variable motor and nonmotor characteristics. ${ }^{1}$ Parkinsonism encompasses a multitude of clinical syndromes characterised by profound movement difficulties that share similar symptoms to PD. ${ }^{2}$ Currently there are estimated to be ten million people worldwide living with PD. ${ }^{3} 85 \%$ of these victims have primary parkinsonism or idiopathic Parkinson's disease (PD). ${ }^{1}$ The remaining have secondary parkinsonism or atypical parkinsonism (APS) which encapsulate vascular parkinsonism, drug induced parkinsonism, dementia with Lewy bodies (DLB) multiple system atrophy (MSA), progressive supranuclear palsy (PSP), normal pressure hydrocephalus (NSA) and corticobasal syndrome (CBS). ${ }^{1}$ There are great difficulties in distinguishing between parkinsonism disorders, therefore research is vital to ensure accurate and early detection. Primary parkinsonism exhibits a strong response to levodopa whereas secondary parkinsonism has a weaker response. ${ }^{1}$ For this reason, a levodopa trial may be used to discriminate between primary and secondary parkinsonism.

APS syndromes, in particular PSP, are largely under-researched solely due to the limited number of patient cases ${ }^{4}$ compared with idiopathic PD. ${ }^{5}$ The deficiency in research dedicated to PSP has led to frequent misunderstandings in pathology and diagnosis. However, in recent years the landscape has transformed. With more attention directed towards PSP, the original classification as an APS syndrome may not hold true, with PSP being a separate disease with a different pathological process. Nevertheless, a sufficient understanding of PD is integral in order to distinguish between PSP and PD pathologies in an attempt to develop and modify effective treatments for PSP. In this paper both diagnostic biomarkers and therapeutic targets for PSP will be discussed. A biomarker is a characteristic that is measured as an indicator of the pathological processes associated with disease. This can be used in diagnosis and predicting progression in PSP. Therapeutic targets concern structures, molecular pathways and processes associated with PSP pathology which are treated using novel agents in an attempt to suppress pathogenesis. 


\subsection{Parkinson's}

In 1817 Dr James Parkinson first described this debilitating disorder PD as "shaking palsy"6 however earlier descriptions had been previously recorded. In 1872 JeanMartin Charcot discovered two prototypes: the tremorous and the akinetic/rigid form. ${ }^{7}$ Since then there has been a revolutionary development in understanding both clinical and pathophysiological aspects of the disease. The dramatic expansion in the clinical spectrum of parkinsonism ${ }^{8}$ has led to numerous difficulties in developing potential drugs and therapeutic treatments. The diversity in neuropathological phenotypes threatens potential drug prospects as questions remain as to whether a drug could be applicable for more than one phenotype. This accentuates the necessity to clinically diagnose the variant phenotype, in order to guide treatment.

The diagnosis of PD is based on the presence of 1) typical signs, 2) significant and sustained response to levodopa, ${ }^{9}$ and 3 ) absence of atypical features that would be suggestive of an alternative parkinsonism syndrome. ${ }^{10} \mathrm{~A}$ range of motor and nonmotor symptoms are associated with PD. The evolution of PD takes 5-7 years during the preclinical period, but conditions worsen under symptomatic diagnosis. ${ }^{11}$ Cardinal motor symptoms include the clinical triad bradykinesia, rigidity and tremor., 911,12 Nonmotor symptoms include autonomic dysfunction (constipation, sweating), neuropsychiatric (anxiety, dementia, depression), sensory (olfactory dysfunction, paraesthesia), sleep disturbance and other less common symptoms like weight loss. ${ }^{9}$ The quality of life for PD patients is severely lowered due to depressive tendencies ${ }^{13}$ where $5 \%-20 \%$ of patients have major depression and $10 \%-30 \%$ have minor depression. ${ }^{14,15,16}$ Research shows that nonmotor features tend to precede motor features of PD, which are only experienced after the loss of $50 \%$ to $80 \%$ of dopaminergic neurons. ${ }^{9}$ An estimated $80 \%$ of patients who suffer from PD twenty years after diagnosis have Parkinson's disease dementia, ${ }^{17}$ which is closely related to Lewy body dementia. ${ }^{18}$ In December 2019, The Guardian publicised that $26 \%$ of people with PD were initially misdiagnosed. ${ }^{19}$ As PD presents with subtle prodromal symptoms there is overlap between PD and other APS which due to the nature of their complex disease course, makes diagnosis challenging. ${ }^{20}$ These challenges highlight the requirement for an effective biomarker to ensure early and accurate detection of 
the disease and its variants. However, the invasiveness and expense of experimental procedures pose questions of the value of the proposed trial.

$P D$ is a synucleinopathy characterised by the abnormal aggregation of a-synuclein in neurons called Lewy bodies (LBs). ${ }^{21}$ The accumulation of abnormal $\alpha$-synuclein aggregates induces the progressive degeneration of nigral dopaminergic neurons located primarily in the substantia nigra pars compacta (SNpc) found in the basal ganglia of the brain. ${ }^{22}$ However, there is also widespread cell loss in several subcortical nuclei, including the locus coeruleus (LC). ${ }^{23}$ Dopamine is a catecholamine neurotransmitter involved in a range of neurological processes including motor control, cognition and movement. ${ }^{24}$ Apoptosis of dopaminergic neurons results in a fall in dopamine concentration in the striatum (the nigrostriatal pathway). ${ }^{24-26}$ As a result, this disturbs the intricate balance between dopaminergic inputs and cholinergic interneuron $(\mathrm{Chl})$ neurotransmission within the striatum inducing a range of the aforementioned motor symptoms. ${ }^{27}$

New evidence suggests that tauopathy is associated with PD onset. ${ }^{28,29}$ Tauopathies refer to heterogenous disorders characterised by abnormal tau aggregates in the brain. ${ }^{29}$ Axons are stabilised by microtubules (MTs) which are integrated with tau proteins encoded by the axonal microtubule associated protein tau gene (MAPT) (Fig. 1). ${ }^{28,30}$ Under pathological conditions tau proteins are post-translationally modified by abnormal hyperphosphorylation primarily at threonines ( $p$ Thr) or serines $(p S e r)^{30}$ causing them to form filamentous neurofibrillary tangles (NFTs) which disintegrate MTs. ${ }^{29-31}$ Hyperphosphorylated tau proteins interact with a-synuclein disrupting the microtubule network, causing aggregation and leading to the formation of LBs and consequent axonal transport malfunction. ${ }^{32}$ The MAPT gene comprises 16 exons on single chromosome $17 q 21 .^{33}$ There are six main isoforms of tau expressed in the human brain due to alternative splicing of exons E2, E3 and E10 around the Nterminal region. ${ }^{34-36}$ The isoforms differ in size ranging from 352 to 441 amino acids and depending on the absence or presence of two N-terminals (N1 and N2) and the three or four microtubule binding domains (3R and $4 R$ ). ${ }^{34,37}$ The $4 R$ tau has four microtubule binding repeat sequences due to the inclusion of $E 10$, which is not included in $3 \mathrm{R}$ tau. ${ }^{37}$ The more repeats that exist in the tau protein the stronger the binding affinity to the microtubule therefore $4 \mathrm{R}$ tau binds more easily and polymerises 
MTs. ${ }^{38}$ There are equal ratios of $3 R: 4 R$ tau in the human brain, however neurodegenerative disorders unbalance this ratio ${ }^{37}$ for example, PSP is characterised by the accumulation of $4 R$ tau in neuronal and glial cells. ${ }^{36}$

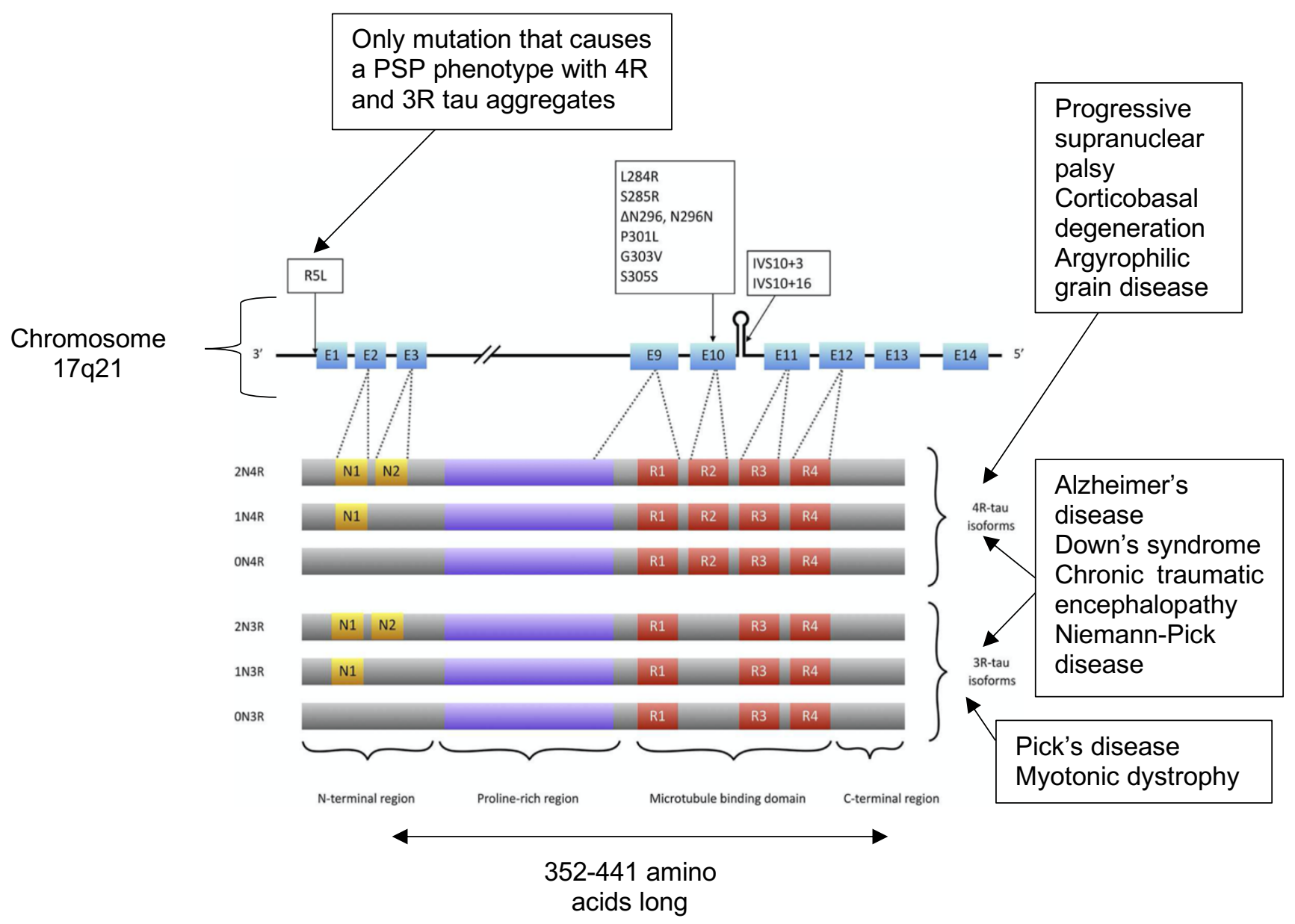

Fig.1 A schematic diagram showing the MAPT gene locus, mutations and human brain tau isoforms. The MAPT gene comprises 16 exons located on a single chromosome $17 q 21$. The six tau isoforms are formed from the alternative splicing of exons 2,3 and 10 (E2, E3 and E10). PSP-associated tau mutations are contained in the boxes above. Most tau mutations are located at E10 or E10's splice site with the exception of R5L. Figure adapted from Ref. 39. 


\subsection{Progressive Supranuclear Palsy}

PSP is a sporadic parkinsonism tauopathy described as the deposition of aggregations of abnormal, hyperphosphorylated 4-repeat tau (4R-tau) forming NFTs in neurons and glial cells in the basal ganglia and brainstem. ${ }^{31,40}$ PSP is the second most common form of parkinsonism after $\mathrm{PD}^{41}$ and the most common cause of death in PSP patients is pneumonia and sepsis. ${ }^{42}$ Over the last ten years there has been a dramatic breakthrough revealing a range of variants syndromes of PSP (VPSP) associated with PSP (Table 1). ${ }^{43}$ The phenotypic variants are related to the location of tau pathology in different brain regions which leads to varying distinguishable phenotypic features (Table 2). ${ }^{44}$ PSP was first described by Drs Steele, Richardson and Olszewski in 1964 and characterised by gait disturbance, joint stiffness, bradykinesia, axial stiffness and supranuclear gaze palsy. ${ }^{45}$ Later scientists discovered clinical presentations of subcortical dementia and early falling. ${ }^{46}$ This phenotype is named as Richardson's syndrome (PSP-RS). ${ }^{47}$ Data concerning PSP mostly comes from PSP-RS reports due to its highest frequency compared with other phenotypes and temporal evolution to PSP-RS in the declining stages of PSP subtypes is common (Table 2). ${ }^{48-50}$ The age-adjusted prevalence rate standardised to the European standard population for PSP was 5.7 per 100,000 of the general population( $\pm 3.8-7.6$ standard deviations). ${ }^{51}$ The age-adjusted incidence rate standardised to the European standard population for PSP was 1.3 per 100,000 of the general population $( \pm 0.9-1.8$ standard deviations $) .{ }^{51}$ This is higher than previously reported ${ }^{52}$ which could be due to an increased awareness of PSP-RS from updated diagnostic criteria and refined methodological practice. 
Table 1. Table containing the different variants of PSP.

\begin{tabular}{|l|l|}
\hline PSP-RS & Richardson's syndrome \\
\hline PSP-P & PSP with predominant parkinsonism \\
\hline PSP-CBS & $\begin{array}{l}\text { PSP with predominant corticobasal } \\
\text { syndrome }\end{array}$ \\
\hline PSP-PGF & $\begin{array}{l}\text { PSP with pure akinesia with progressive } \\
\text { gait freezing }\end{array}$ \\
\hline PSP-SL & $\begin{array}{l}\text { PSP with primary progressive apraxia of } \\
\text { speech or non-fluent variant primary } \\
\text { progressive aphasia (nfvPPA: when } \\
\text { caused by PSP, this disease is named } \\
\text { PSP with predominant speech or } \\
\text { language disorder) }\end{array}$ \\
\hline PSP-OM & $\begin{array}{l}\text { PSP with predominant ocular motor } \\
\text { function }\end{array}$ \\
\hline PSP-PI & PSP with postural instability \\
\hline PSP-F & $\begin{array}{l}\text { PSP with behavioural variant } \\
\text { frontotemporal dementia (bvFTD; when } \\
\text { caused by PSP, this disease is named } \\
\text { PSP with predominant frontal } \\
\text { presentation) }\end{array}$ \\
\hline PSP-PLS & PSP with primary lateral sclerosis \\
\hline PSP-C & PSP with predominant cerebellar ataxia \\
\hline
\end{tabular}

There has been a prolific expansion in the pathophysiology and clinical spectrum of PSP and the development of experimental drugs approved for clinical trials. ${ }^{43,53}$ This progress notwithstanding, there are still significant hurdles to overcome. The association of tau protein in PSP pathogenesis requires more evidence in humans and a greater understanding of the molecular mechanisms associated with tau. ${ }^{43,49}$ Early misdiagnosis of PSP with other parkinsonism disorders is common due to overlapping symptoms. ${ }^{54,55} \mathrm{~A}$ biomarker could alleviate the confounding symptomatology between phenotypes of PSP and other APS which would ensure an earlier and accurate diagnosis. However, different phenotypes react differently to experimental drugs and therapies which makes drug design and manufacture problematic. ${ }^{39,49}$ Table 2 confirms the varying responses to levodopa for PSP phenotypes. Therapeutic agents 
that exhibit new pharmacodynamic effects on their molecular targets and administered during earlier stages of disease are critical in therapy to delay disease progression. ${ }^{43}$ As certain subtypes of PSP are extremely rare, ${ }^{56}$ the progress in clinical trials may be impeded by the lack of eligible patients that are required for a large reputable trial. Furthermore, large pharmacology companies uphold strict regulations concerning global sharing of clinical data which limits therapeutic development. 
The exact aetiology for the multifactorial disease PSP is still unknown, although specific genetic defects and exposure to environmental factors pose as PSPassociated risk factors (Table 3 ). There has been an exponential acceleration in the rate of genetic discovery for PSP with the most well-known risk factor concerning mutations in the MAPT gene. ${ }^{57}$ Identification of additional risk loci have been founded from genome-wide association studies. ${ }^{58}$ These studies will provide a greater understanding of PSP pathogenesis giving direction for therapeutic approaches.

The principal risk factor associated with onset of PSP is age advancement. ${ }^{59}$ The presence of lysosomal and mitochondrial dysfunctions, due to oxidative stress and accumulation of misfolded proteins, initiates neuronal aging. ${ }^{60}$ Older people have been exposed to oxidative stress for a longer period and so endured more genetic mutations. The loss of regulation due to genetic mutation of these genes will result in neuronal impairment and induce the PSP motor and nonmotor symptoms cascade.

The first case-control study to investigate whether exposure to environmental toxins triggers the onset for PSP was only carried out in 2016. ${ }^{61}$ The results fail to provide a causative agent and further identification of specific toxicants remain elusive. Recently it was discovered that induced pluripotent stem cell (iPSC)-derived iNeurons with the PSP-related tau variant R406W were more sensitive to chromium ( $\mathrm{Cr}$ ) and nickel (Ni), which operate through different mechanisms to induce apoptosis. ${ }^{62}$ Exposure to neurotoxic doses of $\mathrm{Cr}$ and $\mathrm{Ni}$ increases the phosphorylation of tau and therefore regarded as a potent risk factor for promoting tauopathy and neuronal death. ${ }^{62}$ PSPrelated mutation carriers with sensitivity to $\mathrm{Cr}$ and Ni-induced apoptosis may predispose neurodegeneration. ${ }^{62}$ In PD studies, results have shown that gene mutations could aggravate the effects of environmental toxins. ${ }^{11}$ This may hold true for PSP which could make data concerning environmental risk factors less reliable. 
Table 3. A summary of the common genetic and environmental risk factors for PSP.

\begin{tabular}{|c|c|}
\hline & Neurological mechanism \\
\hline \multicolumn{2}{|l|}{ Genetic } \\
\hline $\mathrm{Age}^{a}$ & $\begin{array}{l}\text { Higher levels of lysosomal and mitochondrial } \\
\text { dysfunctions due to oxidative stress and accumulation } \\
\text { of misfolded proteins in older people }\end{array}$ \\
\hline$M A P T^{b}$ & $\begin{array}{l}\text { Mutations in MAPT lead to abnormal phosphorylation } \\
\text { and aggregation of tau }\end{array}$ \\
\hline \multicolumn{2}{|l|}{ Environmental } \\
\hline $\begin{array}{l}\text { Heavy metals such as } \\
\text { chromium and nickel }\end{array}$ & $\begin{array}{l}\text { iPSC-derived iNeurons from MAPT more sensitive to } \\
\text { cell death induced by } \mathrm{Cr} \text { and } \mathrm{Ni}\end{array}$ \\
\hline
\end{tabular}

Original table with data taken from ${ }^{a}$ Ref. 59. ${ }^{b}$ Ref. 57. ${ }^{c}$ Ref. 62.

Whilst the primary cause of PSP still remains ambiguous, it is important to define the clinical phenotypes of PSP to guide therapeutic treatment. This paper will analyse PSP pathophysiology; explore potential therapeutic targets and biomarkers; address salient issues with regards to drug development with the ultimate goal of developing a disease-modifying therapy before severe functional disability persists. 


\section{Diagnosis of Progressive Supranuclear Palsy}

\subsection{PSP criteria}

In 2017, the International Parkinson and Movement Disorder Society (MDS) endorsed PSP Study Group established a revised clinical diagnostic criterion for PSP. This transformed diagnosis by allowing recognition of several PSP phenotypes and the development for new therapeutic strategies for PSP. ${ }^{53}$ Experiments have shown that distinguishing between VPSP is hard due to overlapping symptoms forming false positives. ${ }^{55}$ Clinicians must exert a broader diffusion of diagnostic criteria for PSP to ensure results are consistent and therefore comparable. The lack of enrollment from patients with rare phenotypes ${ }^{63}$ will prevent future advances in pathophysiological and mechanistic discovery.

\subsection{Use of clinical scales}

At present, there are two established disease-specific scales for PSP including: the PSP rating scale (PSPRS) and PSP-Quality of Life Scale. These scales act as indicative tools used to evaluate the severity and progression of the disease. ${ }^{64,65}$ Clinicians employ these methods to facilitate experimental predictions and comparisons of PSP phenotypes. An MDS-endorsed PSP study group recently embarked on inventing the PSP-Clinical Deficits Scale (PSP-CDS) ${ }^{66}$ The aim was to develop a scale that is equally applicable to all VPSP to measure motor clinical deficits; predict annual progression rates; compliant in clinical care and research situations and simple to use whilst upholding robust clinimetrics. ${ }^{66}$ PSP-CDS was formulated to encompass seven clinical domains (Akinesia-rigidity, Bradyphrenia, Communication, Eye movements, Finger dexterity and Gait $\&$ balance) which were assessed under four response categories $[0=$ no deficit; $1=$ mild deficits; $2=$ moderate deficits that require some external support to maintain normal daily activities; $3=$ severe deficits that debilitate activities of daily living (ADLs) and need constant external support. ${ }^{66}$ Additionally, clinical studies often use the Schwab and England Activities of Daily Living Scale (SEADL) when assessing patient responses in order to accurately assess the capabilities of participants suffering from impaired mobility. ${ }^{67,68}$ 


\subsection{Comparison of PSP clinical phenotypes}

PSP phenotypes can be defined by physical characteristics (Table 2) and numerical data (Table 4). The oldest age of onset for disease is PSP-PGF and PSP-F compared with other clinical variants. PSP-P has the longest disease duration of 6.6 years. A $p<0.001$ suggests statistical significance. ${ }^{69}$ This is typical for PSP-P as early in the disease course the variant is categorised by the presence of non-PSP clinical features. ${ }^{69}$ The highest rate of dementia was noted in PSP-RS patients $(47.8 \%)$ compared with PSP-PGF with the lowest rate. ${ }^{70}$ Therefore, data in table 4 suggests that PSP-RS is the most severe phenotype whilst PSP-PGF is one of the most benign, findings that are echoed in the literature..$^{53}$ 
Table 4. Key clinical statistics and rates for PSP phenotypes.

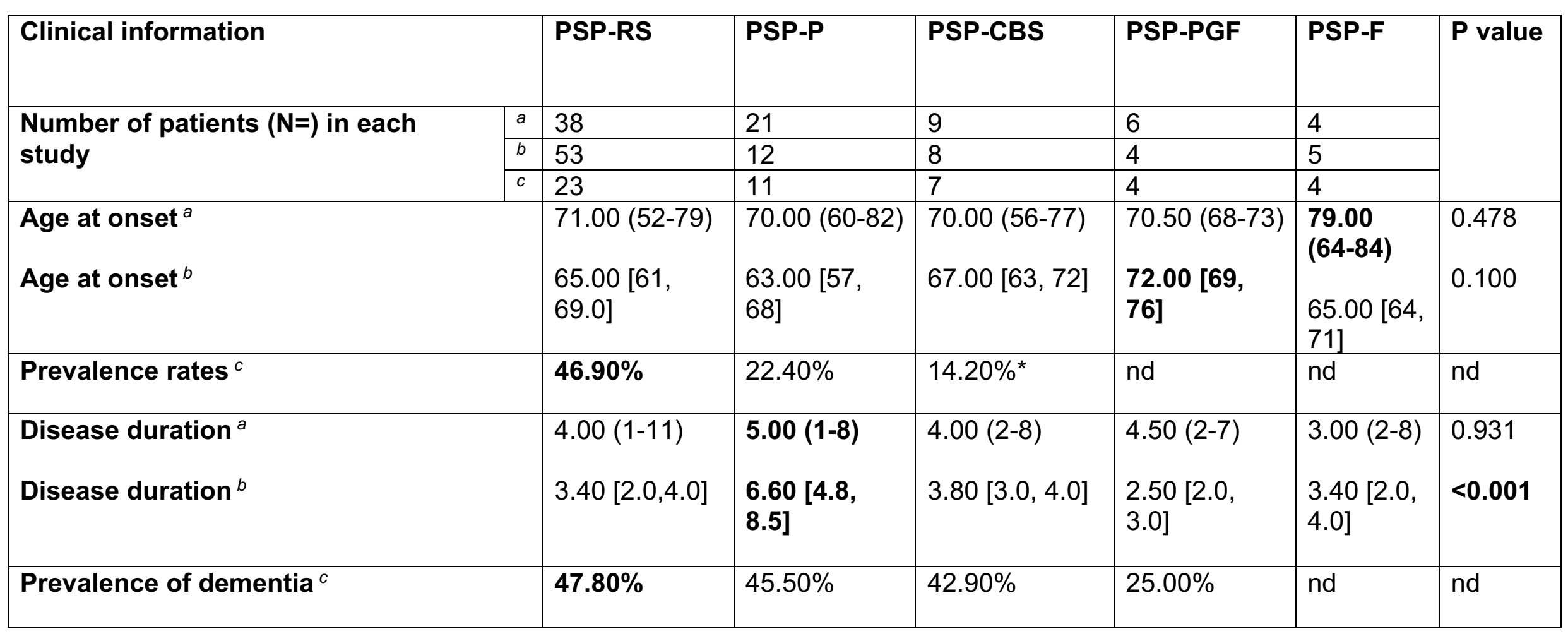

Original table with data taken from ${ }^{a}$ Ref. $63 .{ }^{b}$ Ref. $69 .{ }^{C}$ Ref. 70.

Significant data in bold.

*: Figure is skewed due to larger cohort as group includes PSP and CBS patients.

(): range.

[ , ]: Inter-quartile range.

nd: no data available.

$P$ value $<0.05$ is significant.

Data not available for PSP-OM, PSP-PI, PSP-SL. 


\section{Pathogenesis of Progressive Supranuclear Palsy}

4R-tau is over-expressed in PSP patients compared with healthy individuals who have equal proportions of $3 \mathrm{R}$ and $4 \mathrm{R}$-tau. ${ }^{39} \mathrm{PSP}$ is characterised by tau deposition in NFTs, ${ }^{31}$ coiled bodies, tufted astrocytes and threads. ${ }^{45}$ Hyperphosphorylated 4R-tau amalgamates into 13-14nm straight filaments forming dense NFTs in neurons and glial inclusions which are derived from "tufted" astrocytes. ${ }^{71}$

\subsection{Tau}

The pathology of PSP concerns the microtubule-associated protein, tau which is encoded by MAPT. ${ }^{57,72}$ Tau pathology is strongly associated with interference of microtubule function. ${ }^{73}$ Since the discovery of 4R-tau deposits in clinically diagnosed patients with PSP, the attention to tau-based therapies has been intensified.

\subsubsection{Tau function}

The majority of tau protein is found in axons and expressed extensively in the brain. ${ }^{39}$ Tau binds to the microtubule surface through the microtubule-binding-domain (MBD) and adjacent regions ${ }^{74}$ providing stabilisation to the microtubules that construct neuronal axons. The intercellular binding interaction could be associated with regulation of axonal transport. ${ }^{74,75}$ Recent trials using tau-knockout mice have unveiled novel functions of tau such as: DNA integrity, regulation of neuronal activity, neurogenesis, iron export. ${ }^{74}$ However, the developmental role of tau remains unclear due to inherent difficulties in translating mouse brain data to human brain data. ${ }^{76}$ The ability to assess the biochemical and pathological pathway of tau will improve the chances of developing an effective diagnostic biomarker to monitor tau pathogenesis.

\subsubsection{Abnormal post-translational modifications of tau}

When tau fibrilizes, it undergoes abnormal post-translational modifications (PTMs) of tau which are associated with the pathogenesis of PSP and include primarily phosphorylation and less frequently acetylation, ${ }^{77}$ O-GlcNAcylation, ${ }^{78}$ and truncation. ${ }^{79}$ A schematic diagram summarises the clinical profile of tau pathogenicity for PSP (Fig. 2). PTMs of tau impact the physiological functions of tau such as the structure of tau, binding affinity to MTs and aggregation proclivity. ${ }^{80}$ These 
disturbances alter the toxic profile of tau which plays a crucial role in PSP aetiology. ${ }^{81}$ There is a lack of precise tools and procedures that can introduce site-specific alterations in tau which complicates the understanding of the specific role of PTMs in tau in PSP. 82 


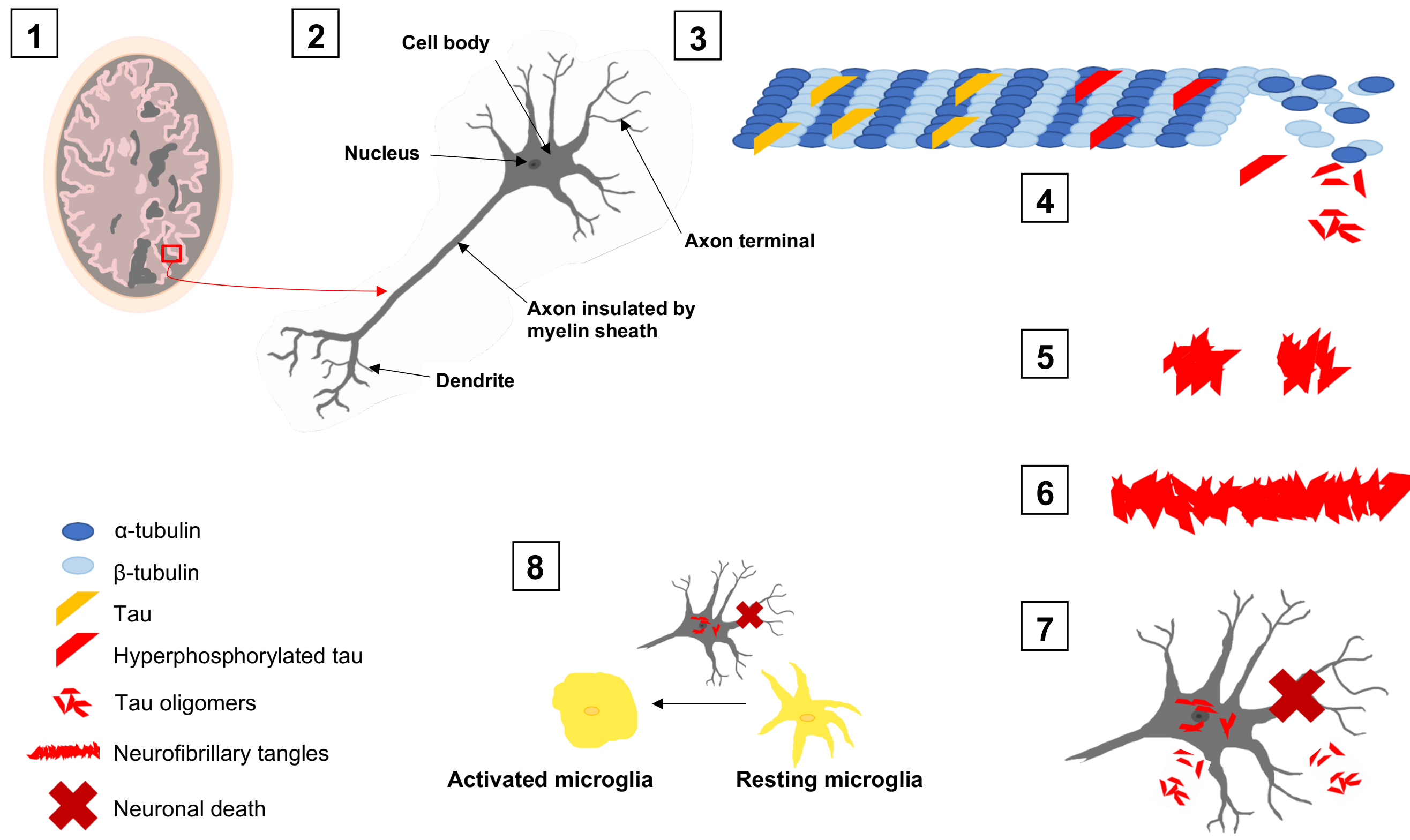

Fig. 2 Schematic diagram of tau pathogenesis in Progressive Supranuclear Palsy. (See full figure legend on next page.)

19


Fig. 2 Schematic diagram of tau pathogenesis in Progressive Supranuclear Palsy.

1. Healthy Vs. PSP brain. MRI images of a PSP brain reveals loss of tissue from grey and white matter atrophy. The LHS shows the healthy brain and the RHS shows the diseased brain.

2. Neuron structure. A labelled structure of a neuron which is made up of microtubules concentrated mainly in the axon and dendrites.

3. Destabilised microtubules. A MT is made up of $\alpha$-tubulin and $\beta$-tubulin heterodimers. MT's are very dynamic constantly switching between polymerisation and depolymerisation states. MT-associated proteins (MAPS) including Tau, stabilise MTs. Mutation in MAPT leads to hyperphosphorylation of tau initiating excessive MT depolymerisation.

4. Release of hyperphosphorylated tau. Hyperphosphorylated tau monomers detach from MTs during MT depolymerisation.

5. Aggregation of tau oligomers. Hyperphosphorylated tau forms oligomers which aggregate into paired helical filaments.

6. Formation of NFTs. Paired helical filaments aggregate to form NFTs.

7. Neuronal death. Microtubule collapse and formation of NFTs impairs neurotransmission along axons and synaptic connections causing neuronal death and release of hyperphosphorylated tau oligomers into extracellular environment.

8. Activation of microglia. Neuronal damage and apoptosis signals production of neuroinflammatory cytokines and microglial activators which convert resting microglia into activated microglia. Activated microglial cells release pro-inflammatory mediators and chemokines such as interleukin-1 $\beta$ which leads to inflammation and activation of kinases that continue the production of hyperphosphorylated tau.

Original figure hand drawn in PowerPoint using information from Ref. 29. Ref. 30. Ref. 31. Ref. 45. Ref. 69. Ref. 74. Ref. 80. Ref. 83. Ref. 84. 


\subsubsection{Hyperphosphorylation}

Most studies have focussed on investigating the role of tau phosphorylation compared with other PTMs due to: 1) pathological tau is hyperphosphorylated in many tauopathies; ${ }^{29,30}$ 2) tau hyperphosphorylation affects microtubule stability; ${ }^{29,30} 3$ ) phosphorylation is the most common tau PTM. ${ }^{29}$ In a human brain there are a potential of 85 epitopes that can be phosphorylated of which 16 epitopes are phosphorylated in PSP brains compared to 10 epitopes in normal brains. ${ }^{85}$ The phosphorylation occurs at threonines or serines in the $\mathrm{N}$ - and $\mathrm{C}$-terminal domains of the amino acid sequence of MAPT and is mediated by GSK-3 $\beta$, DYRK1A and PP2A. ${ }^{76}$ The soluble and linear tau protein which has undergone this post-translational modification becomes insoluble and misfolded resulting in conformational changes in microtubules and formation of aggregates of tau called NFTs. ${ }^{31}$ The discovery of NFTs was detected using antibodies modelled to target phosphorylated tau. ${ }^{86}$ The formation of NFTs is accompanied by the formation of unique binding sites which can be targeted with small molecule probes. ${ }^{87}$ This evidence has been exploited to construct therapeutic ligands ${ }^{88}$ with the goal of identifying the molecular pathway and role of NFTs in disease. Hyperphosphorylation of $\mathrm{N}$ - and C-terminal domains decreases the interaction with the repeat domain and subsequent exposure of the repeat domain may increase tau filament aggregation. ${ }^{89}$ This important finding could direct therapy to focus on manipulation of the repeat domain.

Researchers published that phosphorylated tau displays a positive interaction with $\alpha$ synuclein which are both contained in Lewy bodies surrounded by NFTs. ${ }^{86,90}$ However, investigations into the toxic interaction between the two proteins are on-going. ${ }^{28}$ Scientists propose that there is a cascade reaction at synapses involving the aggregations of abnormal $\alpha$-synuclein and tau which leads to inhibition of axon functionality. ${ }^{91}$ However, repeat experiments are required to confirm this is fact.

Hyperphosphorylation results in neuroinflammation. PET studies show that brain macrophages and microglia are activated in PSP brains. ${ }^{83}$ High levels of proinflammatory cytokines such as interleukin-1 $\beta^{194}$ and 5 -lipoxygenase enzyme ${ }^{92}$ have been reported in PSP brains. These are released in response to neuronal damage following the formation of NFTs (Fig. 2). ${ }^{84,92}$ The creation of a 
proinflammatory cytokine blocker could potentially be included in the therapeutic strategy. 


\section{Differences in pathogenesis between PSP phenotypes}

The severity and distribution of pathological tau and atrophy varies in affected regions of the brain in different PSP phenotypes (Fig. 3 and Fig. 4). PSP-RS tau pathology is estimated to begin in the pallido-luysonigral areas extending to the pontine nuclei, other basal ganglia structures, cerebellar dentate nucleus and frontal and parietal cortices. ${ }^{39}$ It is visible that the subthalamic nucleus (STN) is the most severely affected region of the brain in PSP-RS patients (Fig. 3f). It is clear that patients with PSP-P and PSP-PGF experience less severe tau pathology than PSP-RS patient although there are overlaps in pattern and distribution of tau aggregations (Fig. $3 \mathrm{c}$ and Fig. $3 \mathrm{~d}$ ).

Whitwell et al. presents neuroimaging analyses of brain atrophy using MRI and $\left[{ }^{18}\right]$ flortaucipir uptake on PET across PSP variants to improve understanding of pathological differences and similarities. ${ }^{69}$ The voxel-level analysis (Fig. 4) shows that PSP-SL has the greatest grey and white matter loss throughout the frontal lobes. Fig. 4 shows that white matter volume loss is concentrated to the midbrain for PSP-P and PSP-PGF compared with controls. For PSP-RS, PSP-F and PSP-CBS, considerable white matter volume loss is shown in the midbrain and superior cerebellar peduncle. The findings from the study show that all PSP variants exhibit signs of atrophy in the striatum, thalamus and globus pallidus (GP) which emulates the shared clinical features and allows us to isolate common pathophysiological mechanisms. A comparative analysis of tau burden across all four lesion types in VPSP shows that PSP-P and PSP- PGF had the lowest tau burden in superior frontal and motor cortices whereas PSP-SL and PSP-CBS shows the highest. ${ }^{69} \mathrm{PSP}-\mathrm{SL}$ and PSP-CBS show only mild burden of coiled bodies compared with moderate to severe in other VPSP. ${ }^{69}$ The neuroimaging analysis shows encouraging results to aid in early differential diagnosis between VPSP however no concrete measures to differentiate PSP-CBS from PSP-F and PSP-P from PSP-PGF were found. The study lacks a sufficient number of PSP-PGF and PSP-F patients questioning the reliability of the results obtained. Patients with the PSP-OM or PSP-PI variant were not included instigating that shared mechanistic pathways may not be entirely analogous across the PSP spectrum. The results highlight that anatomical and tau burden heterogeneity reflects the clinical diversity across the VPSP. The different patterns of subcortical 
circuitry discovered suggest there needs to be a targeted approach in developing specific biomarkers for vPSP. 


\section{(a) Core anatomical structures of the brain}

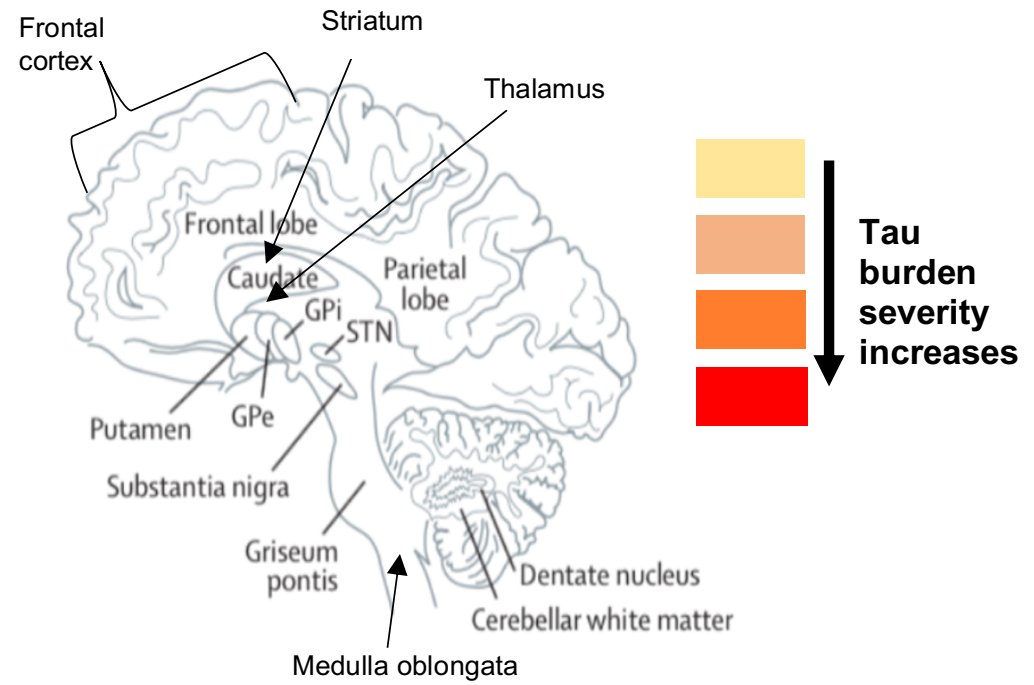

(c) PSP-RS or PSP-P or PSP-PGF

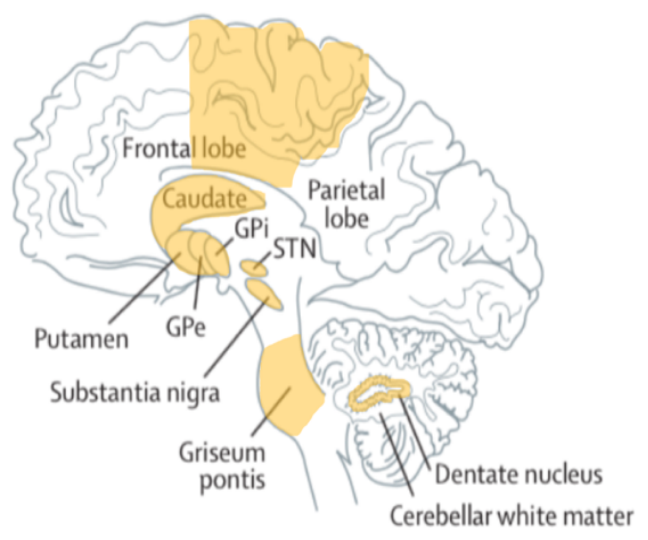

(e) PSP-RS

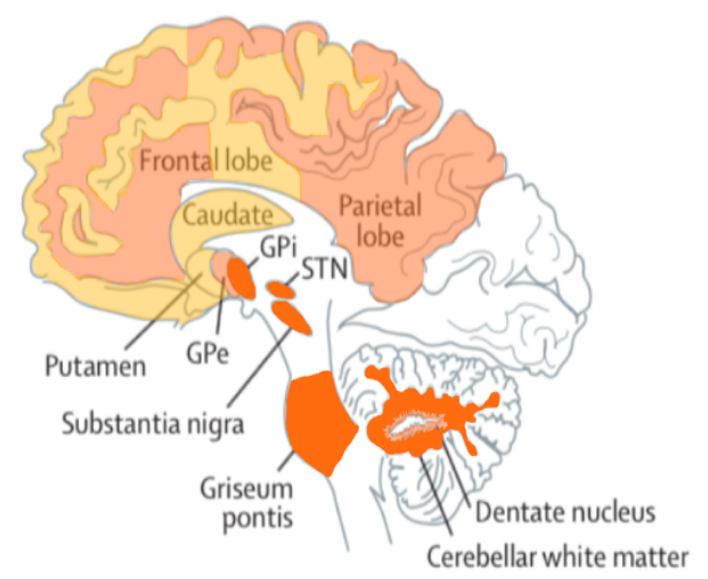

(b) PSP-P or PSP-PGF

STN and SN = most affected areas in all PSP phenotypes

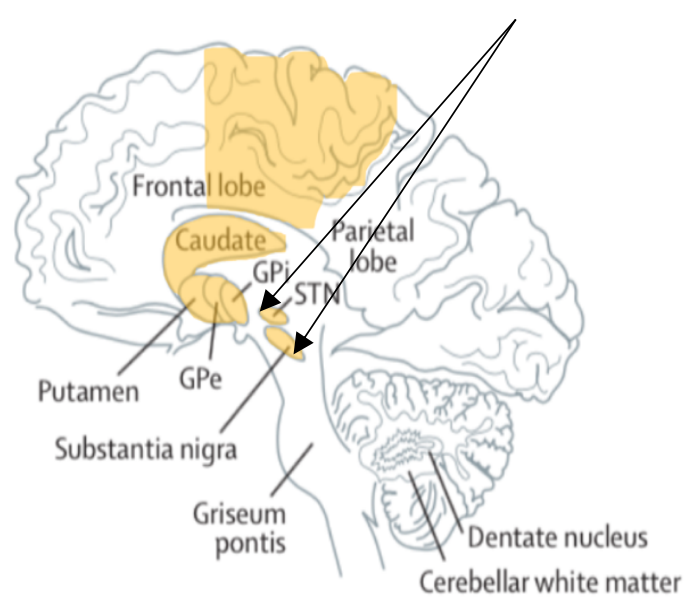

(d)

\section{PSP-RS or PSP-P or PSP-PGF}

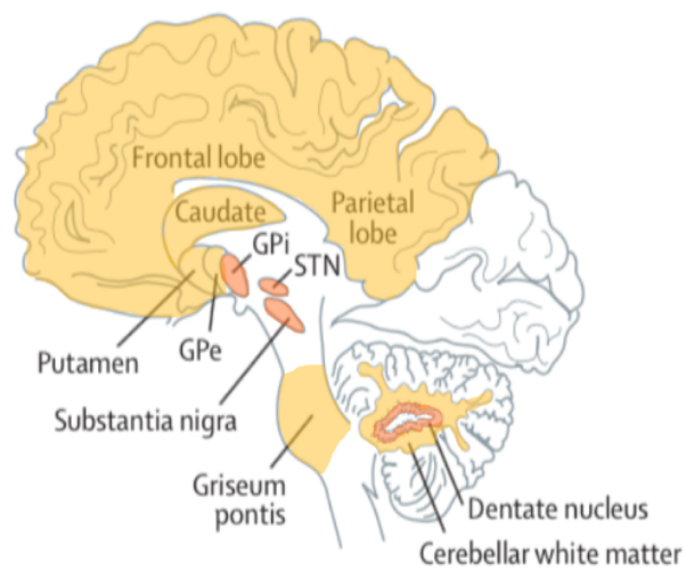

(f)

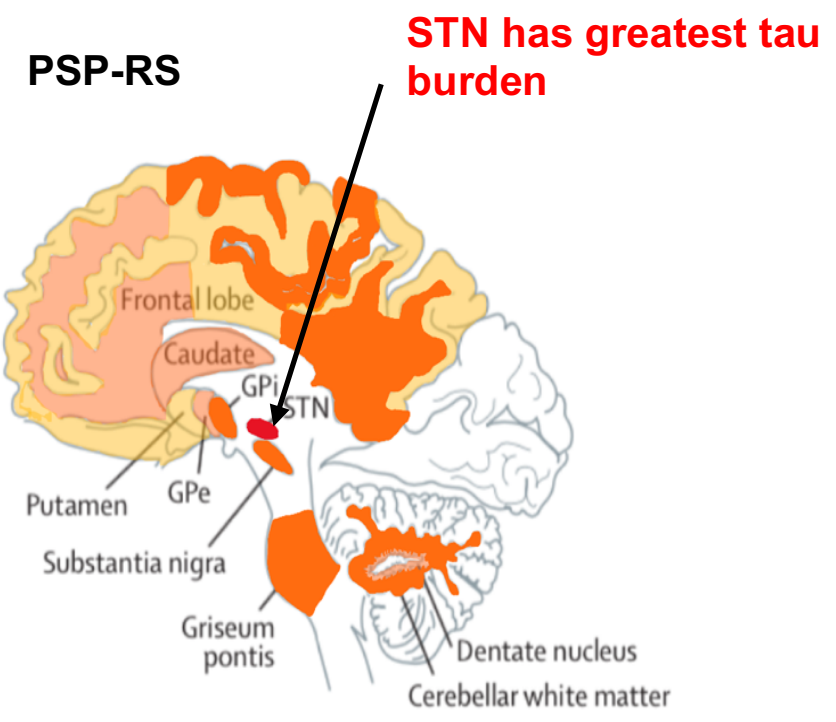

Fig. 3 Changes to distribution and pattern of tau pathology in PSP brains as disease deteriorates. (See full figure legend on next page). 
Fig. 3 Changes to distribution and pattern of tau pathology in PSP brains as disease deteriorates.

a) An annotated diagram of the core anatomical structures of the brain including the particular brain regions affected by PSP.

b) An annotated diagram showing the brain areas affected by tau aggregations for mild or early PSP-P or PSP-PGF.

C) An annotated diagram showing the brain areas affected by tau aggregations for PSP-P, PSP-PGF or early PSP-RS.

d) An annotated diagram showing brain areas affected by different levels of tau burden for PSP-P, PSP-PGF or PSP-RS.

e) An annotated diagram showing brain areas affected by different levels of tau burden for PSP-RS.

f) An annotated diagram showing brain areas severely affected by tau burden for late stage PSP-RS.

GPe: globus pallidus externa.

GPi: globus pallidus interna.

SN: substantia nigra.

STN: subthalamic nucleus.

Data not available for PSP-CBS, PSP-OM, PSP-PI, PSP-SL, PSP-F.

Image of brain taken from Ref. 44. which has been significantly adapted and personalised in (a)-(f) to show disease progression. Original figure using data from Ref. 69. 
Left lateral Right lateral Left medial Right medial

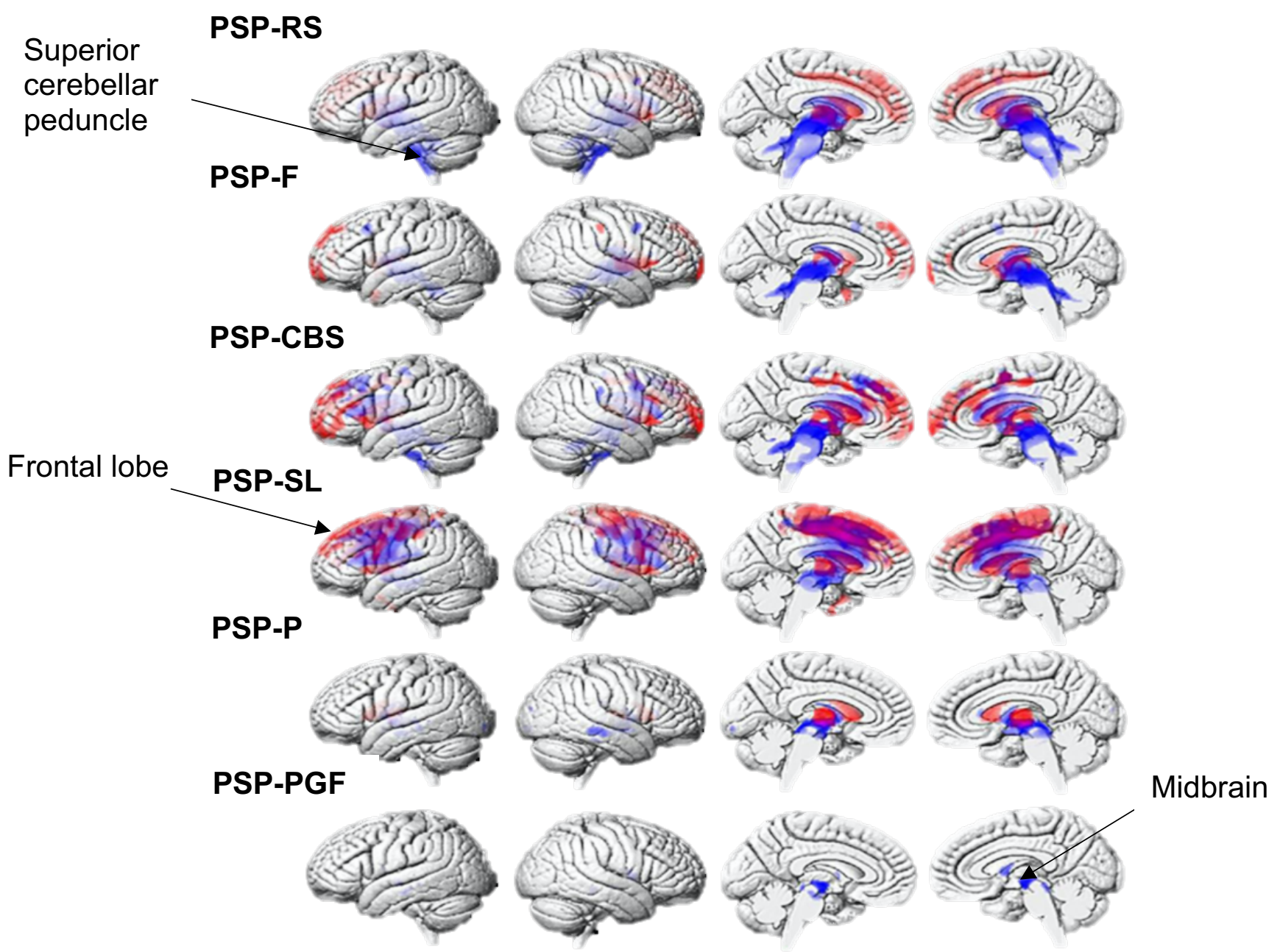

Fig. 4 Three-dimensional MRI volume analysis (voxel-level analysis) showing grey (shown in red) and white (shown in blue) matter volume loss in different PSP phenotypes compared to controls.

Boxes contain important brain structures suffering from high levels of white and/or grey matter atrophy. Data not available for PSP-PI and PSP-OM. Figure adapted from Ref. 69. 


\section{Progressive Supranuclear Palsy Genetics}

Familial (monogenic) PSP is defined as causative mutations in single genes transmitted by Mendelian inheritance in families (autosomal dominant or autosomal recessive).${ }^{93}$ Sporadic (idiopathic) PSP, which is the most common type, is associated with numerous genetic mutations in combination with environmental factors. ${ }^{93}$ As PSP is a prototypical tauopathy, an understanding of PSP-associated alleles will help determine the molecular mechanism of tau pathology ${ }^{94}$

\subsection{Genome-wide susceptibility loci for sporadic PSP}

The largest independent genome wide association study (GWAS) for PSP to date by Höglinger et al. identified the single nucleotide polymorphisms (SNPs) associated with PSP: MAPT, STX6, MOBP, and EIF2AK3. ${ }^{95}$ Three of the previously reported susceptibility loci (MAPT, STX6, MOBP) were confirmed by two recent GWAS meta analyses that combined disease cohorts. ${ }^{94,96}$ Chen et al. and Sanchez-Contreras et al. each identified a total of six genome-wide significant loci with representative SNPs (Table 5) ${ }^{94,96}$ By studying genome-wide meta analyses it is becoming more evident of the oligogenic genetic architecture in PSP which exposes potential inhibitors as a targeted therapeutic strategy. 
Table 5. Summary of significant and suggestive loci associated with PSP.

\begin{tabular}{|c|c|c|c|}
\hline SNP variants* & Chromosome & Gene & Comments/ Judgements \\
\hline rs8070723a & \multirow[t]{4}{*}{$17 q 21.31$} & \multirow[t]{4}{*}{ MAPT } & $\begin{array}{l}\text { Accepted as a risk factor } \\
\mathrm{H} 1-\mathrm{H} 2 \mathrm{SNP}\end{array}$ \\
\hline rs242557a & & & $\begin{array}{l}\text { Accepted as a risk factor } \\
\text { H1c subhaplotype conditioned } \\
\text { on rs } 8070723\end{array}$ \\
\hline rs $12185268^{b}$ & & & $\begin{array}{l}\text { Accepted as a risk factor } \\
\text { Most significant SNP }\end{array}$ \\
\hline rs71920662 & & & Accepted as a risk factor \\
\hline rs57113693 $3^{b, c}$ & \multirow[t]{2}{*}{$1 \mathrm{q} 25.3$} & \multirow[t]{2}{*}{ STX6 } & Accepted as a risk factor \\
\hline rs1411478a & & & Accepted as a risk factor \\
\hline rs $1768208^{a}$ & \multirow[t]{2}{*}{$3 p 22.1$} & \multirow[t]{2}{*}{$M O B P$} & Accepted as a risk factor \\
\hline rs1067554c & & & Accepted as a risk factor \\
\hline rs7571971a & $2 \mathrm{p} 11.2$ & EIF2AK3 & $\begin{array}{l}\text { SNP in EIF2AK3 failed to } \\
\text { reach genome-wide } \\
\text { significance }^{c} \\
\text { Strong association with PSP }\end{array}$ \\
\hline rs35740963 ${ }^{b}$ & $6 \mathrm{p} 21.1$ & RUNX2 & Role in PSP unknown \\
\hline rs7966334 & \multirow[t]{2}{*}{$12 \mathrm{p} 12.1$} & \multirow[t]{2}{*}{ SLCO1A2 } & Strong association with PSP \\
\hline rs11568563a & & & $\begin{array}{l}\text { Mutation in minor allele } \\
\text { reported low expression in } \\
\text { brain }\end{array}$ \\
\hline rs12203592a & 6 & IRF4 & $\begin{array}{l}\text { Age may influence mutation. } \\
\text { Further investigation required. }\end{array}$ \\
\hline rs12125383c & $1 q 41$ & DUSP10 & $\begin{array}{l}\text { Suggestive loci } \\
\text { Possibly impacts tau } \\
\text { hyperphosphorylationa }^{a}\end{array}$ \\
\hline rs564309 & $1 q 42.13$ & TRIM11 & $\begin{array}{l}\text { May be a genetic modifier of } \\
\text { clinical phenotype in PSP }\end{array}$ \\
\hline rs147124286 & $12 q 13.13$ & SP1 & Suggestive loci \\
\hline rs204509c & $8 q 24.21$ & ASAP1 & Suggestive loci \\
\hline rs114573015 & $1 \mathrm{p} 22.3$ & WDR63 & Suggestive loci \\
\hline rs749873e & 2 & CXCR4 & $\begin{array}{l}\text { Mutations in microglial gene } \\
\text { associated with increased risk } \\
\text { of PSP }\end{array}$ \\
\hline
\end{tabular}

Original table with data taken from ${ }^{a}$ Ref. 96. ${ }^{b}$ Ref. 97. ${ }^{C}$ Ref. 94. ${ }^{d}$ Ref. 98. ${ }^{e}$ Ref. 99. *SNPs are inside the gene or near the gene on the chromosome. The SNPS included are the most current variants under review. 


\subsection{1. $M A P T$}

MAPT is the most strongly linked gene to PSP. ${ }^{43}$ Tau encoded by MAPT gene contains 16 exons and is located on chromosome 17q21. ${ }^{35,39}$ The six isoforms of tau are produced by the alternate splicing of exons 2,3, and 10 (Fig. 1). ${ }^{35,39}$ Each tau isoform is formed by 4 domains: phosphatase-activation domain (PAD); MT binding region ( 3 or 4 repeat domains); a proline rich domain; and C-terminal domain. ${ }^{39}$

The human MAPT gene involves an inversion polymorphism defined by two haplotypes: the more common type $\mathrm{H} 1$ and the rare type $\mathrm{H} 2 .{ }^{39,57}$ Scientists established that the sub-haplotype of $\mathrm{H} 1$, MAPT $\mathrm{H} 1$-clade (MAPT $\mathrm{H} 1 \mathrm{C})$, is a genetic risk factor which is over-represented in PSP and homozygous in almost all PSP patients. ${ }^{57}$ The major risk is associated with a SNP in the H1c background, rs242557. ${ }^{100}$ Recently three $\mathrm{H} 1 \mathrm{~d}, \mathrm{H} 1 \mathrm{~g}$ and $\mathrm{H} 10$ have been proposed to be associated with PSP. ${ }^{101}$ Whilst there are some ideas proposed for the role of $\mathrm{H} 1$ haplotype still little is known about the correct pathogenetic mechanism. ${ }^{39}$

The inclusion of exon 10 (Fig. 1) in MAPT leads to production of 4-repeat isoforms for PSP. 58,102 PSP MAPT mutations are located in exon 10 and its splicing region (p.L284R, p.S285R, p.deIN296, p.N296N, p.P301L, p.G303V, p.S305S, IVS10+3, and IVS10+6), except for R5L mutation. The R5L mutation was the first to be discovered and modifies the interaction of tau with tubulin and microtubules. ${ }^{103}$

\subsubsection{STX6}

STX6 encodes protein syntaxin-6, a SNARE class protein, that is involved in intracellular protein trafficking along endoplasmic reticulum. ${ }^{104}$ Although there is a lack of existing studies on the role of STX6 and its effect on tau metabolism in neuronal and glial cells, ${ }^{101}$ it has been confirmed that STX6 is a risk gene. ${ }^{97}$

\subsection{3. МОВP}

MOBP gene is found on chromosome $3 p 22.1^{97}$ encodes the central nervous system (CNS) myelin structural protein which is produced by oligodendrocytes. ${ }^{97,105} \mathrm{MOBP}$ is highly expressed in the affected areas of the brain, particularly the brain stem and 
cerebellum. ${ }^{105}$ Mutations in MOBP cause inaccurate myelin formation resulting in oligodendrocyte dysfunction and subsequent tau inclusions, a feature of PSP. ${ }^{97}$ SNPs associated with both STX 6 and MOBP incur demyelination and strong association with white matter which gives insight into the mechanistic role of tau. ${ }^{97}$

\subsubsection{EIF2AK3}

The eukaryotic translation initiation factor 2 alpha kinase 3 (EIF2AK3) encodes an RNA-like pancreatic endoplasmic reticulum kinase (PERK). ${ }^{106}$ PERK is an endoplasmic reticulum (ER) membrane regulator of the ER unfolded protein response (UPR). ${ }^{39,106}$ Phosphorylated elF2 $\alpha$ (pelF2 $\alpha$ ) reduces overall protein translation, enabling the removal of unfolded proteins from the ER. ${ }^{58,106}$ UPR is activated in regions of affected areas of the brain for PSP patients. ${ }^{106}$ However, the Chen et al. study reported the failure of an SNP in EIF2AK3 to reach genome-wide significance. ${ }^{94}$

\subsection{Emerging loci associated with PSP}

Recently, additional SNPs were discovered with significant association with PSP. ${ }^{94,96}$ The highly expressed SLCO1A2 in PSP brains encodes a solute carrier organic anion transporter (SLCO) protein ${ }^{39}$ and SLCO1A2 mutants are suggested to have a broader role in neurodegeneration. ${ }^{96}$ The intergenic rs6687758 SNP is found near DUSP10. DUSP10 may impact the hyperactivation of p38 and Jun amino-terminal kinases (JNK) leading to uncontrolled hyperphosphorylation of tau, gliosis and synaptic deficits. ${ }^{96}$ The function of p38 and JNK in PSP is yet to be discovered ${ }^{96}$ RUNX2 encodes a transcriptional factor that affects osteoblast differentiation and is shown to have associations with PSP pathogenesis. ${ }^{94}$ TRIM11 has been speculated as a genetic modifier of clinical phenotype in PSP. ${ }^{98}$ The microglial gene CXCR4 has been reported to be significantly upregulated in PSP. ${ }^{99}$ Changes to gene expression of CXCR4 and associated microglial genes (CXCL12, TLR2, RALB, and CCR5) are suggested to strongly influence neuroinflammation. ${ }^{99}$ Further analysis is required to understand the role of GWAS susceptibility loci and regulatory effects of SNPs on genes associated with PSP, in particular those affecting tau pathology, to direct therapeutic strategy. 


\section{Comparisons of Progressive Supranuclear Palsy with Related Neurodegenerative Disorders}

\subsection{Differences in the clinical picture between AD, PD and PSP}

In early stages of PSP, symptoms can be mistakenly diagnosed as idiopathic PD, Alzheimer's (AD) or MSA. ${ }^{4}$ PSP is a rare disease ${ }^{3}$ and so patient data is limited. It is expected that 4000 people in the UK are living with $\mathrm{PSP}^{3}$ at any one time compared with 145,000 people with idiopathic PD ${ }^{5}$ and 520,000 with AD. ${ }^{107}$ The prevalence of PD is expected to increase by $18 \%$ and the incidence is estimated to increase by $14 \%$ or more between $2018-2025 .{ }^{108}$ In 2025 it is expected that $0.32 \%$ of the total population of individuals aged 20 and above in the UK will have PD. ${ }^{108}$ APS has a more distinct degenerative pathway, aggressive clinical presentations and clinical deterioration is faster compared with PD. ${ }^{109}$

Table 6 summarises comparative features between neurodegenerative diseases $A D$, PD and PSP highlighting clear similarities and differences. The mean age of motor symptom onset for early-onset PSP (EOPSP) and PD is around 7 to 20 years younger than early-onset AD. There is a similar trend for late-onset which develops around 210 years later in AD compared to late-onset PSP (LOPSP) and PD. There is a shorter disease duration across all three diseases in late-onset compared to early-onset. However, this could be confounded by the fact that older patients are more vulnerable to other age-dependent comorbidities such as heart and respiratory disease.

Despite PD and PSP sharing more similar clinical features (Table 6), PSP and AD share the same main characteristic protein accumulation, tau. PSP and AD can be separated based on burden of tau-positive lesions and severity and distribution of atrophy in the brain (Fig. 5). 
Table 6. A table to highlight characteristic similarities and differences between Alzheimer's, Parkinson's and Progressive Supranuclear Palsy. (See table footnotes on next page).

\begin{tabular}{|c|c|c|c|}
\hline & Alzheimer's & Parkinson's & $\begin{array}{l}\text { Progressive Supranuclear } \\
\text { Palsy }\end{array}$ \\
\hline $\begin{array}{l}\text { Mean age of motor symptom } \\
\text { onset (years) }\end{array}$ & $\begin{array}{l}\text { EO: } 64.6 \pm 5.8^{\S a}, 58.6 \pm 4.7^{\Uparrow b} \\
\text { LO: } 78.4 \pm 4.3^{\S a}, 74.4 \pm 4.9^{\llbracket b}\end{array}$ & $\begin{array}{l}\text { EO: } 44.5 \pm 5.4^{c} \\
\text { LO: } 72.0 \pm 5.4^{\pi c}\end{array}$ & $\begin{array}{l}\text { EOPSP: } 51.0 \pm 4.8^{\ddagger c} \\
\text { LOPSP: } 68.1 \pm 6.3^{c}\end{array}$ \\
\hline $\begin{array}{l}\text { Average disease duration (from } \\
\text { mean age of onset to death) } \\
\text { (years) }\end{array}$ & $\begin{array}{l}\text { EO: } 4.1 \pm 3.4^{\pi b} \\
\text { LO: } 2.9 \pm 1.7^{\pi b}\end{array}$ & $\begin{array}{l}\text { EO: } 26.6 \pm 9.5^{c} \\
\text { LO: } 2.9 \pm 2.9^{\pi c}\end{array}$ & $\begin{array}{l}\text { EOPSP: } 10.5 \pm 3.9^{\ddagger d} \\
\text { LOPSP: } 6.2 \pm 2.6^{d}\end{array}$ \\
\hline Clinical deterioration & Highly variable ${ }^{b}$ & Slower than $\mathrm{PSP}^{e}$ & Faster than $\mathrm{PD}^{e}$ \\
\hline $\begin{array}{l}\text { Approximate number of people } \\
\text { in UK with disease in } 2020\end{array}$ & $520,000^{f}$ & $145,000^{g}$ & $4000^{h}$ \\
\hline Type of dementia ${ }^{i}$ & Cortical & Subcortical & Subcortical \\
\hline $\begin{array}{l}\text { Early postural instability and/or } \\
\text { falls }\end{array}$ & Present $^{j}$ & Less common ${ }^{k}$ & Present $^{\prime}$ \\
\hline Speech difficulties & $\begin{array}{l}\text { Repetitive questions and long } \\
\text { pauses }^{m}\end{array}$ & Dysarthria $^{n}$ & $\begin{array}{l}\text { Most common }{ }^{\circ} \text { and occurs at } \\
\text { earlier stages of disease }\end{array}$ \\
\hline Eye movements abnormalities & Varied abnormalities $^{q}$ & Close to normal ${ }^{r}$ & Abnormal $^{r}$ \\
\hline Oculomotor feature & No specific feature ${ }^{q}$ & Saccade hypometria ${ }^{s}$ & Slowing of vertical saccades ${ }^{\prime}$ \\
\hline Tremor & Not present $q$ & Common $^{t}$ & Rare $^{\prime}$ \\
\hline Levodopa response & Absent $^{u}$ & Frequent $^{u}$ & Absent/Moderate ${ }^{r}$ \\
\hline $\begin{array}{l}\text { Main type of protein } \\
\text { accumulation }\end{array}$ & Beta-amyloid and tau ${ }^{v}$ & $\alpha$-synuclein $w$ & $\operatorname{Tau}^{x}$ \\
\hline Tau isoform & 3R- and 4R-tau ${ }^{v}$ & & 4R-tau $y$ \\
\hline Tau NFT ${ }^{z}$ & Antiparallel helical & & Straight \\
\hline
\end{tabular}


Table 6. A table to highlight characteristic similarities and differences between Alzheimer's, Parkinson's and Progressive Supranuclear Palsy. Original table with data taken from ${ }^{a}$ Ref. $110 .{ }^{b}$ Ref. $111 .{ }^{c}$ Ref. $112 .{ }^{d}$ Ref. $113 .{ }^{e}$ Ref. 109. ${ }^{f}$ Ref.107. ${ }^{g}$ Ref. 5. ${ }^{h}$ Ref. 3. ${ }^{i}$ Ref. 114. ${ }^{j}$ Ref. 115. ${ }^{k}$ Ref. 116. 'Ref. 53. ${ }^{m}$ Ref. 117. ${ }^{n}$ Ref. 118. ${ }^{o}$ Ref. 3. ${ }^{p}$ Ref. $53 .{ }^{a}$ Ref. 107. 'Ref. 49. ${ }^{\mathrm{s}}$ Ref. 119. ${ }^{t}$ Ref. 12. ${ }^{u}$ Ref. 9. ${ }^{v}$ Ref. 34. ${ }^{w}$ Ref. 21. ${ }^{x}$ Ref. 43. ${ }^{y}$ Ref. $7 .{ }^{z}$ Ref. 120.

\pm standard deviations.

$\S E O$ vs. LO $p<0.0001$.

$\pi_{p}<0.0001$.

$\ddagger_{p}<0.05$ vs. LOPSP.

EO: early-onset.

LO: late-onset.

EOPSP: early-onset progressive supranuclear palsy.

LOPSP: late-onset progressive supranuclear palsy. 


\subsection{Differences in brain pathology between $A D$ and PSP}

Baseline volumetric MRI measurements demonstrated varying levels of atrophy in brains affected by different neurodegenerative diseases (Fig. 5a). Fig. 5A shows that minimal grey matter atrophy exists in PSP brains compared with AD patients. The MRI shows that grey matter atrophy primarily concerns temporal and parietal lobes for $A D$ and white matter atrophy primarily concerns midbrain pons for PSP. For PSP brains, white matter atrophy is predominantly confined to the superior surface of pons which is where the superior cerebellar peduncle emerges (Fig. 5a). Nerves that originate in the pons are strongly associated with regulation of eyeball movement and facial expression ${ }^{121,122}$ which explains the supranuclear gaze palsy witnessed in PSP patients. Tau lesions in AD brains are more concentrated to the central grey matter (CGM), substantia nigra (SN), hippocampal formation (HF) and LC as highlighted in Fig. $5 \mathrm{~b}$. The HF is a region important for short-term memory and subsequent degeneration results in short term memory loss, a common symptom in Alzheimer's. ${ }^{121}$

$4 R$ - and 3R-tau lesions are found in AD compared with only $4 R$-tau lesions found in PSP (Table 6). Ebashi et al. successfully segregated 4R-selecitivity in glia and neurons in the pontine nucleus (PN), red nucleus (RN), inferior olivary nucleus (ION), dentate nucleus (DN), GP, putamen (PU) and $A D$-type $3 R$ and $4 R$ in neurons in $H F$, insular cortex (IC) and LC. ${ }^{123}$ However, as STN, SN, tegmentum (M-TEG) and tegmentum (P-TEG) contain tau lesions in neuron and glia that are positive for $3 R$ and $4 \mathrm{R}$, full distinction is incomplete. For cases where brains harbour both PSP-type and AD-type pathologies, it is not known whether the $4 \mathrm{R}$-tau is biochemically similar in both $A D$ and PSP brains. ${ }^{123}$ The use of immunoprobes to detect post-translational modifications with electron microscopy to distinguish helical NFTs in AD from straight NFTs in PSP ${ }^{120}$ may enhance our mechanistic understanding of disease improving precision of diagnosis. 


\section{(a) \\ Temporal parietal lobes}

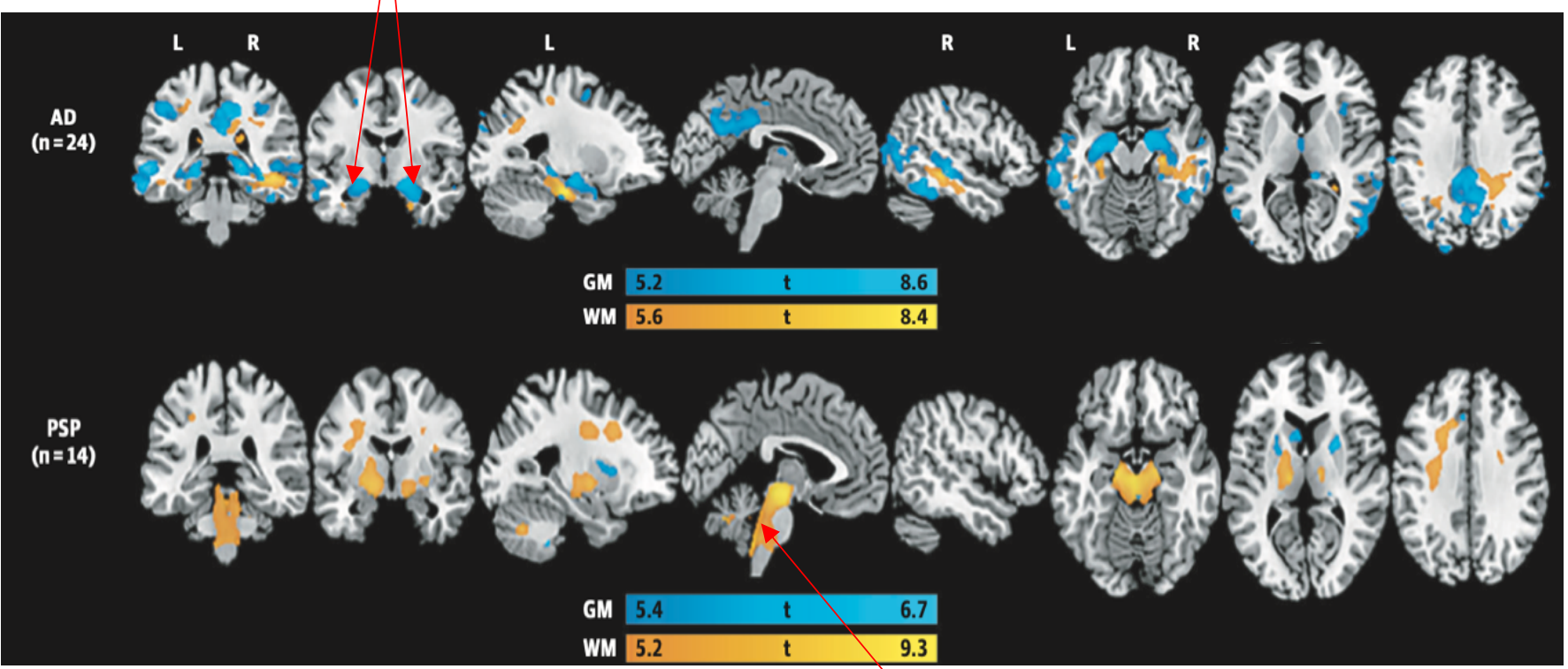

(b)

a
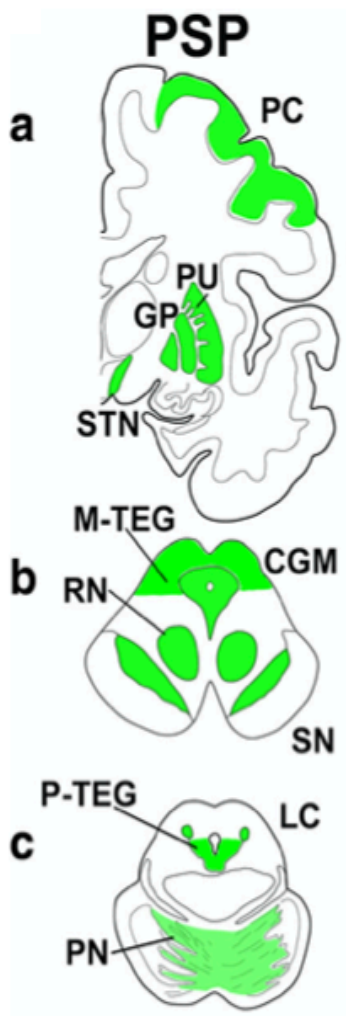

d

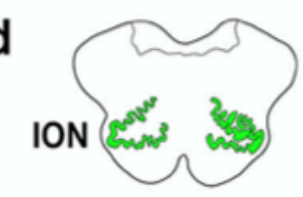

e

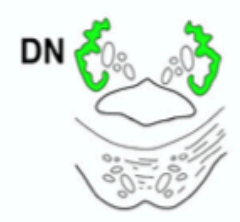

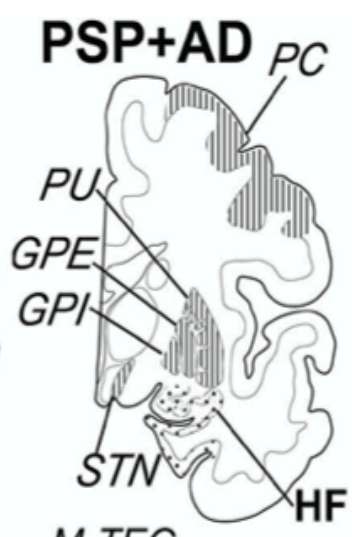

M-TEG
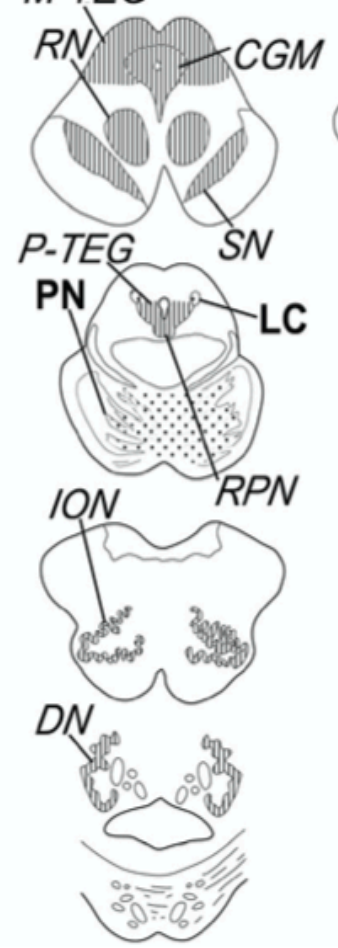

Midbrain pontine
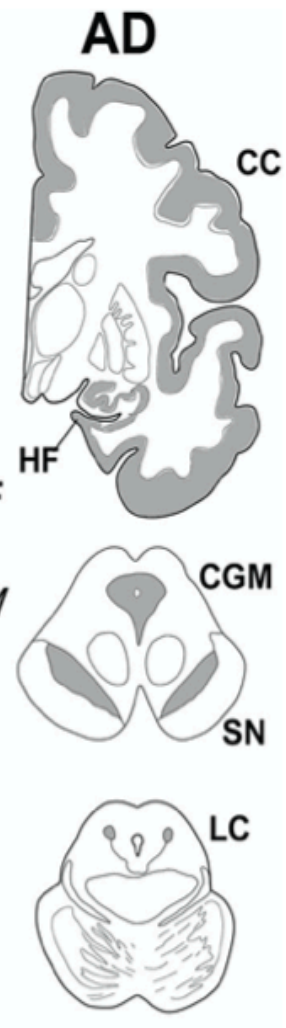

Fig. 5 (a) Schematic comparison of volumetric magnetic imaging measurements for white matter and grey matter atrophy in PSP and $A D$ brains. (b) The difference in location and distribution of tau positive lesions in PSP and AD brains. (See full figure legend on next page). 
Fig. 5 (a) Schematic comparison of volumetric magnetic imaging measurements for white matter and grey matter atrophy in PSP and AD brains. As highlighted, the $M R I$ shows that grey matter atrophy primarily concerns temporal parietal lobes for $A D$ and white matter atrophy primarily concerns midbrain pons for PSP. GM: grey matter. WM: white matter. $t$ : represent $t$ scores. Results are significant $P<0.05$.

Figure taken and adapted from Ref. 124. (b) The difference in location and distribution of tau positive lesions in PSP and AD brains. a: cerebral left hemisphere (coronal), b: Midbrain (axial), c: Pons (axial), d: Medulla oblongata (axial), e: Cerebellum. Tau-positive lesions of PSP shown in green (left column a-e), tau-positive lesions overlapping in comorbid cases, PSP and AD (centre column a-e), tau-positive lesions of $A D$ shown in grey (right column a-c). Tau-positive lesions of PSP are shown in the primary motor cortex (PC), putamen (PU), globus pallidus (GP), subthalamic nucleus (STN), central grey matter (CGM), substantia nigra (SN), red nucleus (RN), tegmentum (M-TEG), locus coeruleus (LC), pontine nucleus (PN) and in the cerebellum region includes the tegmentum (P-TEG), inferior olivary nucleus (ION) and dentate nucleus (DN). Tau-positive lesions of AD are limited to CGM, SN and LC and are more extended in the hippocampal formation (HF) and cerebral cortex (CC). Brain regions containing NFTs with tuft-shaped astrocytes (TAs) are labelled in italics representing PSP-type tau. Brain regions containing NFTs without TAs are labelled in bold face and shown by a spotty appearance (HF, PN, LC), representing AD-type tau.

Figure taken from Ref. 123. 


\section{Potential Therapeutic Biomarkers for Progressive Supranuclear Palsy}

Biomarkers are needed to confirm diagnosis; to monitor progression and to delineate subtypes of PSP to eliminate difficulties confronted at the prodromal stages of the disease. Pathognomonic features alone are highly unreliable due to clinical heterogeneity between PD and APS phenotypes. ${ }^{125}$ Parkinsonism can be divided into two types of neuropathologies: $\alpha$-synucleinopathies (PD, MSA and DLB) and tauopathies (PSP and CBS). ${ }^{126,127} \alpha$-synucleinopathies are characterised by $\alpha$ synuclein in its stable unfolded oligomer state which is the main protein component of Lewy bodies and Lewy neurites and a significant hallmark of PD. 126,127,128 Tauopathies are associated with intracellular deposition of abnormally phosphorylated tau that forms NFTs. ${ }^{31,126,127}$ There is considerable overlap between synucleinopathies and tauopathies potentiating that a spectrum of neurodegenerative disorders could be alleviated by therapeutic strategies that target common processes of tau and $\alpha$ synuclein aggregation. ${ }^{129}$ At present, disease-specific therapy for an individual APS does not exist. ${ }^{130}$ As APS disorders are rare, the suitability and enrollment of patients for clinical trials is limited and therefore studies tend to assess patients with varying APS disorders to increase the size of cohorts. This makes the results less precise because variant APS disorders respond differently to treatment. ${ }^{131}$ There is more research concerning potential $A D$ or $\mathrm{PD}$ biomarkers due to higher incidence rates ${ }^{1,107}$ compared with PSP, ${ }^{3}$ however both are vital for accurate differentiation of the disorders.

To evaluate plausibility and accelerate the prodromal differentiation of PSP from APS or PD, longitudinal cohort studies assessing multiple therapeutic biomarkers with a significant number of diverse patients are required. ${ }^{127}$ Using a basket trial approach and precision medicine, one can determine whether specific therapies are safer in one neurodegenerative disease than another. However, most studies have less PSP participants than PD participants. ${ }^{126,131-135}$ The size of the study required to have a chance of securing a sufficient number of PSP participants should be at least 300 for a PD or APS study. The clinical trial online platform shows that patient cohort sizes for PSP ranges from as little as 10 patients ${ }^{136}$ to as large as 490 patients. ${ }^{137} \mathrm{~A}$ larger cohort may increase reliability as it gives a more accurate mean allowing obvious 
outliers to be identified. However, if a study accepts probable and possible PSP participants, a high chance of misdiagnosis persists which invalidates the results. Furthermore, it takes time for trials to complete and to verify data with previous research to allow PSP pathogenesis to be sufficiently understood.

How is it possible to compare the validity and accuracy of measurements between different therapeutic strategies? A biomolecular algorithm or mechanism to assess the comparability between methods and tracer and between fluid- and imaging-derived biomarkers could be considered. ${ }^{138}$ Recently a PSP genetic risk score (GRS) displayed a significant difference between EOPSP and LOPSP which proves promising for future diagnostic algorithms. ${ }^{113} \mathrm{~A}$ medical algorithm e.g. a flowchart or table, helps improve and standardise decisions for treatment. By using an algorithm to determine whether a patient has EOPSP or LOPSP will aid in selecting the most suited treatment for the individual which is crucial for slowing disease progression.

It has become increasingly recognised that attention must digress from the most universally expressed aggregated proteins to acquire a comprehensive understanding of neurodegenerative pathology. Table 7 categorises diagnostic biomarkers into neuroimaging, fluid and physiological approaches. 
Table 7. Table highlighting the different types of potential PSP diagnostic biomarkers with their associated measurements and application to clinical trials.

\begin{tabular}{|c|c|c|}
\hline $\begin{array}{l}\text { Type of PSP } \\
\text { biomarker }\end{array}$ & Measurement & Discovery \\
\hline \multicolumn{3}{|l|}{ Neuroimaging } \\
\hline \multirow[t]{3}{*}{ MRI } & $\mathrm{MRI}^{a}$ & $\begin{array}{l}\text { 'Hummingbird', 'Mickey Mouse' and } \\
\text { 'Morning Glory' signs }\end{array}$ \\
\hline & $\begin{array}{l}\text { Midbrain/pons } \\
\text { Index (MRPI) }\end{array}$ & $\begin{array}{l}\text { Includes midbrain/pons area ratio } \\
(\mathrm{P} / \mathrm{M}) \text { and } \mathrm{MCP} / \mathrm{SCPs} \text { width ratio. } \\
(\mathrm{P} / \mathrm{M}) \times(\mathrm{MCPd} / \mathrm{SCPd})\end{array}$ \\
\hline & $\begin{array}{l}\text { Midbrain/pons } \\
\text { Index } 2.0 \text { (MRPI } \\
2.0)\end{array}$ & $\begin{array}{l}\text { MRPI } 2.0 \text { incorporates measurement } \\
\text { of third ventricle diameter } \\
\text { MRPI } 2.0=\text { MRPI ratio } \times \text { ratio of third } \\
\text { ventricle width of frontal horn }\end{array}$ \\
\hline & $\begin{array}{l}\text { Diffusion Tensor } \\
\text { Imaging } \\
\text { Diffusion } \\
\text { Weighted } \\
\text { Imaging } \\
\text { Free Water } \\
\text { Imaging, } \\
\text { Diffusion Kurtosis } \\
\text { Imaging }\end{array}$ & $\begin{array}{l}\text { DTI of white matter changes in } \mathrm{PSP}^{d, e} \\
\text { DWI highlights abnormalities in } \\
\text { superior cerebellar peduncle } \\
\\
\text { Free water imaging }{ }^{g} \text { and diffusion } \\
\text { kurtosis imaging more compliant in } \\
\text { PSP compared with other atypical } \\
\text { parkinsonism's and } \text { PD }^{i}\end{array}$ \\
\hline \multirow[t]{2}{*}{ PET } & Tau & $\begin{array}{l}{\left[{ }^{18} \mathrm{~F}\right] \mathrm{AV}-1451 \text { requires further analysis }} \\
\text { - off-target binding present } \mathrm{t}^{j, k} \\
{\left[{ }^{18} \mathrm{~F}\right] \mathrm{PI}-2620 \text { has stronger binding }} \\
\text { affinity to tau aggregates in } \mathrm{AD} \text { and } \\
\mathrm{PSP} \text { brains than }\left[^{18} \mathrm{~F}\right] \mathrm{AV}-1451^{\prime}\end{array}$ \\
\hline & Metabolic & $\begin{array}{l}\text { Assess changes in hypometabolism } \\
\text { characteristic of PSP' } \\
\text { 'Pimple sign' } n\end{array}$ \\
\hline SPECT & HMPAO/IMP & Shown to detect frontal hyperfusion ${ }^{m}$ \\
\hline \multicolumn{3}{|l|}{ Fluid } \\
\hline \multirow[t]{3}{*}{ CSF } & Tau & $\begin{array}{l}\text { Higher t-tau and lower p-tau } \\
\text { associated with increased speed of } \\
\text { clinical deterioration }^{\circ}\end{array}$ \\
\hline & $\begin{array}{l}\text { Neurofilament } \\
\text { light chain (NfL) }\end{array}$ & High levels of NfL in PSP patients ${ }^{p, q}$ \\
\hline & YKL-40 & $\begin{array}{l}\text { Elevated in } \mathrm{PSP}^{p} \\
\text { Targeting the degradative function of } \\
\text { microglia }^{r, s}\end{array}$ \\
\hline
\end{tabular}




\begin{tabular}{|c|c|c|}
\hline \multirow[t]{2}{*}{ Blood } & $\mathrm{NfL}$ & $\begin{array}{l}\text { Elevated in } \mathrm{PSP}^{p} \\
\text { Less invasive than } \mathrm{CSF}^{t, u, v}\end{array}$ \\
\hline & $\begin{array}{l}\text { Plasma } \\
\text { transfusions }^{w}\end{array}$ & $\begin{array}{l}\text { Using young plasma to reverse } \\
\text { neuronal aging }\end{array}$ \\
\hline \multicolumn{3}{|l|}{ Physiological } \\
\hline Eye movements & $\begin{array}{l}\text { Infrared } \\
\text { oculography }\end{array}$ & $\begin{array}{l}\text { Decreased saccade velocity and gain } \\
\text { in PSP }\end{array}$ \\
\hline Retinal thickness & $\begin{array}{l}\text { Optical } \\
\text { coherence } \\
\text { tomography } \\
\text { (OCT) }\end{array}$ & $\begin{array}{l}\text { Thinning in retinal nerve fibre layer } \\
\text { (RNFL) thickness in PSPy }\end{array}$ \\
\hline Sebum & Smell & $\begin{array}{l}\text { Significantly different quantities of four } \\
\text { compounds in sebum of PD patients } \\
\text { compared with controls }\end{array}$ \\
\hline
\end{tabular}

Original table compiled using data from ${ }^{a}$ Ref. 43. ${ }^{b}$ Ref. 50. ${ }^{c}$ Ref. 63. ${ }^{d}$ Ref. 139. ${ }^{e}$ Ref. 140. ${ }^{f}$ Ref. 132. ${ }^{g}$ Ref. 141. ${ }^{h}$ Ref. 142. ${ }^{i}$ Ref. 39. ${ }^{j}$ Ref. $143 . \quad{ }^{k}$ Ref. 144. 'Ref. 145. ${ }^{m}$ Ref. 146. ${ }^{n}$ Ref. 147. ${ }^{\circ}$ Ref. 148. ${ }^{p}$ Ref. 43. ${ }^{a}$ Ref. $149 . \quad{ }^{r}$ Ref. 150. ${ }^{s}$ Ref. 151. ${ }^{t}$ Ref. 88. ${ }^{u}$ Ref. 152. ${ }^{v}$ Ref. 153. ${ }^{w}$ Ref. $154 .{ }^{x}$ Ref. 53. ${ }^{y}$ Ref. $155 .{ }^{z}$ Ref. 156. 


\subsection{Neuroimaging}

Currently neuroimaging measurements are considered supportive features in the MDS-PSP criteria ${ }^{53}$ as they provide only predictive values insufficient for complete diagnosis. Fig. 5a clearly shows the evident differences between AD and PSP brains and therefore potentially in the future this will be regarded more highly as a diagnostic tool. Analysis of neuroimages of PSP brains concern patients in late stages of the disease who have presented with a PSP-RS phenotype. ${ }^{157}$ However, early-stage investigations are crucial to allow comparisons with other phenotypes and determine suitability as a diagnostic biomarker.

\subsubsection{MRI}

Magnetic resonance imaging (MRI) evaluates morphologic parameters associated with neurodegenerative diseases ${ }^{157}$ eradicating the inherent issues that are encountered when solely relying on clinical diagnostic criteria for PSP. ${ }^{55} \mathrm{~A}$ whole-brain meta-analyses was conducted using MRI to isolate disease-related atrophy of PSP. ${ }^{158}$ The aforementioned diagnostic criteria were supported with neuroimaging permitting a more informative judgement for PSP. ${ }^{53,158}$ The qualitative review published by Whitwell et al. shows significant atrophy in midbrain and cerebellar peduncles present at early phases of PSP using radiological biomarkers. ${ }^{159}$ However, a widespread whole-brain meta-analysis will optimise sensitivity and specificity by comparing disease patterns of atrophy in differential diagnosis. ${ }^{158,159}$ Albrecht et al. focussed on examining and combining neural correlates with pathognomonic features of PSP. ${ }^{158}$ The study separately investigates disease-associated atrophy in grey and white matter in PSP and employs two common meta-analytical algorithms to warrant doublevalidation against each other ensuing reliable comparisons of results. ${ }^{158}$ By combining white and grey matter atrophy of PSP and PD patients, subtraction analysis confirms the midbrain atrophy specific for PSP. ${ }^{158}$ Albrecht et al. study is the largest cohort of PSP confirmed patients to date, increasing reliability of results. ${ }^{158}$ Recently it was discovered that the combined use of P/M ratio with cardiac ${ }^{123}$ metaiodobenzylguanidine (MIBG) scintigraphy could enhance the differentiation accuracy of PD from PSP. ${ }^{160}$ Further meta-analyses of MRI studies will open the possibility of MRI use as a more effective diagnostic tool. 


\subsubsection{MRPI}

Quattrone et al. introduces the magnetic resonance parkinsonism index (MRPI) for assessing midbrain atrophy as the product of the ratio of pons to midbrain area (P/M) and middle to superior cerebellar peduncles diameter (MCPd/SCPd). ${ }^{133}$ However, Tipton et al. could not form a conclusive distinction between PSP and other neurodegenerative diseases using measurements of the cerebellar peduncle angle (CPA). ${ }^{125} \mathrm{MRPI}$ is recommended for clinical use and has proven to perform better than $\mathrm{P} / \mathrm{M}$ ratio to distinguish between PSP and PD patients. ${ }^{161} \mathrm{MRI}$ shows midbrain and superior cerebellar peduncles (SCPs) atrophy for PSP patients and pontine atrophy in MSA patients. ${ }^{133}$ Midbrain atrophy in PSP is detected by a decrease in the P/M ratio in MRI and identified by the 'hummingbird sign'. ${ }^{157,162}$ Recently an updated version, MRPI 2.0, which includes measurements of third ventricle diameter, exhibits higher sensitivity and specificity to differentiate PSP-P patients from PD patients. ${ }^{163}$ There has been confirmation that MRPI, MRPI 2.0, P/M and P/M 2.0 presents an acceptable sensitivity and specificity profile offering classification between healthy controls and vPSP. ${ }^{63}$ However, it is yet to be used in diagnosis due to the lack of repeated studies. ${ }^{63}$ Furthermore, MRI brainstem assessments lack stringent image standardization and concurrent method criteria between clinicians limits the validity of structural parameters, indexes or ratios and comparability between measurement tools. ${ }^{125,133,162}$

\subsubsection{Diffusion Tensor, Diffusion Weighted, Free Water and Diffusion Kurtosis Imaging}

Diffusion tensor imaging (DTI) detects white matter microstructure ${ }^{139,140}$ in disease whereas diffusion weighted imaging (DWI) detects basal ganglia abnormalities. ${ }^{132}$ Free water imaging used to distinguish different forms of parkinsonism demonstrates high specificity and sensitivity. ${ }^{141}$ A quantitative assessment of several brain areas in PSP patients using diffusion kurtosis imaging identified pathological changes related to region-specific tau deposits. ${ }^{142}$ However, there is a lack of repeat studies and an inability to compare results as different scanners are used. 


\subsubsection{PET}

\subsubsection{Tau}

In 2013, the development of positron emission tomography (PET) ligands with high binding affinity to paired helical filaments of tau in NFTs in the brain enabled noninvasive detection, quantification and visualisation. ${ }^{88}$ There have been numerous studies involving tau-specific PET ligands including first-generation (e.g. [ $\left.{ }^{18} \mathrm{~F}\right] \mathrm{AV}$ 1451) and second-generation compounds (e.g. [ $\left.\left.{ }^{18} \mathrm{~F}\right] \mathrm{PI}-2620\right) .{ }^{164}$ Notwithstanding, whilst some of these PET ligands may express high binding affinity for tau aggregates in $A D$ brain tissue there has been insignificant levels of interaction with neuronal and glial aggregates in PSP, ${ }^{165}$ which questions the value of PET ligands as a diagnostic tool for PSP.

The efficacy of tau PET ligands binding to 4R tau aggregates in PSP is proving challenging. Several studies produced elusive results on the binding of tau-PET ligands to tau deposits in PSP. ${ }^{143,144,166}$ This is due to several reasons: 1) low affinity of tau-PET ligands for 4R tau 2) low density of tau aggregates in PSP patients 3) inconsistency in distinguishing on-target and off-target binding; and 4) heterogeneity of tau aggregations in 4R tauopathies. ${ }^{145,166}$ Cross-sectional studies involving the recently developed tau ligands such as $\left[{ }^{18} \mathrm{~F}\right] \mathrm{AV}-1451$ show that PSP patients have increased uptake of $\left[{ }^{18} \mathrm{~F}\right] \mathrm{AV}-1451$ in subcortical regions. ${ }^{143}$ The trajectory of $\left[{ }^{18} \mathrm{~F}\right] \mathrm{AV}-$ 1451 as a longitudinal biomarker for measuring disease progression and whether patterns of [ $\left.{ }^{18} \mathrm{~F}\right] \mathrm{AV}-1451$ uptake differ between vPSP has not yet been established. ${ }^{144}$ Furthermore, it is not confirmed whether $\left[{ }^{18} \mathrm{~F}\right] \mathrm{AV}-1451$ binds $4 \mathrm{R}$ tau directly and the presence of off-target binding to monoamine oxidase (MAO)-A (Fig. 6) saturates the binding sites that are available for $4 \mathrm{R}$ tau binding, limiting the success of $\left[{ }^{18} \mathrm{~F}\right] \mathrm{AV}-1451$ as a diagnostic tool. ${ }^{143,144,166,167}$ 
Fig. 6 Structure of $\left[{ }^{18} \mathrm{~F}\right] \mathrm{AV}-1451$.

The biochemical structure for $\left[{ }^{18} \mathrm{~F}\right] \mathrm{AV}-1451$ involves pyrido[4,3b]indole which has a high affinity for tau. The lack of a central pyridine allows high affinity MAOA binding. Figure adapted from Ref. 145.

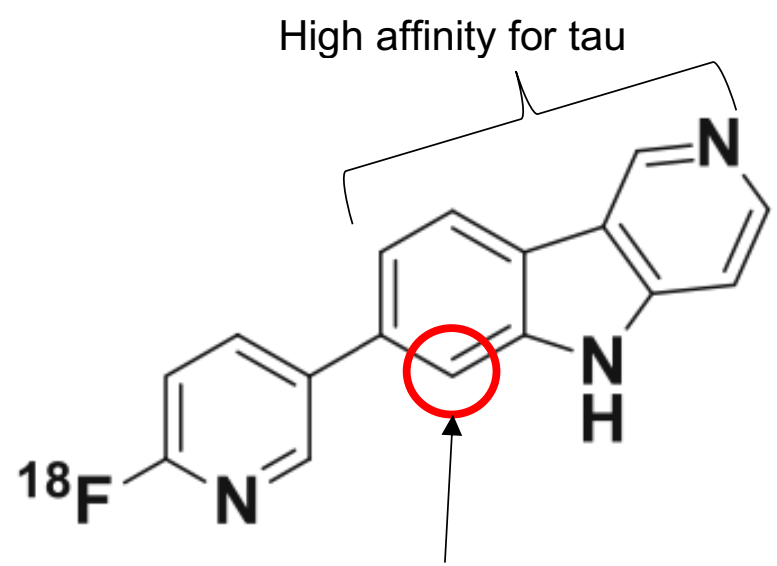

High affinity MAO-A binding

In vitro studies show that $\left[{ }^{18} \mathrm{~F}\right] \mathrm{PI}-2620$ has stronger binding affinity to tau aggregates in AD and PSP brains than $\left[{ }^{18} \mathrm{~F}\right] \mathrm{AV}-1451$ (Fig. 6 and Fig. 7). ${ }^{145}$ Clinical trials to evaluate the utility and pharmacokinetic properties of $\left[{ }^{18} \mathrm{~F}\right] \mathrm{PI}-2620$ in human brains are in progress. ${ }^{145}$ Researchers are concentrating on $\left[{ }^{18} \mathrm{~F}\right] \mathrm{PI}-2620$ due to first clinical impressions portraying positive outlooks with low off-target binding compared with $\left[{ }^{18}\right.$ F]AV-1451 (Fig. 6 and Fig. 7). ${ }^{145,168}$ Positive results permitted the launch of phaseII for PSP patients in March 2019. 168,169

Fig. 7 Structure of $\left[{ }^{18} \mathrm{~F}\right] \mathrm{PI}-2620$.

The biochemical structure for $\left[{ }^{18} \mathrm{~F}\right] \mathrm{AV}-2620$ shows that pyrrolo[2,3-b:4,5-c']dipyridine exhibits high affinity for tau. This fluoropyridine stereoisomer had superior affinity for misfolded tau compared to other stereoisomers. The presence of the central pyridine was responsible for low affinity MAOA binding. Figure adapted from Ref. 145.

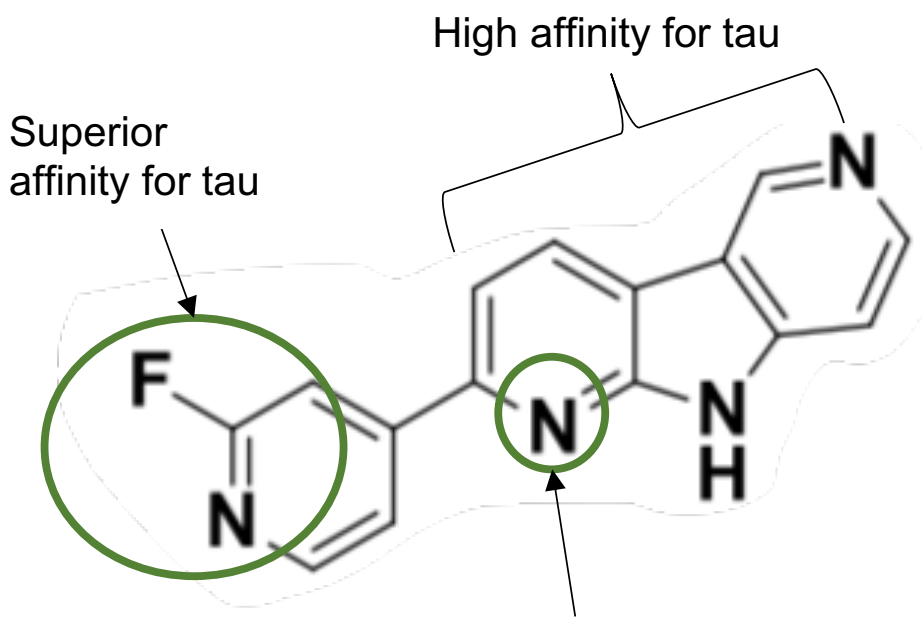

Low affinity MAO-A binding

The main challenges with in vivo tau imaging are due to expression of different tau isoforms and different patterns of deposition. ${ }^{170}$ Consequently, a single tau PET tracer may not be compatible for the heterogenous tau deposits with variable binding affinities. The blood-brain barrier obstructs free movement of molecules due to 
molecular size and lipophilicity. A tau PET tracer must be suitable to cross membranes and fine-tuned to selectively target tau deposits over other proteins with analogous structures. ${ }^{170}$ Most of the clinical studies examines PET ligands in AD patients not PSP patients ${ }^{145,164,165,166,168}$ as $A D$ is the most common form of dementia accounting for $50-70 \%$ of cases. ${ }^{107}$ Despite success, greater standardisation and further crosssectional longitudinal data is required to create a single test that can accurately differentiate tau pathology in neurodegenerative brains.

\subsubsection{Metabolic}

$\left[{ }^{18} \mathrm{~F}\right]-F D G-P E T$ has been shown to assess hypometabolism in PSP. ${ }^{146}$ Previous studies observe hypometabolism at early disease stages and so a PET biomarker could bring an earlier diagnosis. ${ }^{146}$ One study labelled the midbrain hypometabolism on FDG-PET scans as the 'pimple sign'. ${ }^{147}$ This is linked to midbrain atrophy and may be valuable in distinguishing between APS. ${ }^{147}$

\subsubsection{SPECT HMPAO/IMP}

After treatment with a tracer e.g. hexamethylpropyleneamine oxime ( ${ }^{99 m}$ Tc-HMPAO) or [1123] lofetamine (IMP), perfusion single-photon emission computed tomography (SPECT) occurs which is a non-invasive analysis of pathophysiological events in the brain. ${ }^{146}$ In various reports frontal hypoperfusion was detected using SPECT HMPAO and SPECT IMP that were consolidated in Alster et al. study but a lack of specificity delayed future advances. ${ }^{146}$

\subsection{Fluid}

Diagnostic tools for PSP such as radiological biomarkers are well established whilst studies involving serum/plasma biomarkers are only recently emerging. ${ }^{171}$

\subsubsection{CSF biomarkers}

\subsubsection{Tau}

In 1995, the detection of total tau (t-tau) and phosphorylated tau (p-tau) in vivo in cerebrospinal fluid (CSF) became possible through the use of assays ${ }^{172}$ and since then it has been at the forefront of research. ${ }^{72} \mathrm{CSF}$ tau exists as fragments containing 
$\mathrm{N}$-terminal and/or mid-domain epitopes but whether concentrations of these fragments vary between different tauopathies remains unknown. ${ }^{72}$ Increased speed of clinical deterioration of PSP was predicted with higher t-tau and lower p-tau in CSF. ${ }^{148}$

\subsubsection{2. $\quad \mathrm{NfL}$}

The neurofilament light chain (NfL) in CSF is being assessed as a biomarker for differential diagnosis. ${ }^{109}$ Disruption to axonal membrane of neurons causes NfL to be released into the CSF and blood. ${ }^{153}$ PSP shows consistent elevated levels of NfL in CSF and blood compared with healthy controls and PD patients. ${ }^{72,135,149,173}$ This echoes the comparative severity between APS and PD, which could refer to the individual underlying pathological pathways and speed of clinical deterioration.

\subsubsection{3. $\quad Y K L-40$}

YKL-40 is a glycoprotein expressed in astrocytes and microglia which are activated in most neurodegenerative disease. ${ }^{151}$ Current experiments are exploiting the degradative function of microglia using small molecules or antibodies for clearance of aggregated or misfolded proteins such as tau. ${ }^{150,151}$

\subsubsection{Blood biomarkers}

\subsubsection{NfL}

A blood-based biomarker is favourable compared to the invasive lumbar puncture procedure involved in CSF-based biomarkers. ${ }^{88,152,153}$ Results show that plasma NfL concentrations are elevated in PSP patients compared to age-match healthy individuals. ${ }^{152,174-176}$ By conducting comparative analysis, it is clear that the investigation into neurological diseases using blood-based biomarkers is more prevalent. ${ }^{152,175}$ Although data may not be transferable or applicable to PSP or PD, further knowledge around blood-based biomarkers may ignite another avenue of therapeutic exploration.

\subsubsection{Plasma}

Blood biomarkers confer advantages such as easy accessibility of blood sampling, cost and scalability. ${ }^{138,177}$ A trial was created to evaluate the potential diagnostic 
accuracy of combining plasma biomarkers ( $\alpha$-synuclein, total tau, p-Tau181, and $A \beta 42$ ), which express the major pathologies witnessed in PD and APS. ${ }^{127}$ The results show that all four plasma biomarkers improve differential diagnosis of PD from APS. However, only a small number of patients with PSP participated which limits reliability and application to all PSP patients. ${ }^{127}$

The Lawton et al. study investigates four blood-based biomarkers: vitamin $D$, apolipoprotein A1 (ApoA1), uric acid and C-reactive protein (CRP). ${ }^{177}$ Previous evidence shows PD patients have lower levels of vitamin D compared with healthy individuals which may coincide with PSP. ${ }^{178}$ ApoA1 is estimated to offer a form of neuroprotection. ${ }^{177}$ There is evidence that uric acid acts as an antioxidant ${ }^{171,177}$ and may reduce oxidative stress in PD and PSP. ${ }^{179}$ The Lawton et al. study has satisfactory conclusions due to lack of longitudinal serum measurements and spectrum of patients. ${ }^{177}$ Additional cohesive studies are indispensable to determine irrefutable fact.

Santiago et al. study analyses the ability of RNA blood biomarkers ( $\alpha$-synuclein, total tau, p-Tau181, and A 442 ) to improve differential diagnosis of PD from PSP. ${ }^{134}$ However, it failed to reach statistical significance which eradicated the potential to produce a robust biomarker. ${ }^{134}$

Investigation into whether young plasma transfusions administered to aging mice restore the levels of regenerative agents that can rejuvenate neuron growth and cognitive function, show positive development. ${ }^{180}$ Trials are yet to commence in patients with PSP. ${ }^{156}$

\subsection{Physiological}

\subsubsection{Eye movements}

A defining feature in primarily PSP-RS but also other phenotypes, is vertical supranuclear gaze palsy (SGP). ${ }^{53}$ This is associated with decreases in vertical saccade velocity compared with horizonal saccades and decrease in gain. ${ }^{50}$ The downward vertical SGP is only presented in the MDS-PSP criteria as suggestive of PSP. ${ }^{53}$ Infrared and video oculography reveals that deterioration in oculomotor 
performance is associated with more severely damaged disease-specific brain areas and disrupted functional connections. ${ }^{122}$

\subsubsection{Retinal thickness}

A study examining retinal nerve fibre layer (RNFL) thickness by optical coherence tomography (OCT) and scanning laser polarimetry (SLP) reveals that thinning of RNFL is more profound in PSP patients than PD patients. ${ }^{181} \mathrm{~A}$ recent study concludes that thinning of RNFL is greater in PSP patients than PD patients who have had symptoms for more than three years. ${ }^{155}$ OCT and SLP could be implemented in PSP diagnosis to provide further differential utility between parkinsonism syndromes.

\subsubsection{Sebum}

Interestingly, a wife of a PD patient reported that she could detect the disease by a person's odour. ${ }^{156}$ This led to the discovery of sebum obtained from the neck region, which is likely to be the source of the distinct smell. ${ }^{156}$ Analysis of the sebum revealed that there were four compounds with significantly different quantities compared with controls. ${ }^{156}$ This potential non-invasive metabolomic marker could offer large scale production. ${ }^{182} \mathrm{PSP}$ patients are yet to be investigated for a distinct sebum smell which could distinguish PD and PSP patients. 


\section{Therapeutic Targets for Progressive Supranuclear Palsy}

Currently there are various therapeutic agents under review as potential treatments for PSP (Table 8). Those that are successful inhibit pathogenic processes in an attempt to stem the progression of the debilitating disease.

\subsection{Reduction of abnormal post-translational modifications}

Abnormal tau phosphorylation mediates severe complications including axonal transport dysfunction; ${ }^{183}$ tau aggregation; ${ }^{184}$ tau mislocalisation ${ }^{185}$ and impairs the tau degradation pathway. ${ }^{186}$ The main kinase involved in the pathologic tau hyperphosphorylation is glycogen synthase kinase (GSK3 $\beta$ ). ${ }^{187}$ Abnormal exposure of phosphatase activation domain (PAD) is associated with the activation of GSK3 3 , a proline-directed kinase. ${ }^{183}$ Clinical trials of several GSK3 $\beta$ inhibitors such as Tideglusib and AZD0530 failed to prove significant advantage or pass safety reports. ${ }^{188,189}$ 
Table 8. Relevant completed and on-going trials for therapies that aim to suppress PSP pathogenesis.

\begin{tabular}{|c|c|c|c|c|c|}
\hline \multicolumn{2}{|c|}{$\begin{array}{l}\text { Name of therapeutic agent } \\
\text { (synonyms) }\end{array}$} & \multirow[t]{2}{*}{ Role } & \multirow[t]{2}{*}{$\begin{array}{l}\text { Drug } \\
\text { delivery }\end{array}$} & \multirow[t]{2}{*}{ Stage of trial } & \multirow[t]{2}{*}{ Comments/ concerns } \\
\hline \multicolumn{2}{|c|}{ Reduction of abnormal PTMs } & & & & \\
\hline \multirow[t]{2}{*}{$\begin{array}{l}\text { GSK3 } \beta \\
\text { inhibitor }\end{array}$} & $\begin{array}{l}\text { Tideglusib (NP031112, } \\
\text { Nypta }{ }^{\circledR}, Z^{2} \text {.entylor }{ }^{\mathrm{TM}}, \\
\text { Glycogen synthase } \\
\text { kinase } 3 \text { inhibitor, NP12) }^{a}\end{array}$ & $\begin{array}{l}\text { Inhibitor of tau } \\
\text { phosphorylation }\end{array}$ & Oral & Preclinical & $\begin{array}{l}\text { Failed to prove significant advantage or } \\
\text { pass safety reports }\end{array}$ \\
\hline & Lithium $^{b}$ & $\begin{array}{l}\text { Inhibitor of tau } \\
\text { phosphorylation }\end{array}$ & Oral & Completed & Adverse side effects at Phase II \\
\hline \multirow{3}{*}{\multicolumn{2}{|c|}{$\begin{array}{l}\text { Brain specific calpain inhibitor } \\
\text { ROCK inhibitor }^{c} \\
\text { CDK5 }^{c}\end{array}$}} & \multirow{3}{*}{$\begin{array}{l}\text { Inhibitor of } \\
\text { kinases involved } \\
\text { in tau } \\
\text { pathogenesis }\end{array}$} & \multirow[t]{3}{*}{ nd } & \multirow[t]{3}{*}{ Preclinical } & \multirow[t]{3}{*}{ Minimal research } \\
\hline & & & & & \\
\hline & & & & & \\
\hline \multicolumn{2}{|c|}{ Asn120290 } & $\begin{array}{l}\text { O-GlcNAcylase } \\
\text { inhibitor }\end{array}$ & Oral & Ongoing & nd \\
\hline \multicolumn{2}{|c|}{ MK-8719e } & $\begin{array}{l}\text { Inhibits O- } \\
\text { GlcNAcase } \\
\text { enzyme }\end{array}$ & Oral & Ongoing & $\begin{array}{l}\text { Phase I performed well but lack of } \\
\text { recent published results }\end{array}$ \\
\hline \multicolumn{2}{|c|}{ Salsalate $^{f}$} & $\begin{array}{l}\text { Inhibitor of tau } \\
\text { acetylation }\end{array}$ & Oral $^{f}$ & $\begin{array}{l}\text { Phase I - } \\
\text { Ongoing }\end{array}$ & $\begin{array}{l}\text { Trial terminated if three or more } \\
\text { patients experience drug limiting } \\
\text { toxicity (DLT) } \\
\text { Results expected in forthcoming } \\
\text { months }\end{array}$ \\
\hline \multicolumn{6}{|c|}{ Microtubule stabilisers } \\
\hline \multicolumn{2}{|c|}{ TPI-287 ${ }^{h}$} & Binds to tubulin & Intravenous & Ongoing & $\begin{array}{l}\text { Produced undesirable side effects such } \\
\text { as more falls in PSP patients }\end{array}$ \\
\hline
\end{tabular}




\begin{tabular}{|c|c|c|c|c|}
\hline \multirow[t]{2}{*}{ Epothilone D (BMS-241027) } & $\begin{array}{l}\text { Reversed } \\
\text { behavioural and } \\
\text { cognitive deficits } \\
\text { Minimised } \\
\text { effects of tau } \\
\text { pathology }\end{array}$ & Intravenous & Completed & $\begin{array}{l}\text { Failure to qualify on the PSPRS and } \\
\text { SEADL } \\
\text { Only looked at AD patients }\end{array}$ \\
\hline & $\begin{array}{l}\text { Potential } \\
\text { inhibitor for } \\
\text { microglial } \\
\text { migration of } \alpha- \\
\text { synuclein }^{k}\end{array}$ & nd & Not started & $\begin{array}{l}\text { Initial studies only involved MSA } \\
\text { patients }\end{array}$ \\
\hline Davunetide (NAP, AL-108)' & $\begin{array}{l}\text { Promotes } \\
\text { microtubule } \\
\text { stability and } \\
\text { decreases tau } \\
\text { phosphorylation }\end{array}$ & Nasal spray & Completed & $\begin{array}{l}\text { No significant results on PSPRS and } \\
\text { SEADL }\end{array}$ \\
\hline \multicolumn{5}{|l|}{ Reduction of tau gene expression } \\
\hline Tau anti-sense oligonucleotides $^{m}$ & $\begin{array}{l}\text { Reduction of } \\
M A P T \\
\text { expression }\end{array}$ & $\begin{array}{l}\text { CSF } \\
\text { injection }\end{array}$ & Not started & $\begin{array}{l}\text { Only application to ALS } \\
\text { Trials with PSP patients yet to begin }\end{array}$ \\
\hline RNA interference: splicing of tau ${ }^{n}$ & $\begin{array}{l}\text { Reduction of } \\
M A P T \\
\text { expression }\end{array}$ & nd & Hypothetical & nd \\
\hline \multicolumn{5}{|l|}{ Blocking transcellular spread } \\
\hline Novel anti-4R-tau antibodies ${ }^{\circ}$ & $\begin{array}{l}\mathrm{R} 2 \text { specific } \\
\text { repeat domain } \\
\text { anti-tau } \\
\text { monoclonal } \\
\text { antibodies }\end{array}$ & nd & Preclinical & nd \\
\hline
\end{tabular}




\begin{tabular}{|c|c|c|c|c|}
\hline $\begin{array}{l}\text { Gosuranemab (BIIB092, BMS- } \\
\text { 986168, IPN007) }\end{array}$ & $\begin{array}{l}\text { Anti-tau } \\
\text { humanised } \\
\text { monoclonal } \\
\text { antibody binds } \\
\text { to N-terminal tau } \\
\text { with high } \\
\text { affinityq }\end{array}$ & Intravenous ${ }^{p}$ & Completed & $\begin{array}{l}\text { No significant change in the PSPRS } \\
\text { between treated and placebo after one } \\
\text { year } \\
\begin{array}{l}\text { No significant differences in key } \\
\text { secondary endpoints }\end{array}\end{array}$ \\
\hline C2N 8E12 (ABBV-8E12) ${ }^{r}$ & $\begin{array}{l}\text { Anti-tau } \\
\text { monoclonal } \\
\text { antibody }\end{array}$ & Intravenous & Completed & At phase II failed futility test \\
\hline UCB0107s & $\begin{array}{l}\text { Recombinant, } \\
\text { humanised, full- } \\
\text { length IgG4 } \\
\text { monoclonal } \\
\text { antibody } \\
\text { targeting central } \\
\text { tau epitope }\end{array}$ & Intravenous & Ongoing & $\begin{array}{l}\text { Phase I study shows acceptable safety } \\
\text { profile and drug well tolerated }\end{array}$ \\
\hline \multicolumn{5}{|l|}{ Autophagy enhancers } \\
\hline AZP2006 & \begin{tabular}{|l|} 
Stimulates \\
macroautophagy \\
and clearance of \\
misfolded tau
\end{tabular} & Oral & Ongoing & nd \\
\hline \multicolumn{5}{|c|}{ Mitochondrial complex I enhancers } \\
\hline Coenzyme Q10v & \begin{tabular}{|l|} 
Enhance \\
mitochondrial \\
function
\end{tabular} & Oral & Completed & $\begin{array}{l}\text { No benefit. Trials need larger cohorts } \\
\text { and sustained participation }\end{array}$ \\
\hline a-lipoic acid with L-acetyl carnitine ${ }^{w}$ & $\begin{array}{l}\text { Reducing } \\
\text { increased levels } \\
\text { of oxidative } \\
\text { stress and } \\
\text { increased }\end{array}$ & Oral $^{w}$ & Completed & $\begin{array}{l}\text { Adverse side effects such as gastro } \\
\text { disturbances, insomnia and seizures }\end{array}$ \\
\hline
\end{tabular}

53




\subsection{Microtubule stabilisers}

Separation of tau from microtubules displaces normal mitochondrial function and stability resulting in defects in axonal transport and synaptic transmission. ${ }^{202}$ One possible avenue for exploration is the use of microtubule stabilisers as a therapeutic strategy to alleviate microtubule degradation.

In 2013 Epothilone D failed to qualify on PSPRS and SEADL scales. ${ }^{193}$ Since then there has been investigation into the use of epothilone $D$ as an inhibitor of suspected microglial migration of $\alpha$-synuclein, but further PSP-focussed studies are necessary. ${ }^{194}$

TPI-287 is an abeo-taxane, a synthetic derivative which is able to cross the bloodbrain barrier and bind to tubulin offering stability to microtubules. ${ }^{208}$ The results from Phase I trial of TPI-287 in 33 patients (2013) and from Phase I trial of TPI-287 in 66 patients with CBD or PSP (2014) were combined and presented at CTAD conference in $2017 .{ }^{209}$ The results were subsequently published ${ }^{124}$ and a summary in Table 9 highlights the important changes and differences in exploratory outcomes between the neurodegenerative disorders. The aim of the trial was to investigate the tolerability and safety of TPI-287 intravenous infusions administered to PSP, CBS and AD patients. The results show that the Mini-Mental State Examination (MMSE) score declined less in the AD group compared to the placebo whereas for PSP and CBS the MMSE score declined more than the placebo. The result for AD is not likely due to TPI-287 and so the difference should be regarded as insignificant. There was a significant decrease in CSF YKL-40 level in the 4RT trial compared to the placebo whereas for AD patients the CSF YKL-40 level increased compared with the placebo. The zeros recorded at dose $20.0 \mathrm{mg} / \mathrm{m}^{2}$ of TPI-287 in AD patients show that a higher dose of $20.0 \mathrm{mg} / \mathrm{m}^{2}$ of TPI-287 was tolerated more in PSP and CBS compared with in AD patients (Table 9). ${ }^{124}$ However, the trial had to be terminated due to AD patients suffering anaphylactoid hypersensitivity reactions and CBS and PSP patients facing more falls. ${ }^{209}$ The combination of two parallel, double-blind trials; one in patients with $A D$ and one with patients with PSP or CBS (labelled as 4-Repeat Tauopathy [4RT] trial) underlines the importance of using basket trials to investigate the treatment effects at early stages of disease development in various clinical tauopathies. Furthermore, this evidence shows that patients suffering from tau-associated neurodegenerative 
disorders respond differently to targeted therapeutic treatments which accentuates the need for a personalised therapeutic agent for an individual patient. 
Table 9. Changes in exploratory outcomes from baseline to end of study in individuals who received two or more infusions of TPI-287. (See table footnotes on next page).

\begin{tabular}{|c|c|c|c|c|c|c|c|}
\hline \multirow[b]{3}{*}{ Charact } & \multicolumn{7}{|l|}{ TPI-287 } \\
\hline & \multicolumn{3}{|l|}{ AD Trial } & \multicolumn{4}{|l|}{ 4RT Trial } \\
\hline & $\begin{array}{l}\text { Placebo } \\
(n=8)\end{array}$ & $\begin{array}{l}\text { AD } 2.0 \mathrm{mg} \mathrm{m}^{-2} \\
(\mathrm{n}=8)\end{array}$ & $\begin{array}{l}\text { AD } 20.0 \mathrm{mg} \mathrm{m}^{-} \\
(n=3)\end{array}$ & $\begin{array}{l}\text { Placebo } \\
(n=12)\end{array}$ & $\begin{array}{l}\text { PSP } 2.0 \mathrm{mg} \mathrm{m}^{-2} \\
(\mathrm{n}=8)\end{array}$ & $\begin{array}{l}\text { CBS } 2.0 \mathrm{mg} \mathrm{m}^{-2} \\
(\mathrm{n}=7)\end{array}$ & $\begin{array}{l}\text { CBS } 20.0 \mathrm{mg} \mathrm{m}^{-2} \\
(\mathrm{n}=8)\end{array}$ \\
\hline \multicolumn{8}{|l|}{ Clinical } \\
\hline $\begin{array}{l}\text { MMSE } \\
\text { Score }^{(a)}\end{array}$ & $\begin{array}{l}-3.0(-4 \\
\text { to } 1)\end{array}$ & $0(-4$ to 4$)$ & $0(-3$ to 1$)$ & \begin{tabular}{|l|}
$0.5(-3$ \\
to 4$)$
\end{tabular} & $-0.5(-9$ to 6$)$ & $-1.0(-4$ to 2$)$ & $0(-3 \text { to } 4)^{(C)}$ \\
\hline GDS Score ${ }^{(b)}$ & $\begin{array}{l}-0.5(- \\
12 \text { to } 7)\end{array}$ & 0 (-2 to 1$)$ & $0(0$ to 1$)$ & \begin{tabular}{|l|}
$-1.0(-4$ \\
to 1$)$
\end{tabular} & 1.5 (-8 to 6$)$ & 1.0 (-3 to 2$)$ & $1.5(-1$ to 6$)$ \\
\hline \multicolumn{8}{|l|}{ CSF levels } \\
\hline $\mathrm{A} \beta 42, \mathrm{pg} \mathrm{mL}^{-1}$ & $\begin{array}{l}-3.5(- \\
22 \text { to } 5)\end{array}$ & $-8(-23 \text { to } 61)^{(C)}$ & $-4.0(-22$ to 1$)$ & $\begin{array}{l}-33.0(- \\
77 \text { to } \\
42)\end{array}$ & $-36.0(-66$ to 17$)$ & $\begin{array}{l}-18.0(-76 \text { to } \\
121)\end{array}$ & $-4.0(-40$ to 59$)$ \\
\hline t-tau, pg mL $\mathrm{mL}^{-1}$ & $\begin{array}{l}1.5(-24 \\
\text { to } 10)\end{array}$ & $\begin{array}{l}1.0(-15 \text { to } \\
14)^{(C)}\end{array}$ & $-6.0(-24$ to 26$)$ & $\begin{array}{l}-4.0(-9 \\
\text { to } 5)\end{array}$ & $2.0(-6$ to 12$)$ & $-2.0(-18$ to 9$)$ & $1.0(-14$ to 5$)$ \\
\hline p-tau, pg mL $\mathrm{mL}^{-1}$ & $\begin{array}{l}6.5(-35 \\
\text { to } 29)\end{array}$ & $\begin{array}{l}-5.0(-18 \text { to } \\
17)^{(C)}\end{array}$ & 0 (-21 to 26$)$ & \begin{tabular}{|l|}
$1.0(-9$ \\
to 12$)$ \\
\end{tabular} & 0.5 (-8 to 7$)$ & $-4.0(-12$ to 3$)$ & $-0.5(-7$ to 5$)$ \\
\hline $\mathrm{NfL}, \mathrm{pg} \mathrm{mL} \mathrm{m}^{-1}$ & $\begin{array}{l}-0.5(- \\
141 \text { to } \\
256)\end{array}$ & $\begin{array}{l}-5.0(-159 \text { to } \\
370)^{(C)}\end{array}$ & $\begin{array}{l}-21.0(-132 \text { to } \\
72)\end{array}$ & $\begin{array}{l}92.0(- \\
575 \text { to } \\
1856)\end{array}$ & $\begin{array}{l}148.0(-464 \text { to } \\
1267)\end{array}$ & $\begin{array}{l}-161.0(-578 \text { to } \\
105)\end{array}$ & $\begin{array}{l}-36.0(-2114 \text { to } \\
2304)\end{array}$ \\
\hline $\begin{array}{l}\text { YKL-40, ng } \\
\mathrm{mL}^{-1}\end{array}$ & $\begin{array}{l}-30.5(- \\
37 \text { to } \\
20)\end{array}$ & $\begin{array}{l}-3.0(-94 \text { to } \\
18)^{(C)}\end{array}$ & $\begin{array}{l}17.0(-42 \text { to } \\
30)\end{array}$ & $\begin{array}{l}4.0(-30 \\
\text { to } 134)\end{array}$ & $-19.0(-34$ to 76$)$ & $-23.0(-49$ to 29$)$ & $-14.0(-26$ to 7$)$ \\
\hline
\end{tabular}


Table 9. Change in exploratory outcomes from baseline to end of study in individuals who received two or more infusions of TPI-287. Data taken from Ref. 124.

(): range.

MMSE: Mini-Mental State Examination.

GDS: Geriatric Depression Screen.

Aß42: $\beta$-amyloid 1-42.

$\mathrm{t}$-tau: total tau.

p-tau: phosphorylated tau.

NfL: neurofilament light chain.

YKL-40: chitinase-3-like-protein 1.

(a): Scores range from -9 to 6 - positive scores represent a worsening from baseline and negative scores represent an improvement from baseline.

(b): Scores range from -8 to 6 - positive scores represent a worsening of depressive symptoms from baseline and negative scores represent an improvement from baseline.

(C)One participant was missing data. 


\subsection{Reduction of tau gene expression}

\subsubsection{Anti-sense oligonucleotides}

Anti-sense oligonucleotides (ASOs) are small single stranded DNA oligonucleotides made up of $\sim 20$ base pairs with a DNA base sequence complementary (anti-sense) to specific messenger RNA (mRNA). ${ }^{210}$ The binding interaction between ASO and mRNA results in mRNA degradation which can be exploited in tau therapy. A recent study demonstrated that the regulation of MAPT using ASOs reduced murine tau levels. ${ }^{195}$ The positive outcome enhances the feasibility of transferal to human trials. IONIS-MAPT $T_{R X}$ (BIIB080) is currently the only ASO targeted to MAPT gene expression that is under clinical evaluation in mild AD Phase $\mathrm{I} / \mathrm{Il}$ study. ${ }^{39}$

ASOs injected into the CSF have been used for superoxide dismutase 1 gene (SOD1) in the treatment of amyotrophic lateral sclerosis (ALS) ${ }^{211}$ which due to positive early trial progress is about to embark on Phase III of clinicals trial. ${ }^{212}$ Application of intrathecally ASOs could be administered for PSP patients. There have been suggestions that stabilising the $3 \mathrm{R} / 4 \mathrm{R}$ ratio using $\mathrm{ASO}$ strategy could be a possible therapeutic approach. ${ }^{43}$

\subsubsection{Alternative RNA splicing modulators}

Splicing therapy can be manipulated to exclude or induce a mutation to produce nonfunctional transcript in a disease-causing gene. Designing therapies to target RNA splicing is a novel approach which is yet to be applied to candidate genes such as $M A P T$ in PSP.

\subsection{Blocking transcellular spread of tau}

Tau therapeutic antibodies are constructed to block the intracellular spread of pathologic tau ${ }^{213}$ by targeting specific, altered forms of tau protein. ${ }^{214} \mathrm{~A}$ novel antibody could neutralise and/or eliminate tau that is structurally altered;214 aggregated;215 monomeric; ${ }^{216}$ or phospho-specific. ${ }^{214,217}$ The unique binding site of anti-tau antibodies recognises either $\mathrm{N}$-terminus, ${ }^{218} \mathrm{C}$-terminus, ${ }^{214}$ proline rich region ${ }^{217}$ or microtubule binding region of tau. ${ }^{216}$ Novel monoclonal antibodies targeting R2 or R4 repeat domains of $4 \mathrm{R}$ tau have shown to be highly specific allowing preclinical trials to 
begin. ${ }^{196}$ UCB0107, a recombinant, humanised IgG4 monoclonal antibody that targets the mid region of tau, ${ }^{189,200}$ performed satisfactory with an acceptable safety profile allowing trials to begin in $2020 .^{200}$

\subsection{Autophagy enhancers}

AZP2006 is a small molecule that stimulates macroautophagy to promote tau clearance and eliminate misfolded proteins. ${ }^{202}$ The drug passed safety targets allowing Phase Ila study to begin with estimated completion date at the end of this year. 201

\subsection{Attenuation of microglial activation and inflammation}

Benfotiamine (BFT), a synthetic S-acyl thiamine derivative ${ }^{219}$ could be offered to activate the nuclear factor erythroid 2-related factor (Nrf2)/antioxidant response element (ARE) pathway and alleviate thiamine deficiency which is associated with PSP pathogenesis. ${ }^{207}$ Long-term treatment of BFT shows neuroprotectivity in ADinfected murine models which initiated the design for preclinical PSP trials. ${ }^{207}$ Additionally, neuroinflammation is associated with the proinflammatory cytokine 5lipoxygenase enzyme ${ }^{92}$ and so 5-lipoxygenase blockers could be a potential therapy. 


\section{Discussion}

\subsection{Current therapeutic strategies and associated problems}

The immune system is a highly tractable therapeutic target. ${ }^{177}$ The ability to target protein aggregation is critical to deliver effective neuroprotective intervention for PSP but it is yet to have shown efficacy in clinical trials. ${ }^{177}$ Recently the proposition of the gut microbiome playing an important part in neurodevelopment has presented an entirely new opportunity for exploitation. Previous studies concerning PD have suggested that alterations of gut microbiota composition might influence gut permeability, a-synuclein aggregation and regulation of T-cell immune and inflammatory response. ${ }^{220,221}$ It remains unknown as to how the microbiota precisely modulates brain function. ${ }^{221}$ However, it is acknowledged that the microbiome has a symbiotic relationship with metabolic and immunologic pathways in neurodegenerative disorders. ${ }^{222}$ The regulation of bi-directional communication of the gut-brain axis involved in immune-driven pathogenesis is now considered a potential target for therapeutic intervention.

The associated problems for therapeutic intervention for PSP concern its sporadic occurrence and methodological confusion. The lack of eligible patients suitable for trial deters hopes for developing a biomarker available for market. In previous studies there have been disorder in methodological and experimental practice which has limited the ability to form conclusive results as well as distracting clinical focus. Only recently has diagnostic criteria become more advanced and defined, empowering clinicians to strengthen their understanding in providing an earlier symptomatic diagnosis. Furthermore, a thorough analysis of positive and negative results using a standardised model will provide clearer objectives for novel researchers to exploit.

\subsection{Evidence of drug administration, efficacy and delivery}

Data received from murine models is not solely transferrable to humans ${ }^{76}$ due to molecular pathway and genetic differences. For example, the Kroth et al. study evaluates off-target binding of PET ligands to MAO-A. ${ }^{145} \mathrm{~A}$ reversible MAO-A binder binds to MAO-A and misfolded human tau aggregates but not murine tau 
aggregates. ${ }^{145}$ This explicitly demonstrates that tau data using murine models cannot be fully applicable to humans.

The need to trial potential drugs on humans who bear different genetic and environmental exposures is vital to underpin target efficiency. Drugs are most commonly administered orally or intravenously. Oral drugs need to tolerate digestive enzymes in the stomach; drug metabolism in the liver; overcome the blood-brain barrier and withstand absorption by fat tissue to reach its specific protein target. Intravenous (IV) medication offers direct access to the site of distribution with immediate drug onset. Similarly, IV drugs must overcome the blood-brain barrier and withstand absorption by fat tissue. Furthermore, if IV administration is too fast toxic levels of drug can result in end-organ damage.

\subsection{Potential application of novel Drugs for use in combination with existing therapies}

Multimodal biomarkers which combine biomarkers, imaging and clinical tests will embody a more detailed analysis. The use of protein, RNA, imaging and other clinical tests to build a diagnostic model for PSP is likely to produce refined and definitive results. It has been suggested that a complimentary approach in neuroimaging using DTI with tau-PET will increase precision and accuracy of diagnosis of PSP. ${ }^{223}$ However, advances in neuroimaging requires longer observation times and fine tuning of instruments. ${ }^{146}$

\subsection{Proposed therapeutic direction and future implications}

Recent technological investigations into tau pathology has proposed the hypothesis of prion-like propagation which revealed a new extracellular tau (eTau). ${ }^{224}$ However, this has only been investigated in AD and yet to be studied in PSP brains. Nonetheless, this proposes a different avenue of anti-tau therapeutic approaches to explore. Furthermore, an investigation into pharmacologic restoration of genomic architecture of tau with focus on the ability to slow tauopathy could be proposed.

Latest therapeutic developments have concerned the LC, which releases noradrenaline via widespread projections into multiple target areas. ${ }^{225}$ The extensive 
connectivity concerts modulatory effects in behaviour, movement and cognition. ${ }^{226}$ As PSP pathology is strongly associated with noradrenergic cell loss in the LC, noradrenergic restoration could be plausible as potential treatment. ${ }^{225}$

I have identified two fundamental practices that could instil an effective trial and diagnostic procedure: larger clinical cohorts and improved training for doctors. A larger cohort increases reliability of replicated results; supports comparative validations between separate laboratories with independent cohorts; and offers a clearer differentiation between phenotypes. Combining patients from different phenotypes or with similar neurodegenerative diseases could implicate a larger trial allowing more data to be recorded.

What is the extent to which an accurate diagnosis is impeded by doctor negligence or science discovery? The recent development of the PSP-CDS scale provides standardisation for an expediated diagnosis and alleviates intensive training for clinicians which will help reduce misdiagnosis. Trials undergoing scale analysis need larger cohorts, longer follow-up periods and comprehensive psychometric assessments to enable clinicians to improve judgement. Despite scale modification and enhancements, the lack of cohesion and uniformity within clinician practices still exists. The quota for funding in the NHS may need to be redistributed towards training of geriatricians and nurses to monitor and record novel symptoms of PSP patients. This could expose alternative areas for treatment which could aid in the endeavour to slow decline. 


\section{Conclusion}

The intricacy of the pathogenic mechanisms underlying PSP, has many multifactorial implications at molecular level that are influenced by genetic and environmental interactions. At present, no drugs can stop the progressive neurodegeneration caused by PSP due to the deficit in our molecular understanding of pathogenesis, integral for therapeutic development. Two types of biomarkers are needed for PSP: one to provide an accurate diagnosis and the other to target pathogenic processes of PSP in attempt to slow down progression of the disease. As the UK population is increasingly ageing and as PSP is more common in older people, prevalence and incidence of PSP is likely to increase over time. This expands the market for the development of drugs that could alleviate neurodegenerative decline.

PSP pathology concerns aggregations of hyperphosphorylated tau which differs in distribution and pattern between PSP phenotypes. Therefore, therapies must be tailored to the individual patient which requires immense precision and thorough neuroimaging analysis. Treatments to identify and suppress pathogenic processes of PSP represent a novel therapeutic strategy for the amelioration of pathological deficits. However, amending individual consequential defects associated with PSP may not improve human health considerably. Therefore, a more combined targeted approach will improve therapeutic success.

Studies using $\left[{ }^{18} \mathrm{~F}\right] \mathrm{Pl}-2620$ tau ligand as a neuroimaging biomarker have presented positive results. ${ }^{168,169}$ Therefore, if these biomarkers are applicable to human physiology, they will transform accuracy for diagnosis. There are several on-going or prospective trial procedures which focus on reducing tau gene expression or attenuating microglial activation and inflammation. However, improved stratification procedures in clinical trials are needed to augment efficiency and proficiency in trial design, condensing the timeframe to discover an effective revolutionary treatment.

In a world where life expectancy is rapidly increasing, and age-related neurodegenerative decline is becoming more frequent; the discovery of novel therapeutic treatments is vitally important as a prerequisite to maintaining a fully functioning society. Although larger PSP cohort studies are needed to reliably confirm 
treatment outcomes, only future experimental refinements will allow the therapeutic strategy for PSP to evolve. 


\section{Abbreviations}

AD

ADLs

ALS

ApoA1

APS

ARE

ASO(s)

A $\beta 42$

BFT

BG

CBS

CC

CGM

Chl(s)

CNS

CoQ10

CPA

$\mathrm{Cr}$

CRP

CSF

DLB

DLT

DN

DTI

DWI

EIF2AK3

elF2 $\alpha$

EO

EOPSP

ER

eTau
Alzheimer's

Activities of daily living

Amyotrophic lateral sclerosis

Apolipoprotein A1

Atypical parkinsonism

Antioxidant response element

Anti-sense oligonucleotide(s)

$\beta$-amyloid 1-42

Benfotiamine

Basal ganglia

Corticobasal syndrome

Cerebral cortex

Central grey matter

Cholinergic interneuron(s)

Central nervous system

Coenzyme Q10

Cerebellar peduncle angle

Chromium

C-reactive protein

Cerebrospinal fluid

Dementia with Lewy bodies

Drug limiting toxicity

Dentate nucleus

Diffusion tensor imaging

Diffusion weighted imaging

Eukaryotic translation initiation factor 2 alpha kinase 3

Eukaryotic translation-initiation factor $2 \alpha$

Early-onset

Early-onset PSP (see PSP)

Endoplasmic reticulum

Extracellular tau 


\begin{tabular}{|c|c|}
\hline GDS & Geriatric depression screen \\
\hline GlcNAc & $\mathrm{N}$-acetylglucosamine \\
\hline GP & Globus pallidus \\
\hline $\mathrm{GPe}$ & Global pallidus externa \\
\hline GPi & Global pallidus interna \\
\hline GRS & Genetic risk score \\
\hline GSK3 $\beta$ & Glycogen synthase kinase $3 \beta$ \\
\hline GWAS & Genome wide associated study \\
\hline $\mathrm{HF}$ & Hippocampal formation \\
\hline $\mathrm{H} 1 \mathrm{c}$ & H1-clade \\
\hline IMP & [1123] lofetamine \\
\hline IC & Insular cortex \\
\hline ION & Inferior olivary nucleus \\
\hline iPSC & Induced pluripotent stem cell \\
\hline IV & Intravenous \\
\hline JNK & Jun amino-terminal kinases \\
\hline LBs & Lewy bodies \\
\hline LC & Locus coeruleus \\
\hline LO & Late-onset \\
\hline LOPSP & Late-onset PSP (see PSP) \\
\hline MAO-A & Monoamine oxidase \\
\hline $\operatorname{MAP}(S)$ & MT-associated protein(s) (see MT ) \\
\hline MAPT & Microtubule associated protein tau gene \\
\hline MAPT $\mathrm{H} 1 \mathrm{c}$ & MAPT H1-clade (see MAPT) \\
\hline MBD & Microtubule-binding-domain \\
\hline MC & Motor cortex \\
\hline MCP & Middle cerebellar peduncle \\
\hline MDS & Movement Disorder Society \\
\hline MIBG & ${ }^{123}$ I-metaiodobenzylguanidine \\
\hline MMSE & Mini-mental state examination \\
\hline MRI & Magnetic resonance imaging \\
\hline mRNA & Messenger RNA \\
\hline MRPI & Magnetic resonance parkinsonism index \\
\hline
\end{tabular}




$\begin{array}{ll}\text { MSA } & \text { Multiple system atrophy } \\ \text { MSNs } & \text { Medium spiny neurons } \\ \text { MT(s) } & \text { Microtubule(s) } \\ \text { M-TEG } & \text { Tegmentum } \\ \text { NfL } & \text { Neurofilament light chain } \\ \text { NFTs } & \text { Neurofibrillary tangles } \\ \text { Ni } & \text { Nickel } \\ \text { Nrf2 } & \text { Nuclear factor erythroid 2-related factor } \\ \text { NSA } & \text { Normal pressure hydrocephalus } \\ \text { OCT } & \text { Optical coherence tomography } \\ \text { OGA } & \text { O-GlcNAcase } \\ \text { OGT } & \text { O-GlcNAc transferase } \\ \text { PAD } & \text { Phosphatase-activation domain } \\ \text { PC } & \text { Primary motor cortex } \\ \text { PD } & \text { Parkinson's } \\ \text { pelF2 } \alpha & \text { Phosphorylated elF2 } \alpha \text { (see elF2 } \alpha \text { ) } \\ \text { PERK } & \text { Pancreatic endoplasmic reticulum kinase } \\ \text { PET } & \text { Positron emission tomography } \\ \text { PN } & \text { Pontine nucleus } \\ \text { pSer } & \text { Phosphorylated serine } \\ \text { PSP } & \text { Progressive supranuclear palsy } \\ \text { PSP-C } & \text { PSP with predominant cerebellar ataxia (see PSP) } \\ \text { PSP-CBS } & \text { PSP with predominant corticobasal syndrome (see PSP) } \\ \text { PSP-CDS } & \text { PSP-Clinical Deficits Scale (see PSP) } \\ \text { PSP-F } & \text { PSP with behavioural variant frontotemporal dementia (see } \\ \text { PSP-OM } & \text { PSP) } \\ \text { PSP-P } & \text { PSP with predominant ocular motor function (see PSP) } \\ \text { PSP-PGF } & \text { PSP with predominant parkinsonism (see PSP) } \\ \text { PSP-PI } & \text { PSP with pure akinesia with progressive gait freezing (see } \\ \text { PSP-PLS } & \text { PSP) } \\ \text { PSP-RS } & \text { PSP with postural instability (see PSP) } \\ & \\ \text { Pichardson's syndrome } \\ \text { PStis lateral sclerosis } \\ \text { PSP }\end{array}$




$\begin{array}{ll}\text { PSP-SL } & \text { PSP with primary progressive apraxia of speech or non-fluent } \\ & \text { variant primary progressive aphasia (see PSP) } \\ \text { PSPRS } & \text { PSP rating scale (see PSP) } \\ \text { p-tau } & \text { Phosphorylated tau } \\ \text { P-TEG } & \text { Tegmentum } \\ \text { pThr } & \text { Phosphorylated threonine } \\ \text { PTM(s) } & \text { Post-translational modification(s) } \\ \text { PU } & \text { Putamen } \\ \text { RN } & \text { Red nucleus } \\ \text { RNFL } & \text { Retinal nerve fibre layer } \\ \text { SCP(s) } & \text { Superior cerebellar peduncle(s) } \\ \text { SEADL } & \text { Schwab and England Activities of Daily Living Scale } \\ \text { SGP } & \text { Supranuclear gaze palsy } \\ \text { SLCO } & \text { Solute carrier organic anion transporter } \\ \text { SLP } & \text { Scanning lase polarimetry } \\ \text { SN } & \text { Substantia nigra } \\ \text { SNCA } & \text { Synuclein alpha gene } \\ \text { SNP(s) } & \text { Single nucleotide polymorphism(s) } \\ \text { SNpc } & \text { Substantia nigra pars compacta } \\ \text { SOD1 } & \text { Superoxide dismutase 1 gene } \\ \text { SPECT } & \text { Single-photon emission computed tomography } \\ \text { STN } & \text { Subthalamic nucleus } \\ \text { TAs } & \text { Tuft-shaped astrocytes } \\ \text { t-tau } & \text { Total tau } \\ \text { UPR } & \text { Unfolded protein response } \\ \text { vPSP } & \text { Variant syndromes of PSP (see PSP) } \\ \text { YKL-40 } & \text { Chitinase-3-like-protein 1 } \\ \text { 3R-tau } & \text { Three-repeat domain containing tau } \\ \text { 4R-tau } & \text { Four-repeat domain containing tau } \\ \text { 4RT } & \text { Four repeat tauopathy } \\ \text { 99mTc-HMPAO } & \text { Hexamethylpropyleneamine oxime } \\ & \end{array}$




\section{References}

1. Parkinson's Foundation, Parkinson's Disease vs. Parkinsonism, https://www.parkinson.org/sites/default/files/attachments/Parkinsons-Diseasevs-Parkinsonisms.pdf, (accessed September 2019).

2. Parkinson's UK, Types of Parkinsonism, https://www.parkinsons.org.uk/information-and-support/types-parkinsonism, (accessed December 2019).

3. Parkinson's Foundation, Statistics, https://www.parkinson.org/UnderstandingParkinsons/Statistics, (accessed September 2019).

4. PSPA, A brief Guide to PSP, https://pspassociation.org.uk/information-andsupport/what-is-psp/brief-guide-to-psp/ , (accessed January 2020).

5. Parkinson's UK, What is Parkinson's?

https://www.parkinsons.org.uk/information-and-support/what-parkinsons, (accessed December 2019).

6. J. Parkinson, An essay on the shaking palsy, Whittingham and Rowland for Sherwood, Needly and Jones, London, 1817.

7. J.M.Charcot, On Parkinson's disease in Lectures on diseases of the nervous system delivered at the Salp^etri`ere, ed. G.Sigerson, New Sydenham Society, London, $2^{\text {nd }}$ edn, 1881, pp. 129-156.

8. C.Goetz, The History of Parkinson's Disease: Early Clinical Descriptions and Neurological Therapies, Cold Spring Harbor Perspectives in Medicine, 2011, 1, a008862.

9. G.DeMaagd, A. Philip, Part 1: Disease Entity, Risk Factors, Pathophysiology, Clinical Presentation, and Diagnosis, Parkinson's Disease and It's Management, 2015, 40, 504-532.

10. S.G.Reich, J.M.Savitt, Parkinson's Disease, Medical Clinics of North America, 2019, 103, 337-350.

11. H.M.Gao, J.S.Hong, Gene-environment interactions: key to unravelling the mystery of Parkinson's disease, Progress in Neurobiology, 2011, 94, 1-19.

12. A.Kouli, K.M Torsney, W.L.Kuan, Chapter 1, Parkinson's Disease: Etiology Neuropathology and Pathogenesis in Parkinson's Disease: Pathogenesis and Clinical Aspects, ed. T.Stoker, J.Greenland, Codon Publications, Brisbane (AU), 2018, 1-56.

13. A.Nagy, A.Schrag, Neuropsychiatric aspects of Parkinson's disease, Journal of Neural Transmission, 2019, 126, 889-896. 
14. J.S.Reijinders, U.Ehrt, W.E.Weber, D.Aarsland, A.F.Leentjens, A systematic review of prevalence studies of depression in Parkinson's disease, Movement Disorders, 2008, 23, 183-189.

15. M.H.M.Timmer, M.H.C.T.van Beek, B.R.Bloem, R.A.J.Esselink, What a neurologist should know about depression in Parkinson's disease, Practical Neurology, 2017, 17, 359-368.

16. D.Weintraub, E.Mamikonyan, The Neuropsychiatry of Parkinson Disease: A perfect Storm, The American Journal of Geriatric Psychiatry, 2019, 27, 9981018.

17. M.A.Hely, W.G.Reid, M.A.Adena, G.M.Halliday, J.G.Morris, The Sydney multicentre study of Parkinson's disease: the inevitability of dementia at 20 years, 2008, 23, 837-844.

18. Alzheimer's Society United, What Causes Dementia? https://www.alzheimers.org.uk/about-dementia/types-dementia/dementiacauses\#content-start, (accessed December 2019).

19. The Guardian, Quarter of Parkinson's sufferers were wrongly diagnosed, says charity, https://www.theguardian.com/society/2019/dec/30/quarter-ofparkinsons-sufferers-were-wrongly-diagnosed-says-charity, (accessed January 2020).

20. N.R.McFarland, C.W.Hess, Recognizing Atypical Parkinsonisms: 'Red Flags' and Therapeutic Approaches, Seminars in Neurology, 2017, 37, 215-227.

21. M.G.Spillantini,M.Schmidt, M.L.Schmidt,V.M.Y.Lee, J.Q.Trojanowski, R.Jakes, M.Goedert, a-Synuclein in Lewy bodies, Nature, 1997, 388, 839-830.

22. L.Parkkinen, S.S.O'Sullivan, C.Collins, A.Petrie, J.L.Holton, T.Revesz, A.J.Lees, Disentangling the relationship between Lewy bodies and nigral neuronal loss in Parkinson's disease, Journal of Parkinson's Disorders, 2011, 1, 277-286.

23. N.Giguére, S.B.Nanni, L-E.Trudeau, On cell loss and selective vulnerability of neuronal populations in Parkinson's disease, Frontiers in Neurology, 2018, 9, 455.

24. S.M.Matt, P.J.Gaskill, Where is Dopamine and how do immune cells see it?: Dopamine-mediated immune cell function in health and disease, Journal of Neuroimmune Pharmacology, 2020, 15, 114-164.

25. E.Caggiu, G.Arru, S.Hosseni, M.Niegowska, G.Sechi, I.R.Zarbo, L.A.Sechi, Inflammation, Infectious triggers, and Parkinson's Disease, Frontiers in Neurology, 2019, 10, 122.

26. L.F.Burbulla, P.Song, J.R.Mazzulli, E.Zampese, Y.CWong, S.Jeon, D.P.Santos, J.Blanz, C.D.Obermaier, C.Strojny, J.N.Savas, E.Kiskinis, X.Zhuang, R.Krüger, 
D.J.Surmeier, D.Krainc, Dopamine oxidation mediates mitochondrial and lysosomal dysfunction in Parkinson's disease, Science, 2017, 357, 1255-1261.

27. P.Aldrin-Kirk, A.Heuer, D.R.Ottosson, M.Davidsson, B.Mattsson, T.Björklund, Chemogenetic modulation of cholinergic interneurons reveals their regulating role on the direct and indirect output pathways from the striatum, Neurobiology of disease, 2018, 109, 148-162.

28. X.Zhang, F.Gao, D.Wang, C.Li, Y.Fu, W.He, J.Zhang, Tau pathology in Parkinson's disease, Frontiers in Neurology, 2018, 9, 809.

29. M.E.Orr, A.C.Sullivan, B.Frost, A brief overview of tauopathy: causes, consequences and therapeutic strategies, Trends in Pharmacological Sciences, 2017, 38, 637-648.

30. M.M.Hefti, S.Kim, A.J.Bell, R.K.Betters, K.L.Fiock, M.A.lida, M.E.Smalley, K.Farrell, M.E.Fowkes, J.F.Crary, Tau Phosphorylation and Aggregation in the Developing Human Brain, Journal of Neuropathology and Experimental Neurology, 2019, 78, 930-938.

31. O.Bugiani, G.L.Mancardi, A.Brusa, A.Ederli, The fine structure of subcortical neurofibrillary tangles in progressive supranuclear palsy Acta Neuropathology, 1979, 45, 147-152.

32. T.Ishizawa, P.Mattila, P.Davies, DWang, D.WDickson, Colocalization of tau and alpha-synuclein epitopes in Lewy bodies, Journal of Neuropathology and Experimental Neurology, 2003, 62, 389-397.

33. A.Andreadis, W.M.Brown, K.S.Kosik, Structure and novel exons of the human tau gene, Biochemistry, 1992, 31, 10626-10633.

34. M.Goedert, M.G.Spillantini, R.Jakes, D.Rutherford, R.A.Crowther, Multiple isoforms of human microtubule-associated protein tau: sequences and localisation in neurofibrillary tangles of Alzheimer's disease, Neuron, 1989, 3 , 519-526.

35. M-L.Caillet-Boudin, L.Buée, N.Sergeant, B.Lefebvre, Regulation of human MAPT gene expression, Molecular Neurodegeneration, 2015, 10, 28.

36. G.G.Kovacs, Invited review: Neuropathology of tauopathies: principles and practice, Neuropathology and applied neurobiology, 2015, 41, 3-23.

37. M.A.Sealey, E.Vourkou, C.Cowan, T.Bossing, S.Quraishe, S.Grammenoudi, E.M.C.Skoulakis, A.Mudher, Distinct phenotypes of three-repeat and four-repeat human tau in transgenic model of tauopathy, Neurobiology of disease, 2017, $105,74-83$.

38. C.A.Alonso, A.Mederlyova, M.Novak, I.Grundke-lqbal, K.Iqbal, Promotion of hyperphosphorylation by frontotemporal dementia Tau mutations, The Journal of Biological Chemistry, 2004, 279, 34873-3488. 
39. A.Shoeibi, N.Olfati, I.Litvan, Frontrunner in Translation: Progressive Supranuclear Palsy, Frontiers in Neurology, 2019, 10, 1125.

40. M.Mimuro, M.Yoshida, Chameleons and mimics: Progressive supranuclear palsy and corticobasal degeneration, Neuropathology, 2019, 40, 57-67.

41. Z.Stejskalova, Z.Rohan, R.Rusina, A.Tesar, J.Kukal, G.G.Kovacs, A.Bartos, R.Matej, Pyramidal system involvement in progressive supranuclear palsy - a clinicopathological correlation, BMC Neurology, 2019, 19, 42.

42. M.Moscovich, G.Boschetti, A.Moro, H.A.G.Teive, A.Hassan, R.P.Munhoz, Death certificate data and causes of death in patients with parkinsonism, Parkinsonism and Related Disorders, 2017, 41, 99-103.

43. A.L.Boxer, J.T.Yu, L.I.Golbe, I.Litvan, A.E.Lang, G.U.Höglinger, Advances in progressive supranuclear palsy: new diagnostic criteria, biomarkers, and therapeutic approaches, Lancet Neurology, 2017, 16, 552-563

44. D.R.Williams, A.J.Lees, Progressive supranuclear palsy: clinicopathological concepts and diagnostic challenges, Lancet Neurology, 2009, 8, 270-279.

45. J.C.Steele, J.C.Richardson, J.Olszewski, Progressive supranuclear palsy: a heterogeneous degeneration involving the brain stem, basal ganglia and cerebellum with vertical gaze and pseudobulbar palsy, nuchal dystonia and dementia, Archives of Neurology, 1964, 10, 333-359.

46. I.Litvan, Y.Agid, D.Calne, G.Campbell, B.Dubois, R.C.Duvoisin, C.G.Goetz, L.I.Golbe, J.Grafman, J.H.Growdon, M.Hallett, J.Jankovic, N.P.Quinn, E.Tolosa, D.S.Zee, Clinical research criteria for the diagnosis of progressive supranuclear palsy (Steele-Richardson-Olszewski syndrome), Neurology, 1996, 47,1 LP-9.

47. A.Shoeibi, I.Litvan, E.Tolosa, T.D.Ser, E.Lee, TAUROS Investigators, Progression of two progressive supranuclear palsy phenotypes with comparable initial disability, Parkinsonism and related disorders, 2019, 66, 87-93.

48. I.T.Coyle-Gilchrist, K.M.Dick, K.Patterson, P.V.Rodríquez, E.Wehmann, A.Wilcox, C.J.Lansdall, K.E.Dawson, J.Wiggins, S.Mead, C.Brayne, J.B.Rowe, Prevalence, characteristics, and survival of frontotemporal lobal degermation syndromes, Neurology, 2016, 86, 1736-1743.

49. H.Ling, Clinical approach to progressive supranuclear palsy, Journal of Movement Disorders, 2016, 9, 3-13.

50. N.Giagkou, G.U.Höglinger, M.Stamelou, Progressive supranuclear palsy in International Review of Neurobiology: Parkinsonism Beyond Parkinson's Disease Volume 149. ed. M.Stamelou, G.U.Höglinger, Academic Press, London, 2019, London, Ch.3, pp 49-86. 
51. V.Fleury, P.Brindel, N.Nicastro, P.R.Burkhard, Descriptive epidemiology of parkinsonism in the Canton of Geneva Switzerland, Parkinsonism and Related Disorders, 2018, 54, 30-39.

52. L.I.Golbe, The epidemiology of PSP, Journal of Neural Transmission Supplementa, 1994, 42, 263-273.

53. G.U.Höglinger, G.Respondek, M.Stamelou, C.Kurz, K.A.Josephs, A.E.Lang, B.Mollenhauer, U.Müller, C.Nilsson, J.L.Whitwell, T.Arzberger, E.Englund, E.Gelpi, A.Giese, D.J.Irwin, W.G.Meissner, A.Pantelyat, A.Rajput, J.C.van Swieten, C.Troakes, A.Antonini, K.P.Bhatia, Y.Bordelon, Y.Compta, J.C.Corvol, C.Colosimo, D.W.Dickson, R.Dodel, L.Ferguson, M.Grossman, J.Kassubek, F.Krismer, J.Levin, S.Lorenzl, H.R.Morris, P.Nestor, W.H.Oertel, W.Poewe, G.Rabinovici.G, J.B.Rowe, G.Dchellenberg, K.Seppi, T.van Eimeren, G.K.Wenning, A.L.Boxer, L.I.Golbe, I.Litvan, Movement Disorder Societyendorsed PSP study group, Clinical diagnosis of progressive supranuclear palsy: the Movement Disorder Society criteria, Movement Disorders, 2017, 32 , 853-864.

54. I.Litvan, C.A.Mangone, A.McKee, M.Verny, A.Parsa, K.Jellinger, L.D'Olhaberriague, K.R.Chaudhuri, R.K.Pearce, Natural history of progressive supranuclear palsy (Steele-Richardson-Olszewski syndrome) and clinical predictors of survival: a clinicopathological study, Journal of Neurology, Neurosurgery and Psychiatry, 1996, 60, 615-620.

55. F.Ali, P.R.Martin, H.Botha, J.E.Ahlskog, J.H.Bower, J.Y.Masumoto, D.Maraganore, A.Hassan, S.Eggers, B.F.Boeve, D.S.Knopman, D.Drubach, R.C.Petersen, E.D.Dunkley, J.van Gerpen, R.Utti, J.L.Whitwell, D.W.Dickson, K.A.Josephs, Sensitivity and specificity of diagnostic criteria for progressive supranuclear palsy, Movement disorders, 2019, 34, 1144-1153.

56. M.Picillo, S.Cuoco, M.F.Tepedino, A.Cappiello, G.Volpe, R.Erro, G.Santagelo, M.T.Pellecchia, P.Barone, The PSP Salerno Study Group, Motor, cognitive and behavioural differences in MDS PSP phenotypes, Journal of Neurology, 2019, 266, 1727-1735.

57. M.Baker, I.Litvan,H.Houlden, J.Adamson, D.Dickson, J.Perez-Tur, J.Hardy, T.Lynch, E.Bigio, M.Hutton, Association of an extended haplotype in the tau gene with progressive supranuclear palsy, Human Molecular Genetics, 1999, 8, 711-715.

58. S.Y.Im, E.K.Kim, Y.J.Kim, Genetics of progressive supranuclear palsy, Journal of Movement Disorders, 2015, 8, 122-129.

59. D.A.Bennet, L.A.Beckett, A.M.Murray, K.M.Shannon, C.G.Goetz, D.M.Pilgrim, D.A.Evans, Prevalence of Parkinsonian Signs and Associated Mortality in a Community Population of Older People, New England Journal of Medicine, 1996, 334, 71-76. 
60. E.M.Rocha, G.A.Smith, E.Park, H.Cao, E.Brown, P.Hallett, O.Isacson, Progressive decline of glucocerebrosidase in aging and Parkinson's disease, Annals of clinical and translational neurology, 2015, 2, 433-438.

61. I.Litvan, P.S.Lees, C.R.Cunningham, S.N.Rai, A.C.Cambon, D.G.Standaert, C.Marras, J.Juncos, D.Riley, S.Reich, D.Hall, B.Kluger, Y.Bordelon, D.R.Shprecher, Environmental and occupational risk factors for progressive supranuclear palsy: Case-control study, Movement Disorders, 2016, 31, 644652.

62. C.Alquezar, J.B.Felix, E.McCandlish, B.T.Buckley, D.Caparros-Lefebvre, C.M.Karch, L.I.Golbe, A.W.Kao, Heavy metals contaminating the environment of a progressive supranuclear palsy cluster induce tau accumulation and cell death in cultured neurons, Science Reports, 2020, 10, 569.

63. M.Picillo, M.F.Tepedino, F.Abate, R.Erro, S.Ponticorvo, S.Tartaglione, G.Volpe, D.Frosini, P.Cecchi, M.Cosottini, R.Ceravolo, F.Esposito, M.T.Pellecchia, P.Barone, R.Manara, Midbrain MRI assessments in progressive supranuclear palsy subtypes, Journal of Neurology, Neurosurgery, Psychiatry, 2020, 91, 98103.

64. L.I.Golbe, P.A.Ohman-Strickland, A clinical rating scale for progressive supranuclear palsy, Brain, 2007, 130, 1552-1565.

65. C.A.Payan, F.Viallet, B.G.Landwehrmeyer, A.M.Bonnet, M.Borg, F.Durif, L.Lacomblez, F.Bloch, M.Verny, J.Fermanian, Y.Agid, A.C.Ludolph, P.N.Leigh, G.Bensimon, NNIPPS Study Group, Disease Severity and Progression in Progressive Supranuclear Palsy and Multiple System Atropy: Validation of the NNIPPS- PARKINSON PLUS SCALE, PLOS ONE, 2011, 6, e22293.

66. I.Piot, K.Schweyer, G.Respondek, M.Stamelou, DescribePSP study group, ProPSP study group, MDS-endorsed PSP study group, P.Sckopke, T.Schenk, C.G.Goetz, G.T.Stebbins, G.U.Höglinger, The Progressive Supranuclear Palsy Clinical Deficits Scale, Movement Disorders, 2020, 35, 650-661.

67. A.L.Boxer, A.E Lang, M Grossman, D.S Knopman, B.L Miller,L.S Schneider, R.S.Doody, A.Lees, L.I.Golbe, D.R.Williams, J-C.Corvol, A.Ludolph, D.Burn, S.Lorenzl, I.Litvan, E.D.Roberson, G.U.Höglinger, M.Koestler, C.R.Jack Jr, V.V.Deerlin, C.Randolph, I.V.Lobach, H.W.Heuer, I.Gozes, L.Parker, S.Whitaker, J.Hirman, A.J.Stewart, M.Gold, B.H.Morimoto, on behalf of the AL108-231 investigators, Davunetide for Progressive Supranuclear Palsy: a multicenter, randomized, double-blind, placebo controlled trial, Lancet Neurology, 2014, 13, 676-685.

68. B.Zhang, J.Carroll, Q.Trojanowski, Y.Yao, M.Iba, J.S.Potuzak, A.M.Hogan, S.X.Xie, C.Ballatore, A.B.Smith, V.M.Lee, K.R.Brunden, The microtubulestabilizing agent, epothilone $D$, reduces axonal dysfunction, neurotoxicity, cognitive deficits, and Alzheimer-like pathology in an interventional study with aged tau transgenic mice, The Journal of neuroscience, 2012, 32, 3601-3611. 
69. J.L.Whitwell, N.Tosakulwong, H.Botha, F.Ali, H.N.Clark, J.R.Duffy., R.L.Utianski, C.A.Stevens, S.D.Weigand, C.G.Schwarz, M.L.Senjem, C.R.Jack, V.J.Lowe, E.Ahlskog, D.W.Dickson, K.A.Josephs, Brain volume and flortaucipir analysis of progressive supranuclear palsy clinical variants, Neuroimage: Clinical, 2020, 25, 102152.

70. M.Picillo, S.Cuoco, M.F.Tepedino, A.Cappiella, G.Volpe, R.Erro, G.Santagelo, M.T.Pellecchia, P.Barone, The PSP Salerno Study Group. Motor, cognitive and behavioural differences in MDS PSP phenotypes, Journal of Neurology, 2019, 266, 1727-1735.

71. K.Arima, Ultrastructural characteristics of tau filaments in tauopathies: immunoelectron microscopic demonstration of tau filaments in tauopathies, Neuropathology, 2006, 26, 475-483.

72. E.Jabbari, H.Zetterberg, H.R.Morris, Tracking and predicting disease progression in progressive supranuclear palsy: CSF and blood biomarkers, Journal of Neurology, Neurosurgery and Psychiatry, 2017, 88, 883-888.

73. D.M.Walsh, D.J.Selkoe, A critical appraisal of the pathogenic protein spread hypothesis of neurodegeneration, Nature Reviews Neuroscience, 2016, 17, 251-260.

74. Y.L.Gao, N.Wang, F.R.Sun, X.P.Cao, W.Zhang, J.T.Yu, Tau in neurodegenerative disease, Annals Translational Medicine, 2018, 6, 175.

75. N.M.Kanaan, G.Morfini, G.Pigino, N.E.LaPointe, A.Andreadis, Y.Song, E.Leitman, L.I.Binder, S.T.Brady, Phosphorylation in the amino terminus of tau prevents anterograde axonal transport, Neurobiology of Aging, 2012, 33, 826.e15-826.e30.

76. M.M.Hefti, S.Kim, A.J.Bell, R.K.Betters, K.L.Fiock, M.A.lida, M.E.Smalley, K.Farrell, M.E.Fowkes, J.F.Crary, Tau phosphorylation and aggregation in the developing human brain, Journal of Neuropathology and Experimental Neurology, 2019, 78, 930-938.

77. T.J.Cohen, J.LGuo, D.E.Hurtado, L.K.Kwong, I.P.Mills., J.Q.Trojanowski, V.M.Lee, The acetylation of tau inhibits its function and promotes pathological tau aggregation, Nature Communications, 2011, 2, 252.

78. N.B.Hastings, X.Wang, L.Song, B.D.Butts, D.Grotz, R.Hargreaves, J.F.Hess, KK.Hong, C.R.Huang, L.Hyde, M.Laverty, J.Lee, D.Levitan, S.X.Lu, M.Maguire, V.Mahadomrongkul, E.J.McEachern, X.Ouyang, T.W.Rosahl, H.Selnick, M.Stanton, G.Terracina, D.J.Vocadlo, G.Wang, J.L.Duffy, E.M.Parker, L.Zhang, Inhibition of O-GIcNAcase leads to elevation of O-GIcNAc tau and reduction of tauopathy and cerebrospinal fluid tau in rTg4510 mice, Molecular Neurodegeneration, 2017, 12, 39.

79. T.Guo, W.Noble, D.P.Hanger, Roles of tau protein in health and disease, Acta Neuropathology, 2017, 133, 665-704. 
80. Y.Wang, E.Mandelkow, Tau in physiology and pathology, Nature Reviews Neuroscience, 2016, 17, 5-21.

81. P.Ryan, M.Xu, A.K.Davey, J.J.Danon, G.D.Mellick, M.Kassiou, S.Rudrawar, OGlcNAc Modification protects against protein misfolding and aggregation in neurodegenerative disease, ACS Chemical Neuroscience, 2019, 10, 22092221.

82. M.Haj-Yahya, H.A.Lashuel, Protein Semisynthesis Provides Access to Tau Disease-Associated Post-translational Modifications (PTMs) and Paves the Way to Deciphering the Tau PTM Code in Health and Diseased States, Journal of the American Chemical Society, 2018, 140, 6611-6621.

83. K.Ishizawa, D.W.Dickson, Microglial Activation Parallels System Degeneration in Progressive Supranuclear Palsy and Corticobasal Degeneration, Journal of Neuropathology and Experimental Neurology, 2001, 60, 647-657.

84. R.Fernández-Botrán, Z.Ahmed, F.A.Crespo, C.Gatenbee, J.Gonzalez, D.W.Dickson, I.Litvan, Cytokine Expression and Microglial Activation In Progressive Supranuclear Palsy, Parkinsonism Related Disorders, 2011, 17, 683-688.

85. D.P.Hanger, H.L.Byers, S.Wray, K-Y.Leung, M.J.Saxton, A.Seereeram, C.H.Reynolds, M.A.Ward, Novel phosphorylation sites in tau from Alzheimer brain support a role for casein kinase 1 in disease pathogenesis, Journal of biological chemistry, 2007, 282, 23645-23654.

86. K.Arima, S.Hirai, N.Sunohara, K.Aoto, Y.Izumiyama, K.Uéda.K, K.Ikeda, M.Kawai, Cellular co-localization of phosphorylated tau- and NACP/asynuclein-epitopes in Lewy bodies in sporadic Parkinson's disease and in dementia with Lewy bodies, Brain Research, 1999, 843, 53-61.

87. J.Kuret, E.E.Congdon, G.Li, H.Yin, X.Yu, Q.Zhong, Evaluating triggers and enhancers of tau fibrillization, Microscopy research and technique, 2005, 67, 141-155.

88. D.T.Chien, A.K.Szardenings, S.Bahri, J.C.Walsh, F.Mu, C.Xia, W.R.Shankle, A.J.Lerner, M.Y.Su, A.Elizarov, H.C.Kolb, Early clinical PET imaging results with the novel PHF-tau radioligand [F18]-T808, Journal of Alzheimer's disease, 2014, 38, 171-184.

89. L.Xu, J.Zheng, M.Margittai, R.Nussinov, B.Ma, How does hyperphosphorylation promote tau aggregation and modulate filament structure and stability? ACS Chemical Neuroscience, 2016, 7, 565-575.

90. J.E.Duda, B.IGiasson, M.E.Mabon, D.C.Miller, L.I.Golbe, V.M.Lee, J.Q.Trojanowski, Concurrence of alpha-synuclein and tau brain pathology in the Contursi kindred, Acta Neuropathologica, 2002, 104, 7-11. 
91. G.Muntané, A.Dalfó, A.Matinez, I.Ferrer, Phosphorylation of tau and $\alpha-$ synuclein in synaptic enriched fractions of the frontal cortex in Alzheimer's disease and in Parkinson's disease and related $\alpha$-synucleinopathies, Neuroscience, 2008, 152, 913-923.

92. P.F.Giannopoulos, J.Chu, M.Sperow, J.G.Li, W.H.Yu, L.G.Kirby, M.Abood, D.Praticò, Pharmacologic inhibition of 5-Lipoxygenase improves memory, rescues synaptic dysfunction and ameliorates tau pathology in a transgenic model of tauopathy, Biological Psychiatry, 2015, 78, 693-701.

93. S.Weis, M.Sonnberger, A.Dunzinger, E.Voglmayr, M.Aichholzer, R.Kleiser, P.Strasser, Neurodegenerative Disease: Progressive Supranuclear Palsy (PSP) - Cortico-Basal Degeneration (CBD) in Imaging Brain Diseases: A Neuroradiology, Nuclear Medicine, Neurosurgery, Neuropathology and Molecular Biology-based Approach, Springer, Vienna, 2019, ch.35, pp 973-985.

94. J.A.Chen, Z.Chen, H.Won, A.Y.Huang, J.K.Lowe, K.Wojta, J.S.Yokoyama, G.Bensimon, P.N.Leigh, C.Payan, A.Shatunov, A.R.Jones, C.M.Lewis, P.Deloukas, P.Amouyel, C.Tzourio, J.F.Dartigues, A.Ludolph, A.L.Boxer, J.M.Bronstein, A.Al-Chalabi, D.H.Geschwind, G.Coppola, Joint genome-wide association study of progressive supranuclear palsy identifies novel susceptibility loci and genetic correlation to neurodegenerative diseases, Molecular Neurodegeneration, 2018, 13, 41.

95. G.U.Höglinger, N.M.Melhem, D.W,Dickson, P.M.Sleiman, L.S.Wang, L.Klei, R.Rademakers, R.de Silva, I.Litvan, D.E.Riley, J.C.van Swieten, P.Heutink, Z.K.Wszolek, R.J.Uitti, J.Vandrovcova, H.I. Hurtig, R.G.Gross, W.Maetzler, S.Goldwurm, E.Tolosa, B.Borroni, P.Pastor, PSP genetics Study Group, L.B.Cantwell, M.R.Han, A.Dillman, M.P.van der Brug, J.R.Gibbs, N.R.Cookson, D.G.Hernandez, A.B.Singleton, M.J.Farrer, C.E.Yu., L.I.Golbe, T.Revesz, J.Hardy, A.J.Lees, B.Devlin, H.Hakonarson, U.Müller, G.D.Schellenberg, Identification of common variants influencing risk of the tauopathy progressive supranuclear palsy, Nature Genetics, 2011, 43, 699-705.

96. M.Y.Sanchez-Contreras, N.Kouri, C.N.Cook, D.J.Serie, M.G.Heckman, N.A.Finch, R.J.Caselli, R.J.Uitti, Z.K.Wszolek, N.Graff-Radford, L.Petrucelli, L.S.Wang, G.D.Schellenberg, D.W.Dickson, R.Rademakers, O.W.Ross, Replication of progressive supranuclear palsy genome-wide association study identifies SLCO1A2 and DUSP10 as new susceptibility loci, Molecular Neurodegeneration, 2018, 13, 37.

97. Z.Chen, J.A.Chen, A.Shatunov, A.R.Jones, S.N.Kravitz, A.Y.Huang, L.Lawrence, J.K.Lowe, C.M.Lewis, C.A.M.Payan, W.Lieb, A.Franke, P.Deloukas, P.Amouyel, C.Tzourio, J.F.Dartigues, NNIPPS and BBBIPPS Study Groups, A.Ludolph, G.BensimoN, P.L. Leigh, J.M.Bronstein, G.Coppola, D.H.Geschwind, A.Al-Chalabi, Genome-Wide Survey of Copy Number Variants Finds MAPT Duplications in Progressive Supranuclear Palsy, Movement disorders, 2019, 34, 1049-1059. 
98. E.Jabbari, J.Woodside, M.M.X.Tan, M.Shoai, A.Pittman, R.Ferrari, K.Y.Mok, D.Zhang, R.H.Reynolds, R.de Silva, M.J.Grimm, G.Respondek, U.Müller, S.AlSarraj, S.M.Gentleman, A.J.Lees, T.T.Warner, J.Hardy, T.Revesz, G.U.Höglinger, J.L.Holton, M.Ryten.M, H.R.Morris, Variation at the TRIM11 Locus Modifies Progressive Supranuclear Palsy Phenotype, Annals of Neurology, 2018, 84, 485-496.

99. L.W.Bonham, C.M.Karch, C.C.Fan, C.Tan, E.G.Geier, Y.Wang, N.Wen, I.J.Broce, Y.Li, M.J.Barkovich, R.Ferrari, J.Hardy, P.Momeni, G. Höglinger, U.Müller, C.P.Hess, L.P.Sugrue, W.P.Dillon, G.D.Schellenberg, B.L.Miller, O.A.Andreassen, A.M.Dale, A.J.Barovich, J.S.Yokoyama, R.S.Desikan, Disease Genetics Consortium (IPDGC), International Genomics of Alzheimer's Progect (IGAP), CXCR4 involvement in neurodegenerative diseases, Translational Psychiatry, 2018, 8, 73.

100. N N.Kouri, O.A Ross, B.Dombroski, C.S.Younkin, D.J.Serie, A.Soto-Ortolaza, M.Baker, N.C.A.Finch, H.Yoon, J.Kim, S.Fujioka, C.A.McLean, B.Ghetti, S.Spina, L.B.Cantwell, M.R.Farlow, J.Grafman, E.D.Huey, M.R.Han, S.Beecher, E.T.Geller, H.A.Kretzschmar, S.Roeber, M.Gearing, J.L.Juncos., J.P.G.Vonsattel, V.M.Van Deerlin, M.Grossman, H.I.Hurtig, R.G.Gross, S.E.Arnold, J.Q.Trojanowski, V.M.Lee, G.K.Wenning, C.L.White, G.U.Höglinger, U.Müller, B.Devlin, L.I.Golbe, J.Crook, J.E.Parisi, B.F.Boeve, K.A.Josephs, Z.K.Wszolek, R.J.Uitti, N.R.Graff-Radford, I.Litvan, S.G.Younkin, L.S.Wang, N.Ertekin-Taner, R.Rademakers, H.Hakonarsen, G.D.chellenberg, D.W.Dickson, Genome-wide association study of corticobasal degeneration identifies risk variants shared with progressive supranuclear palsy. Nature communications, 2015, 6, 7247.

101. M.G.Heckman, R.R.Brennan, C.Labbe, A.I. Soto, S.Koga, M.A.DeTure, M.E.Murray, R.C.Petersen, B.F.Boeve, J.A.van Gerpen, R.J.Uitti, Z.K.Wszolek, R.Rademakers, D.W.Dickson, O.A.Ross, Association of MAPT subhaplotypes with risk of progressive supranuclear palsy and severity of tau pathology, JAMA Neurology, 2019, 76, 710-717.

102. L.N.Clark, P.Poorkaj, Z.Wszolek, D.H.Geschwind, Z.S.Nasreddine, B.Miller, D.Li, H.Payami, F.Awert, K.Markopoulou,A. Andreadis, I.D'Souza, V.M.Lee, L.Reed, J.Q.Trojanowski, V.Zhukareva, T.Bird, G.Schellenberg, K.C.Wilhelmsen, Pathogenic implications of mutations in the tau gene in pallido-ponto- nigral degeneration and related neurodegenerative disorders linked to chromosome 17, Proceedings of the National Academy of Sciences USA, 1998, 95, 13103-13107.

103. P.Poorkaj, N.A.Muma, V.Zhukareva, E.J.Chochran, K.M.Shannon, H.Hurtig, W.C.Koller, T.D.Bird, J.Q.Trojanowski. V.M.-Y.Lee, D.Gerrard, An ${ }^{R}{ }^{\circ}{ }^{\llcorner} \mathrm{T}$ Mutation in a subject with a Progressive supranuclear palsy, Annals of Neurology, 2002, 52, 511-516. 
104. J.J.Jung, S.M.Inamdar, A.Tiwari, A.Choudhury, Regulation of intracellular membrane trafficking and cell dynamics by syntaxin-6, Bioscience Reports, 2012, 32, 383-391.

105. P.Montague, A.S.McCallion, R.W.Davies, I.R.Griffiths, Myelin-associated oligodendrocytic basic protein: a family of abundant CNS myelin proteins in search of a function, Developmental Neuroscience, 2006, 28, 479-487.

106. L.D.Stutzbach, S.X.Xie, A.C.Naj, R.Albin, S.Gilman, PSP Genetics Study Group, V.M.Y.Lee, J.Q.Trojanowski, B.Devlin, G.D.Schellenberg, The unfolded protein response is activated in disease-affected brain regions in progressive supranuclear palsy and Alzheimer's disease, Acta Neuropathologica Communications, 2013, 1, 31.

107. Alzheimer's Society United, Alzheimer's Disease, https://www.alzheimers.org.uk/about-dementia/types-dementia/alzheimersdisease, (accessed December 2019).

108. Parkinson's UK, The incidence and prevalence of Parkinson's in the UK, https://www.parkinsons.org.uk/sites/default/files/201801/CS2960\%20Incidence\%20and\%20prevalence\%20report $\% 20$ branding $\% 20$ s ummary\%20report.pdf, (accessed September 2019).

109. R.Constantinescu, L.Rosengren, B.Eriksson, K.Blennow, M.Axelsson, Cerebrospinal fluid neurofilament light and tau protein as mortality biomarkers in parkinsonism, Acta Neurologica Scandinavica, 2019, 140, 147-156.

110. D.Altomare, C.Ferrari, A.Caroli, S.Galluzi, A.Prestia, W.M.van der Flier, R.Ossenkoppele, B.V.Berckel, F.Barkhof, C.E.Teunissen, A.Wall, S.F.Carter, M.Schöll, I.H.Choo, T.Grimmer, A.Redolfi, A.Nordberg, P.Scheltens, A.Drzezga, G.B.Frisoni, For the Alzheimer's Disease Neuroimaging Initiative. Prognostic value of Alzheimer's biomarkers in mild cognitive impairment: the effect of age at onset, Journal of Neurology, 2019, 266, 2535-2545.

111. C.Wattmo, Å.K.Wallin, Early- versus late-onset Alzheimer's disease in clinical practice: cognitive and global outcomes over 3 years, Alzheimer's Research \& Therapy, 2017, 9, 70.

112. L.Ferguson, A.H.Rajput, A.Rajput, Early-onset vs. Late-onset Parkinson's disease: A Clinical-pathological study, The Canadian Journal of Neurological Sciences, 2016, 43, 113-119.

113. E.Jabbari, J.Woodside, M.M.X.Tan, N.Pavese, O.Bandmann, B.C.P.Ghosh, L.A.Massey, E.Capps, T.T.Warner, A.J.Lees, T.Revesz, J.L.Holton, N.M.Williams, D.G.Grosset, H.R.Morris, The Genetic and Clinico-Pathological Profile of Early-Onset Progressive Supranuclear Palsy, Movement Disorders, 2019, 34, 1307-1314. 
114. F.J.Dunne, Subcortical dementia, British Medical Journal, 1993, 307, 1LP-2.

115. Y.W.Lee, H.Lee, I.S.Chung, H.A.Yi, Relationship between postural instability and subcortical volume loss in Alzheimer's disease, Medicine, 2017, 96, e7286.

116. B.Palakurthi, S.P.Burugupally, Postural Instability in Parkinson's Disease: A Review. Brain Sciences, 2019, 9, 239.

117. S.H.Ferris, M.Farlow, Language impairment in Alzheimer's disease and benefits of acetylcholinesterase inhibitors, Clinical Interventions in Aging, 2013, 8, 1007-1014.

118. J.Müller, G.K.Wenning, M.Verny, A.McKee, K.R.Chaudhuri, K.Jellinger, W.Poewe, I.Litvan, Progression of Dysarthria and Dysphagia in Post-mortemConfirmed Parkinsonian Disorders, Archives of Neurology, 2001, 58, 259-264.

119. Y.Terao, H.Fukuda, Y.Ugawa, O.Hikosaka, New perspectives on the pathophysiology of Parkinson's disease as assessed by saccade performance: A clinical review, Clinical Neurophysiology, 2013, 124, 1491-1506.

120. M.Kidd, Paired helical filaments in electron microscopy of Alzheimer's disease. Nature, 1963, 197, 192-193.

121. Institute of Medicine and National Academy of Sciences. Major structures and function of the brain in Discovering the Brain, edited by S.Ackerman, The National Academies Press, Washington DC, 1992, ch.2, pp. 1333. DOI:10.17226/1785.

122. M.Gorges, H.P.Müller, J.Kassubek, Structural and functional brain mapping correlates of impaired eye movement control in Parkinsonism syndromes: A systems-based concept, Frontiers in Neurology, 2018, 9, 319.

123. M.Ebashi, Y.Ito, M.Uematsu, A.Nakamura, K.Hirokawa, S.Kamei, T.Uchihara, How to demix Alzheimer-type and PSP-type tau lesion out of their mixturehybrid approach to dissect comorbidity-, Acta Neuropathologica Communications, 2019, 7, 71.

124. R.M.Tsai, Z.Miller, M.Koestler, J.C.Rojas, P.A.Ljubenkov, H.J.Rosen, G.D.Rabinovici, A.M.Fagan, Y.Cobigo, J.A.Brown, J.I.Jung, E.Hare, D.S.Geldmacher, M.Natelson-Love, E.C.McKinley, P.N.Luong, E.L.Chuu, R.Powers, P.Mumford, A.Wolf, P.Wang, M.Shamloo, B.L.Miller, E.D.Roberson, A.L.Boxer, Reactions to Multiple Ascending Doses of the Microtubule Stabilizer TPI-287 in Patients With Alzheimer Disease, Progressive Supranuclear Palsy, and Corticobasal Syndrome: A Randomized Clinical Trial, JAMA Neurology, 2019, DOI:10.1001/jamaneurol.2019.3812. 
125. P.W.Tipton, T.Konno, D.F.Broderick, D.W.Dickson, Z.K.Wszolek, Cerebral peduncle angle: unreliable in differentiating progressive supranuclear palsy from other neurodegenerative diseases, Parkinsonism Related Disorders, 2016, 32, 31-35.

126. I.Rodríguez-Leyva, E.G.Chi-Ahumada, J.Carrizales, M.Rodríguez-Violante, S.Velázquez-Osuna, V.Medina-Mier, M.G.Martel-Gallegos, S.Zarazúa, L.Enríquez-Macías, A.Castro, A.L.Calderón-Garcidueñas, M.E.JiménezCapdeville, Parkinson disease and progressive supranuclear palsy: protein expression in skin, Annals of Clinical and Translational Neurology, 2016, 3, 191-199.

127. C.H.Lin, S.Y.Yang, H.E.Horng, C.C.Yang, J.J.Chieh, H.H.Chen, B.H.Liu, M.J.Chiu, Plasma biomarkers differentiate Parkinson's disease from atypical Parkinsonism syndromes, Frontiers in aging neuroscience, 2018, 10, 123.

128. C.Galvaginon, The role of lipids interacting with $\alpha$-synuclein in the pathogenesis of Parkinson's disease, Journal of Parkinson's disease, 2017, 7, 433-450.

129. S.Moussaud, D.R.Jones, E.L.Moussaud-Lamodire, M.Delenclos, O.A.Ross, P.J.McLean, Alpha-synuclein and tau: teammates in neurodegeneration? Molecular neurodegeneration, 2014, 9, 43.

130. N.Olfati, A.Shoeibi, I.Litvan, Progress in the treatment of Parkinson-plus syndromes, Parkinsonism and related disorders, 2019, 59, 101-110.

131. R.Vasta, A.Nicoletti, G.Mostile, V.Dibilio, G.Sciacca, D.Contrafatto, C.E.Cicero, L.Raciti, A.Luca, M.Zappia, Side effects induced by the acute levodopa challenge in Parkinson's Disease and atypical parkinsonisms, PLOS ONE, 2017,12, e0172145.

132. K.Seppi, M.F.H.Schocke, R.Esterhammer, C.Kremser, C.Brenneis, J.Mueller, S.Boesch, W.Jaschke, W.Poewe, G.K.Wenning, Diffusion-weighted imaging discriminates progressive supranuclear palsy from PD, but not from the Parkinson variant of multiple system atrophy, Neurology, 2003, 60, 922-927.

133. A.Quattrone, G.Nicoletti, D.Messina, F.Fera, F.Condino, P.Pugliese, P.Lanza, P.Barone, L.Morgante, M.Zappia.M, U.Aguglia, O.Gallo, MRI imaging index for differentiation of progressive supranuclear palsy from Parkinson disease and the Parkinson variant of multiple system atrophy, Radiology, 2008, 246, 214221.

134. J.A.Santiago, V.Bottero, J.A.Potashkin, Evaluation of RNA blood biomarkers in the Parkinson's disease biomarkers program, Frontiers in aging neuroscience, 2018, 10, 157. 
135. T.M.Marques, A.van Rumund, P.Oeckl, B.Kuiperij, R.A.J.Esselink, B.R.Bloem, M.Otto, M.M.Verbeek, Serum NFL discriminates Parkinson disease from atypical parkinsonism, Neurology, 2019, 92, e1479 LP - e1486.

136. ClinicalTrials.gov, A 6-month, Open-label, Pilot Futility Clinical Trial of Oral Salsalate for Progressive Supranuclear Palsy, https://clinicaltrials.gov/ct2/show/record/NCT02422485?recrs=abd\&cond=Progr essive+Supranuclear+Palsy\&cntry=US\&draw=2\&rank=3, (accessed January 2020).

137. A.L.Boxer, I.Qureshi, M.Ahlijanian, M.Grundman, L.I.Golbe, I.Litvan, L.S.Honig, P.Tuite, N.R.McFarland, P.O'Suilleabhain, T.Xie, G.S.Tirucherai, C.Bechtold, Y.Bordelon, D.S.Geldmacher, M.Grossman, S.Isaacson, T.Zesiewicz, T.Olsson, K.K.Muralidharan, D.L.Graham, J.O'Gormon, S.B.Haeberlein, T.Dam, Safety of the tau-directed monoclonal antibody BIIB092 in progressive supranuclear palsy: a randomised, placebo-controlled, multiple ascending dose phase $1 \mathrm{~b}$ trial, Lancet Neurology, 2019, 18, 549-558.

138. M.Scholl, A.Maass, N.Mattsson, N.J.Ashton, K.Blennow, H.Zetterberg, W.Jagust, Biomarkers for tau pathology, Molecular and cellular neuroscience, 2019, 97, 18-33.

139. A.Padovani, B.Borroni, S.M.Brambati, C.Agosti, M.Broli, R.Alonso, P.Scifo, G.Bellelli, A.Alberici, R.Gasparotti, D.Perani, Diffusion tensor imaging and voxel based morphometry study in early progressive supranuclear palsy, Journal of Neurology, Neurosurgery and Psychiatry, 2006, 77, 457-463.

140. Y.Zhang, R.Walter, P.Ng, P.N.Luong, S.Dutt, H.Heuer, J.C.Rojas-Rodriguez, R.Tsai, I.Litvan, B.C.Dickerson, M.C.Tartaglia, G.Rabinovici, B.L.Miller, H.J.Rosen, N.Schuff, A.L.Boxer, Progression of Microstructural Degeneration in Progressive Supranuclear Palsy and Corticobasal Syndrome: A Longitudinal Diffusion Tensor Imaging Study, PLOS ONE, 2016, 11, e0157218.

141. P.J.Planetta, E.Ofori, O.Pasternak, R.G.Burciu, P.Shukla, J.C.DeSimone, M.S.Okun, N.R.McFarland, D.E.Vaillancourt, Free-water imaging in Parkinson's disease and atypical parkinsonism, Brain, 2016, 139, 495-508.

142. K.Ito, C.Ohtsuka, K.Yoshioka, H.Kameda, S.Yokosawa, R.Sato, Y.Terayama, M.Sasaki, Differential diagnosis of parkinsonism by a combined use of diffusion kurtosis imaging and quantitative susceptibility mapping, Neuroradiology, 2017, 59, 759-769.

143. L.Passamonti, P.Vázquez Rodriguez, Y.T.Hong, K.S.J.Allinson, D.Williamson, R.J.Borchert, S.Sami, T.E.Cope, R.W.Bevan-Jones, S.P.Jones, R.Arnold, A.Surendranathan, E.Mak, L.Su, T.D.Fryer, F.I.Aigbirhio, J.T.O'Brien, J.B.Rowe, $\left[{ }^{18} \mathrm{~F}\right] \mathrm{AV}-1451$ positron emission tomography in Alzheimer's disease and progressive supranuclear palsy, Brain, 2017, 140, 781-791. 
144. J.L.Whitwell, N.Tosakulwong, C.G.Schwarz, H.Botha, M.L.Senjem, A.J.Spychalla, J.E.Ahlskog, D.S.Knopman, R.C.Petersen, C.R.Jack, V.J.Lowe, K.A.Josephs, MRI outperforms [ $\left.{ }^{18} \mathrm{~F}\right] \mathrm{AV}-1451 \mathrm{PET}$ as a longitudinal biomarker in progressive supranuclear palsy, Movement Disorders, 2019, 34,105-113.

145. H.Kroth, F.Oden, J.Molette, H.Schieferstein, F.Capotosti, A.Mueller, M.Berndt, H.Schmitt-Willich, V.Darmency, E.Gavellieri, C.Boudou, T.Juergens, Y.Varisco, E.Vokali, D.T.Hickman, G.Tamagnan, A.Pfeifer, L.Dinkelborg, A.Muhs, A.Stephens, Discovery and preclinical characterisation of $\left[{ }^{18} \mathrm{~F}\right] \mathrm{PI}-2620$, a nextgeneration tau PET tracer for the assessment of tau pathology in Alzheimer's disease and other tauopathies, European Journal of Nuclear Medicine and Molecular Imaging, 2019, 46, 2178-2189.

146. P.Alster, N.A.Madetko, D.M.Koziorowski, L.Królicki, S.Budrewicz, A.Friedman, Accumulation of Tau Protein, Metabolism and perfusion - application and efficacy of positron emission tomography (PET) and single photon emission computed tomography (SPECT) imaging in the examination of progressive supranuclear palsy (PSP) and corticobasal syndrome (CBS), Frontiers in Neurology, 2019, 10, 101.

147. H.Botha, J.L.Whitwell, A.Madhaven, M.L.Senjem, V.Lowe, K.A.Josephs, The pimple sign of progressive supranuclear palsy syndrome, Parkinsonism related disorders, 2014, 20, 180-185.

148. J.C.Rojas, J.Bang, I.V.Lobach, R.M.Tsai, G.D.Rabinovici, B.L.Miller, A.L.Boxer, CSF neurofilament light chain and phosphorylated tau 181 predict disease progression in PSP, Neurology, 2018, 90, e273-e281.

149. B.Holmberg, L.Rosengren, J.E.Karlsson, B.Johnels, Increased cerebrospinal fluid levels of neurofilament protein in progressive supranuclear palsy and multiple-system atrophy compared with Parkinson's disease, Movement Disorders, 1998, 13, 70-77.

150. W.Luo, W.Liu, X.Hu, M.Hanna, A.Caravaca, S.M.Paul, Microglial internalisation and degradation of pathological tau is enhanced by an anti-tau monoclonal antibody, Scientific reports, 2015, 5, 11161.

151. K.Simrén, N.J.Ashton, K.Blennow, H.Zetterberg, An update on fluid biomarkers for neurodegernative disease: recent success and challenges ahead, Current Opinion in Neurobiology, 2020, 61, 29-39.

152. N.J.Ashton, A.Leuzy, Y.M.Lim, C.Troakes, T.Hortobágyi, K.Höglund, D.Aarsland, S.Lovestone, M.Schöll, K.Blennow, H.Zetterberg, A.Hye, Increased plasma neurofilament light chain concentration correlates with severity of postmortem neurofibrillary tangle pathology and neurodegeneration, Acta Neuropathologica Communications, 2019, 7, 5.

153. J.Gaiottino, N.Norgren, R.Dobson, J.Topping, A.Nissim, A.Malaspina, J.P.Bestwick, A.U.Monsch, A.Regeniter, R.L.Lindberg, L.Kappos, D.Leppert, 
A.Petzold, G.Giovannoni, K.Kuhle, Increased neurofilament light chain blood levels in neurodegenerative neurological diseases, PLOS ONE, 2013, 8 , e75091.

154. ClinicalTrials.gov, A Study to Assess Tolerability, Safety, Pharmacokinetics and Effect of AZP2006 in Patients with PSP, https://clinicaltrials.gov/ct2/show/NCT04008355, (accessed January 2020).

155. S.Alkabie, A.Lange, P.Manogaran, A.J.Stoessl, F.Costello, J.J.S.Barton, Optical coherence tomography of patients with Parkinson's disease and progressive supranuclear palsy, Clinical Neurology and Neurosurgery, 2020, 189, 105635.

156. D.K.Trivedi, E.Sinclair, Y.Xu, D.Sarkar, C.Walton-Doyle, C.Liscio, P.Banks, J.Milne, M.Silverdale, T.Kunath, R.Goodacre, P.Barran, Discovery of Volatile Biomarkers of Parkinson's Disease from Sebum, ACS Central Science, 2019, 5, 559-606.

157. C.Eraslan, A.Acarer, S.Guneyli, E.Akyuz, E.Aydin, Z.Colakoglu, O.Kitis, M.C.Calli, MRI evaluation of progressive supranuclear palsy: differentiation from Parkinson's disease and multiple system atrophy, Neurological research, 2019, 41, 110-117.

158. F.Albrecht, S.Bisenius, J.Neumann, J.Whitwell, M.L.Schroeter, Atrophy in midbrain and cerebral/cerebellar pedunculi is characteristic for progressive supranuclear palsy - a double-validation whole-brain meta-analysis, Neurolmage:Clinical, 2019, 22, 101722.

159. J.L.Whitwell, G.U.Höglinger, A.Antonini, Y.Borderlon, A.L.Boxer, C.Colosimo, T.van Eimeren, L.I.Golbe, J.Kassubek, C.Kurz, I.Litvan, A.Pantelyat, G.Rabinovici, G.Respondek, A.Rominger, J.B.Rowe, M.Stamelou, K.A.Josephs,. Radiological biomarkers for diagnosis in PSP: where are we and where do we need to be? Movement disorders, 2017, 32, 955-971.

160. H.Sakuramoto, H.Fujita, K.Suzuki, T.Matsubara, Y.Watanabe, M.Hamaguchi, K.Hirata, Combination of midbrain-to-pontine ratio and cardiac MIBG scintigraphy to differentiate Parkinson's disease from multiple system atrophy and progressive supranuclear palsy, Clinical Parkinsonism and Related Disorders, 2020, 2, 20-24.

161. K.Zhang, Z,Liang, C.Wang, X.Zhang, B.Yu, X.Liu, Diagnostic validity of magnetic resonance parkinsonism index in differentiating patients with progressive supranuclear palsy from patients with Parkinson's disease. Parkinsonism and related disorders, 2019, 66, 176-181

162. H.Oba, A.Yagishita, H.Terada, A.J.Barkovich, K.Kutomi, T.Yamauchi, S.Furui, T.Shimizu, M.Uchigata, K.Matsumura, M.Sonoo, M.Sakai, K.Takada, A.Harasawa, K.Takeshita, H.Kohtake, H.Tanaka, S.Suzuki, New and reliable MRI diagnosis for progressive supranuclear palsy, Neurology, 2005, 64, 20502055. 
163. A.Quattrone, M.Morelli, S.Nigro, A.Quattrone, B.Vescio, G.Arabia, G.Nicoletti, R.Nisticó, M.Salsone, F.Novellino, G.Barbagallo, E.Le Piane, P.Pugliese, D.Bosco, M.G.Vaccaro, C.Chiriaco, U.Sabatini, V.Vescio, C.Stanà, F.Rocca, D.Gullà, M.Caracciolo, A new MR imaging index for differentiation of progressive supranuclear palsy-parkinsonism from Parkinson's disease, Parkinsonism and Related Disorders, 2018, 54, 3-8.

164. A.Leuzy, K.Chiotis, L.Lemoine, P.G.Gillberg, O.Almkvist, E.Rodriguez-Vieitez, A.Nordberg, Tau PET imaging in neurodegenerative tauopathies - still a challenge, Molecular psychiatry, 2019, 24, 112-1134.

165. C.Aguero, M.Dhaynaut, M.D.Normandin, A.C.Amaral, N.J.Guehl, R.Neelamegam, M.Marquie, K.A.Johnson, G.El Fakhri, M.P.Frosch, T.GomezIsla, Autoradiography validation of novel tau PET tracer [F-18]-MK-6240 on human postmortem brain tissue, Acta Neuropathologica Communications, 2019, 7, 37.

166. M.Marquié, M.D.Normandin, C.R.Vanderburg, I.Costantino, E.A.Bien, L.G.Rycyna, W.E.Klunk, C.A.Mathis, M.D.Ikonomovic, M.L.Debnath, N.Vasdev, B.C.Dickerson, S.N.Gomperts, J.H.Growdon, K.A.Johnson, M.P.Frosch, B.T.Hyman, T.Gomez-Isla, Validating novel tau PET tracer [F-18]-AV-1451 (T807) on postmortem brain tissue, Annals of Neurology, 2015, 78, 787-800.

167. V.J.Lowe, G.Curran, P.Fang, A.M.Liesinger, K.A.Josephs, J.E.Parisi, K.Kantarci, B.F.Boeve, M.K.Pandey, T.Bruinsma, D.S.Knopman, D.T.Jones, L.Petrucelli, C.N.Cook, N.R.Graff-Radford, D.W.Dickson, R.C.Petersen, C.R.Jack Jr, M.E.Murray, An autoradiographic evaluation of AV-1451 Tau PET in dementia, Acta Neuropathologica Communications, 2016, 4, 58.

168. A.Mueller, S.Bullich, O.Barret, J.Madonia, M.Berndt, C.Papin, A.Perrotin, N.Koglin, H.Kroth, A.Pfeifer, G.Tamagnan, J.P.Seibyl, K.Marek, S.de Santi, L.M.Dinkelborg, A.W.Stephens, Tau PET imaging with ${ }^{8} \mathrm{~F}-\mathrm{PI}-2620$ in patients with Alzheimer's disease with healthy controls: a first-in-human study, The Journal of Nuclear Medicine, 2019, DOI:10.2967/jnumed.119.236224.

169. Adis Insight, PI 2620, https://adisinsight.springer.com/drugs/800049185, (Accessed December 2019).

170. C.Lois, I.Gonzalez, K.A.Johnson, J.C.Price, PET imaging of tau protein targets: a methodology perspective, Brain Imaging and Behavior, 2019, 13, 333-334.

171. A.Mori, K.I.Ishikawa, S.Saiki, T.Hatano, Y.Oji, A.Okuzumi, M.Fujimaki, T.Koinuma, S.I.Ueno, Y.Imamichi, N.Hattori, Plasma metabolite biomarkers for multiple system atrophy and progressive supranuclear palsy, PLOS ONE, 2019, 14, e0223113.

172. K.Blennow, A.Wallin, H.Agren, C.Spenger, J.Siegfried, E.Vanmechelen, Tau protein in cerebrospinal fluid: a biochemical marker for axonal degeneration in 
Alzheimer disease? Molecular and Chemical Neuropathology, 1995, 26, 231 245.

173. L.Donker Kaat, L.H.Meeter, W.Z.Chiu, S.Melhem, A.J.W.Boon, K.Blennow, H.Zetterberg, J.C.van Swieten, Serum neurofilament light chain in progressive supranuclear palsy. Parkinsonism \& Related Disorders, 2018, 56, 98-101.

174. J.C.Rojas, A.Karydas, J.Bang, R.M.Tsai, K.Blennow, V.Liman, J.H.Kramer, H.Rosen, B.L.Miller, H.Zetterberg, A.L.Boxer, Plasma neurofilament light chain predicts progression in progressive supranuclear palsy, Annals of clinical and translational neurology, 2016, 3, 216-225.

175. L.Gaetani, K.Blennow, P.Calabresi, M.Di Filippo, L.Parnetti, H.Zetterberg, Neurofilament light chain as a biomarker in neurological disorders, Journal of Neurology, Neurosurgery and Psychiatry, 2019, 90, 870-881.

176. O.Hansson, S.Janelidze, S.Hall, N.Magdalinou, A.J.Lees, U.Andreasson, N.Norgren, J.Linder, L.Forsgen, R.Constantinescu, H.Zetterberg, K.Blennow, Swedish BioFINDER study, Blood-based NfL: A biomarker for differential diagnosis of parkinsonian disorder, Neurology, 2017, 88, 930-937.

177. M.Lawton, F.Baig, G.Toulson, A.Morovat, S.G.Evetts, Y.Ben-Shlomo, M.T.Hu, Blood biomarkers with Parkinson's disease clusters and prognosis: the Oxford Discovery Cohort, Movement disorders, 2020, 35, 279-287.

178. L.M.Rimmelzwaan, N.M.van Schoor, P.Lips, H.W.Berendse, E.M.W.Eekhoff, Systematic review of the relationship between vitamin $D$ and Parkinson's disease, Journal of Parkinson's disease, 2016, 6, 29-37.

179. J.M.Oropesa-Ruiz, I.Huertas-Fernández, S.Jesús, M.T.Cáceres-Redondo, L.Vargas-Gonzalez, F.Carrillo, M.Carballo, P.Gómez-Garre, P.Mir, Low serum uric acid levels in progressive supranuclear palsy, Movement disorders: official journal of the Movement Disorder Society, 2016, 31, 402-405.

180. M.Pandika, Looking to Young Blood to Treat the Disease of Aging. ACS Central Science, 2019, 5, 1481-1484.

181. B.Stemplewitz, R.Kromer, E.Vettorazzi, U.Hidding, A.Frings, C.Buhmann, Retinal degeneration in progressive supranuclear palsy measured by optical coherence tomography and scanning laser polarimetry, Science Reports, 2017, 7, 5357 .

182. W.Poewe, Smelling Parkinson's Disease: New Metabolomic Biomarker for PD, ACS Central Science, 2019, 5, 575-576

183. N.M.Kanaan, G.A.Morfini, N.E.LaPointe, G.F.Pigino, K.R.Patterson, Y.Song, A.Andreadis, Y.Fu, S.T.Brady, L.I.Binder, Pathogenic forms of tau inhibit kinesin-dependent axonal transport through a mechanism involving activation of axonal phosphotransferases, Journal of Neuroscience, 2011, 31, 9858-9868. 
184. F.Liu, B.Li, E.J.Tung, I.Grundke-Iqbal, K.Iqbal, C.X.Gong, Site-specific effects of tau phosphorylation on its microtubule assembly activity and selfaggregation, European Journal of Neuroscience, 2007, 26, 3429-3436.

185. B.R.Hoover, N.M.Reed, J.Su, R.D.Penrod, L.A.Kotilinek, M.K.Grant, R.Pitstick, G.A.Carlson, L.M.Lanier, L.L.Yuan, K.H.Ashe, D.Liao, Tau mislocalisation to dendritic spines mediates synaptic dysfunction independently of neurodegeneration, Neuron, 2010, 68, 1067-1081.

186. C.A.Dickey, A.Kamal, K.Lundgren, N.Klosak, R.M.Bailey, J.Dunmore, P.Ash, S.Shoraka, J.Zlatkovic, C.B.Eckman, C.Patterson, D.W.Dickson, N.S.Nahman Jr, M.Hutton, F.Burrows, L.Petrucelli,The high-affinity HSP90-CHIP complex recognises and selectively degrades phosphorylated tau client proteins, Journal of Clinical Investigation, 2007, 117, 648-658.

187. I.Ferrer, M.Barrachina, B.Puig, Glycogen synthase kinase-3 is associated with neuronal and glial hyperphosphorylated tau deposits in Alzheimer's disease, Pick's disease, progressive supranuclear palsy and corticobasal degeneration, Acta Neuropathology, 2002, 104, 583-591.

188. E.Tolosa, I.Litvan, G.U.Höglinger, D.Burn, A.Lees, M.V.Andrés, B.GómezCarollo, T.León, T.Del Ser, TAUROS Investigators, A phase 2 trial of the GSK3 inhibitor tideglusib in progressive supranuclear palsy, Movement disorders, 2014, 29, 470-478.

189. W.Noble, M.Jimenez-Sanchez, B.G.Perez-Nievas, D.P.Hanger, Considerations for future tau-targeted therapeutics: can they deliver? Expert Opinion on Drug Discovery, 2019, 15, 265-267.

190. ClinicalTrials.gov, A Pilot Trial of Lithium in Subjects With Progressive Supranuclear Palsy or Corticobasal Degeneration, https://clinicaltrials.gov/ct2/show/results/NCT00703677?recrs=abdefghim\&cond =Progressive+Supranuclear+Palsy\&cntry=US\&draw=2\&rank=40, (accessed January 2020).

191. P.Sandhu, J.Lee, J.Ballard, B.Walker, J.Ellis, J.Marcus, D.Toolan, D.Dreyer, T.McAvoy, J.Duffy, M.Michener, C.Valiathan, N.Trainor, M.Savage, E.McEachern, D.Vocadlo, S.M.Smith, A.Struyk, P4-036: Pharmacokinetics and pharmacodynamics to support clinical studies of MK-8719: An O-GIcNAcase inhibitor for progressive supranuclear palsy, Alzheimer's and Dementia, 2016, 12, P1028-P1028.

192. S.W.Min, X.Chen, T.E.Tracy, Y.Li, Y.Zhou, C.Wang, K.Shirakawa, S.S.Minami, E.Defensor, S.A.Mok, P.D.Sohn, B.Schilling, X.Cong, L.Ellerby, B.W.Gibson, J.Johnson, N.Krogan, M.Shamloo, J.Gestwicki. E.Masliah, E.Verdin, L.Gan, Critical role of acetylation in tau-mediated neurodegeneration and cognitive effects, Nature Medicine, 2015, 21, 1154-1162.

193. ClinicalTrials.gov, Study to Evaluate the Safety, Tolerability and the Effect of BMS-241027 on Cerebrospinal Fluid Biomarkers in Subjects With Mild 
Alzheimer's Disease, https://www.clinicaltrials.gov/ct2/show/study/NCT01492374, (accessed January 2020).

194. D.Valdinocci, G.D.Grant, T.R.Dickson, D.L.Pountney, Epothilone D inhibits microglia-mediated spread of alpha-synuclein aggregates, Molecular and Cellular Neuroscience, 2018, 89, 80-94.

195. S.L.DeVos, R.L.Miller, K.M.Schoch, B.B.Holmes, C.S.Kebodeaux, A.J.Wegener, G.Ghen, T.Schen, H.Tran, B.Nichols, T.A.Zanardi, H.B.Kordasiewicz, E.E.Swayze, C.F.Bennett, M.I.Diamond, T.M.Miller, Tau reduction prevents neuronal loss and reverses pathological tau deposition and seeding in mice with tauopathy, Science Translation Medicine, 2017, 9, DOI: 10.1126/scitranslmed.aag0481.

196. C.L.Croft, B.D.Moore, Y.Ran, P.Chakrabarty, Y.Levites, T.E.Golde, B.I.Giasson, Novel monoclonal antibodies targeting the microtubule-binding domain of human tau, PLOS ONE, 13, e0195211.

197. ALZFORUM, Gosuranemab, https://www.alzforum.org/therapeutics/gosuranemab, (accessed January 2020).

198. M.Ahlijanian, H.Malone, D.Kukral, et al, Unpublished results in Qureshi.I.A, Tirucherai.G, Ahiljanian.M.K, Kolaitis.G, Bechtold.C, Grundman.M. A randomized, single ascending dose study of intravenous BIIB092 in healthy participants. Alzheimer's \& Dementia: Translational Research \& Clinical Interventions, 2018, 4, 746-755.

199. ALZFORUM: Networking for a cure, AbbVie's Tau Antibody Flops in Progressive Supranuclear Palsy, https://www.alzforum.org/news/researchnews/abbvies-tau-antibody-flops-progressive-supranuclear-palsy, (accessed January 2020).

200. UCB, UCB presents UCB0107 anti-tau immunotherapy Phase I study results at World Movement Disorders Conference, https://www.ucb.com/storiesmedia/Press-Releases/article/UCB-presents-UCB0107-anti-Tauimmunotherapy-Phase-I-study-results-at-World-Movement-DisordersConference, (accessed January 2020)

201. ClinicalTrials.gov, A Study to Assess Tolerability, Safety, Pharmacokinetics and Effect of AZP2006 in Patients with PSP, https://clinicaltrials.gov/ct2/show/NCT04008355, (accessed January 2020)

202. M.Medina, An overview on the Clinical Development of Tau-Based Therapeutics, International journal of Molecular Sciences, 2018, 19, 1160.

203. D.Apetauerova, S.A.Scala, R.W.Hamill, D.K.Simon, S.Pathak, R.Ruthazer, D.G.Standaert, T.A.Yacoubian, CoQ10 in progressive supranuclear palsy. Neurology: Neuroimmunology \& Neuroinflammation, 2016, 3, e266. 
204. ClinicalTrials.gov, Alpha-lipoic Acid/L-acetyl Carnitine for Progressive Supranuclear Palsy, https://clinicaltrials.gov/ct2/show/results/NCT01537549?recrs=e\&cond=Progres sive+Supranuclear+Palsy\&cntry=US\&draw=2\&rank=1, (accessed January 2020).

205. T.M.Hagen, R.T.Ingersoll, J.Lykkesfeldt, J.Liu, C.M.Wehr, V.Vinarsky, J.C.Bartholomew, B.N.Ames, $(R)$-alpha-Lipoic acid-supplemented old rats have improved mitochondrial function, decreased oxidative damage, and increased metabolic rate, FASEB J, 1999, 13, 411-418.

206. H.A.S.Alzahrani, Protective effect of L-carnitine against acrylamide induced DNA damage in somatic and germ cells of mice. Saudi Journal of Biological Sciences, 2011, 18, 29-36.

207. V.Tapias, S.Jainuddin, M.Ahuja, C.Stack, C.Elipenahli, J.Vignisse, M.Gerges, N.Starkova, H.Xu, A.A.Starkov, L.Bettendorff, D.M.Hushpulian, N.A.Smirnova, I.G.Gazaryan, N.A.Kaidery, S.Wakade, N.Y.Calingasan, B.Thomas, G.E.Gibson, M.Dumont, M.F.Beal, Benfotiamine treatment activates the Nrf2/ARE pathway and is neuroprotective in a transgenic mouse model of tauopathy, Human Molecular Genetics, 2018, 27, 2874-2892.

208. D.P.Fitzgerald, D.L.Emerson, Y.Qian, T.Anwar, D.J.Liewehr, S.M.Steinberg, S.Silberman, D.Palmieri, P.S.Steeg, TPI-287, a New Taxane Family Member, Reduces the Brain Metastatic Colonization of Breast Cancer Cells, Molecular Cancer Therapy, 2012, 11, 1959LP-1967.

209. ALZFORUM, At Least We Know These Don't Work: Negative Trials at CTAD, https://www.alzforum.org/news/conference-coverage/least-we-know-thesedont-work-negative-trials-ctad, (accessed January 2020).

210. D.R.Scoles, S.M.Pulst, Antisense Therapies for Movement Disorders. Movement Disorders, 2019, 34, 1112-1119.

211. E.Tokuda, Y.I.Takei, S.Ohara, N.Fujiwara, I.Hozumi, Y.Furukawa, Wild-type $\mathrm{Cu} / \mathrm{Zn}$-superoxide dismutase is misfolded in cerebrospinal fluid of sporadic amyotrophic lateral sclerosis, Molecular neurodegeneration, 2019, 14, 42.

212. ClinicalTrials.gov, An Efficacy, Safety, Tolerability, Pharmacokinetics and Pharmacodynamics Study of BlIB067 in Adults with Inherited Amyotrophic Lateral Sclerosis (ALS) (VALOR (PART C)), https://clinicaltrials.gov/ct2/show/NCT02623699/, (accessed January 2020).

213. K.Yanamandra, T.K.Patel, H.Jiang, S.Schindler, J.D.Ulrich, A.L.Boxer, B.L.Miller, D.R.Kerwin, G.Gallardo, F.Stewart, M.B.Finn, N.J.Cairns, P.B.Verghese, I.Fogelman, T.West, J.Braunstein, G.Robinson, J.Keyser, J.Roh, S.S.Knapik, Y.Hu, D.M.Holtzman, Anti-tau administration increases plasma tau in transgenic mice and patients with tauopathy, Science Translational Medicine, 2017, 9, eaal2029. 
214. A.Boutajangout, J.Ingadottir, P.Davies, E.M.Sigurdsson, Passive immunisation targeting pathological phosphor-tau protein in a mouse model reduces functional decline and clears tau aggregates from the brain, Journal of Neurochemistry, 2011, 118, 658-667.

215. D.L.Castillo-Carranza, U.Sengupta, M.J.Guerrero-Muños, C.A.LasagnaReeves, J.E.Gerson, G.Singh, D.M.Estes, A.D.T.Barrett, K.T.Dineley, G.R.Jackson, R.Kayed, Passive immunisation with tau oligomer monoclonal antibody reverses tauopathy phenotypes without affecting hyperphosphorylated neurofibrillary tangles, 2014, 34, 4260-4272.

216. K.Yanamandra, N.Kfoury, H.Jiang, D.F.Wozniak, M.I.Diamond, D.M.Holtzman, Anti-tau antibodies that block tau aggregate seeding in vitro markedly decrease pathology and improve cognition in vivo, Neuron, 2013, 80, 402-414.

217. K.C.Walls, R.R.Ager, V.Vasilevko, D.Cheng, R.Medeiros, F.M.LaFerla, p-Tau immunotherapy reduces soluble and insoluble tau in aged 3xTg-AD mice, Neuroscience Letters, 2014, 575, 96-100.

218. M.G.Agadjanyan, K.Zagorski, I.Petrushina, H.Davtyan, K.Kazarian, M.Antonenko, J.Davis, C.Bon, M.Blurton-Jones, D.H.Cribbs, A.Ghochikyan, Humanised monoclonal antibody armanezumab specific to N-terminus of pathological tau: characterisation and therapeutic potency, Molecular Neurodegeneration, 2017, 12, 33.

219. M.L.Volvert, S.Seyen, M.Piette, B.Evrard, M.Gangolf, J.C.Plumier, L.Bettendorff, Benfotiamine, a synthetic S-acyl thiamine derivative, has different mechanisms of action and a different pharmacological profile than lipid-soluble thiamine disulfide derivatives, BMC Pharmacology, 2008, 8, 10.

220. C.Bullich, A.Keshavarzian, J.Garssen, A.Kraneveld, P.Perez-Parkdo, Gut vibes in Parkinson's Disease: The Microbiota-Gut-Brain Axis. Movement Disorders Clinical Practice, 2019, 6, 639-651.

221. W.Zheng, R.He, Z.Yan, Y.Huang, W.Huang, Z.Cai, Y.Su, S.Liu, Y.Deng, Q.Wang, H.Xie, Regulation of immune-driven pathogenesis in Parkinson's disease by gut microbiota, Brain, Behavior and Immunity, 2020, S0889-1591, 30526-4.

222. C.Benakis. C.Martin-Gallausiaux, J.P.Trezzi, P.Melton, A.Liesz, P.Wilmes, The microbiome-gut-brain axis in acute and chronic brain diseases, Current Opinion in Neurobiology, 2020, 61, 1-9.

223. Y.L.Chen, Z.A.Zhao, S.H.Ng, C.S.Lu, Y.C.Lin, J.S.Cheng, C.C.Tsai, J.J.Wang, Prediction of the clinical severity of progressive supranuclear palsy by diffusion tensor imaging, Journal of Clinical Medicine, 2020, 9, 40.

224. M.Colin, S.Dujardin, S.Schraen-Maschke, G.Meno-Tetang, C.Duyckaerts, J.P.Courade, L.Buée, From the prion-like propagation hypothesis to therapeutic strategies of anti-tau immunotherapy, Acta Neuropathologica, 2020, 139, 3-25. 
225. S.S.Kaalund, L.Passamonti, K.S.L.Allinson, A.G.Murley, T.W.Robbins, M.G.Spillantini, J.B.Rowe, Locus coeruleus pathology in progressive supranuclear palsy, and its relation to disease severity, medRxiv, 2020, DOI: $10.1101 / 2020.01 .13 .20016360$.

226. C.W.Berridge, B.D.Waterhouse, The locus coeruleus-noradrenergic system: modulation of behavioural state and state-dependent cognitive processes, Brain Research Reviews, 2003, 42, 33-84. 